Florida International University

FIU Digital Commons

FIU Electronic Theses and Dissertations

University Graduate School

$11-5-2014$

\title{
Non-Consumptive Effects of Predators in Coral Reef Communities and the Indirect Consequences of Marine Protected Areas
}

Laura Catano

Florida International University, lbhatti@fiu.edu

DOI: $10.25148 /$ etd.FI14110733

Follow this and additional works at: https://digitalcommons.fiu.edu/etd

Part of the Behavior and Ethology Commons, Biology Commons, Marine Biology Commons, and the Other Ecology and Evolutionary Biology Commons

\section{Recommended Citation}

Catano, Laura, "Non-Consumptive Effects of Predators in Coral Reef Communities and the Indirect Consequences of Marine Protected Areas" (2014). FIU Electronic Theses and Dissertations. 1621.

https://digitalcommons.fiu.edu/etd/1621

This work is brought to you for free and open access by the University Graduate School at FIU Digital Commons. It has been accepted for inclusion in FIU Electronic Theses and Dissertations by an authorized administrator of FIU Digital Commons. For more information, please contact dcc@fiu.edu. 


\section{FLORIDA INTERNATIONAL UNIVERSITY \\ Miami, Florida}

\section{NON-CONSUMPTIVE EFFECTS OF PREDATORS IN CORAL REEF COMMUNITIES AND THE INDIRECT CONSEQUENCES OF MARINE PROTECTED AREAS}

A dissertation submitted in partial fulfillment of the requirements for the degree of DOCTOR OF PHILOSOPHY

in

BIOLOGY

by

Laura Bhatti Catano 
To: Interim Dean Michael R. Heithaus

College of Arts and Sciences

This dissertation, written by Laura Bhatti Catano, and entitled Non-consumptive Effects of Predators in Coral Reef Communities and the Indirect Consequences of Marine Protected Areas, having been approved in respect to style and intellectual content, is referred to you for judgment.

We have read this dissertation and recommend that it be approved.

Michael R. Heithaus

James W. Fourqurean

Jennifer S. Rehage

Deron E. Burkepile, Major Professor

Date of Defense: November 5, 2014

The dissertation of Laura Bhatti Catano is approved.

Interim Dean Michael R. Heithaus College of Arts and Sciences

Florida International University, 2014 
The following chapter has been published in a peer-reviewed journal. Copyright release has been obtained from the journal for inclusion in this dissertation.

\section{CHAPTER II}

Catano LB, Shantz A and Burkepile DE (2014) Predation risk, competition, and territorial damselfishes as drivers of herbivore foraging on Caribbean coral reefs. Marine Ecology Progress Series. 511: 193-207, doi 10.3354/meps10921

http://www.int-res.com/abstracts/meps/v511/p193-207/

All other materials/chapters $\mathbb{C}$ Copyright 2014 by Laura Bhatti Catano All rights reserved. 


\section{ACKNOWLEDGMENTS}

I would like to sincerely thank the people whose invaluable support and encouragement helped me to complete this dissertation. First I would like to thank my family, especially Mohinder, Maria and Jason Bhatti, Elena Zachary, and Julie Scavelli, for always encouraging me to pursue my love of science. I would also like to thank my husband, Christopher Catano for his unwavering support and encouragement and for his valuable insight and advice with this Ph.D.

I would particularly like to thank my major professor, Deron Burkepile for giving me an opportunity to study in his lab and for supporting me in my research endeavors. I am also grateful for the valuable expertise and advice I received from my other committee members including: Michael Heithaus, James Fourqurean, Joel Trexler and Jennifer Rehage; and from other faculty in the department including: William Anderson, Craig Layman and Kevin Boswell. They all improved the quality of this Ph.D. by contributing their unique viewpoints in the areas of their expertise.

I would like to thank my labmates, Andrew Shantz, Mark Ladd, Nathan Lemoine Tom Adam and Alain Duran for their help and feedback in the design and execution of this dissertation. Additionally, I would like to thank my other classmates including Robin Sarabia, Nitzan Soffer and Cindy Bessey for their friendship and encouragement during my time at FIU. This research would not have been possible without a team of FIU students and undergraduate volunteers that helped me with both lab and field work including: Joseph Peters, Catherine Pritchard, Mark Barton, Megan Kelley, Theodora Vaughn, Robin McQueen, Bridgette Gunn, Maria Rojas, Ryan Malossi, Hans Gonzembach, Marilyn Hernandez, Cory Fuchs, Ryan McMinds, and William Sturrup. 
I would also like to thank my funding sources. I received grants from the PADI Foundation and The Florida Sea Grant Scholar Program in support of my research. I received additional support for travel and research expenses from The College of Arts Science, The University Graduate School, and The BBC Excellence Fund Fellowship. 


\begin{abstract}
OF THE DISSERTATION
NON-CONSUMPTIVE EFFECTS OF PREDATORS IN CORAL REEF

COMMUNITIES AND THE INDIRECT CONSEQUENCES OF MARINE

PROTECTED AREAS
\end{abstract}

by

Laura Bhatti Catano

Florida International University, 2014

Miami, Florida

Professor Deron E. Burkepile, Major Professor

Predators exert strong direct and indirect effects on ecological communities by intimidating their prey. Non-consumptive effects (NCEs) of predators are important features of many ecosystems and have changed the way we understand predator-prey interactions, but are not well understood in some systems. For my dissertation research I combined a variety of approaches to examine the effect of predation risk on herbivore foraging and reproductive behaviors in a coral reef ecosystem. In the first part of my dissertation, I investigated how diet and territoriality of herbivorous fish varied across multiple reefs with different levels of predator biomass in the Florida Keys National Marine Sanctuary. I show that both predator and damselfish abundance impacted diet diversity within populations for two herbivores in different ways. Additionally, reef protection and the associated recovery of large predators appeared to shape the trade-off reef herbivores made between territory size and quality. In the second part of my dissertation, I investigated context-dependent causal linkages between predation risk, herbivore foraging behavior and resource consumption in multiple field experiments. I 
found that reef complexity, predator hunting mode, light availability and prey hunger influenced prey perception of threat and their willingness to feed. This research argues for more emphasis on the role of predation risk in affecting individual herbivore foraging behavior in order to understand the implications of human-mediated predator removal and recovery in coral reef ecosystems. 


\section{TABLE OF CONTENTS}

CHAPTER

PAGE

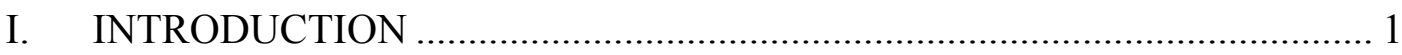

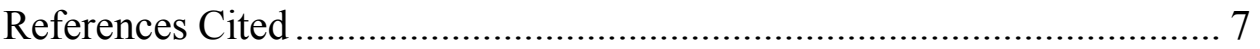

II. PREDATION RISK, COMPETITION, AND TERRITORIAL DAMSELFISHES AS DRIVERS OF HERBIVORE FORAGING ON CARIBBEAN CORAL REEFS .............................................................. 11

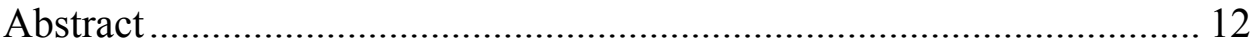

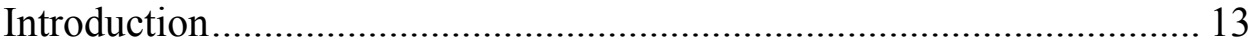

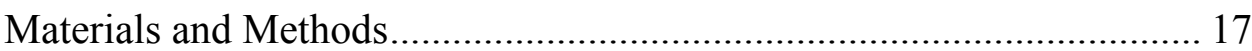

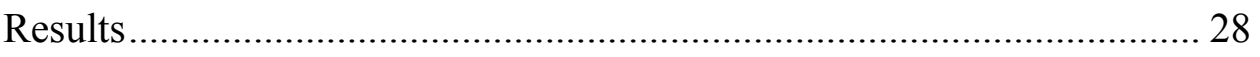

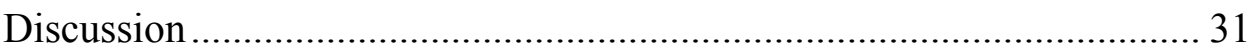

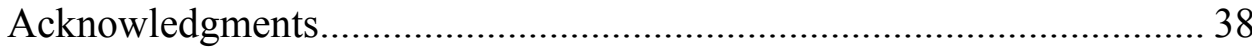

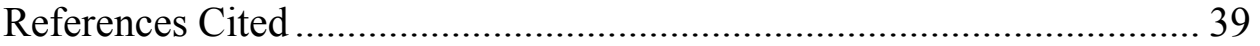

III. PREDATION RISK, RESOURCE QUALITY, AND REEF

STRUCTURAL COMPLEXITY SHAPE TERRITORIALITY IN A

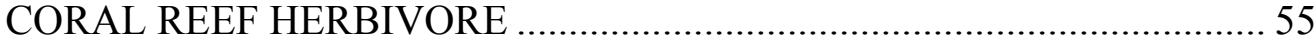

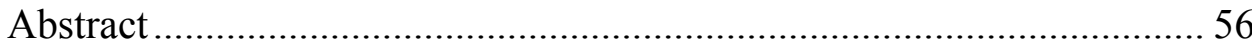

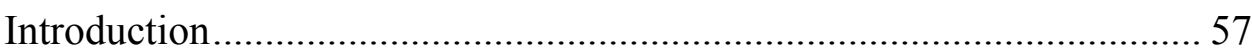

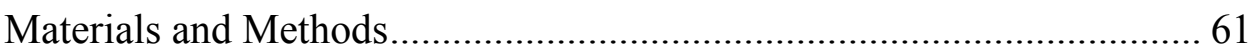

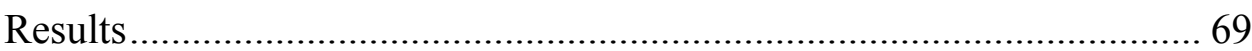

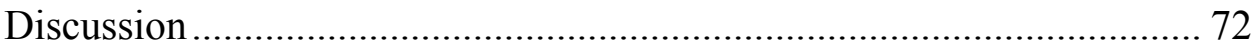

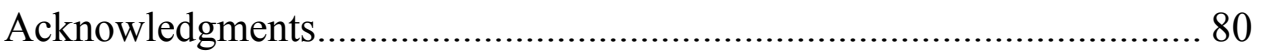

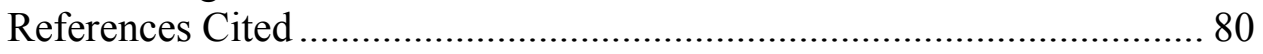

IV. REEFSCAPES OF FEAR: PREDATION RISK AND REEF

HETEROGENEITY INTERACT TO SHAPE HERBIVORE

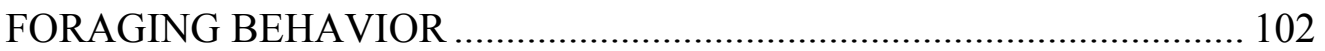

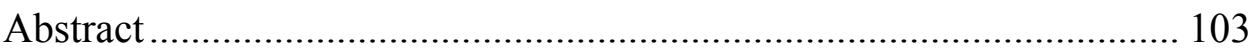

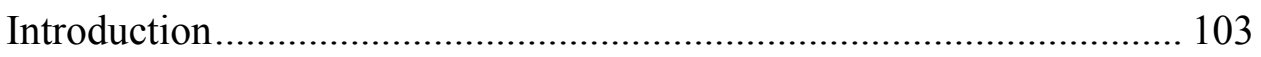

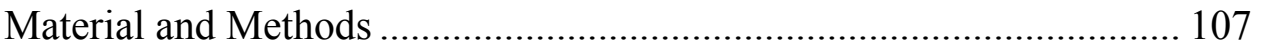

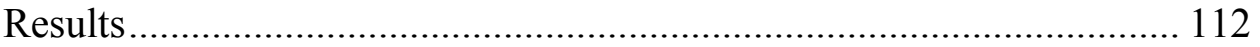

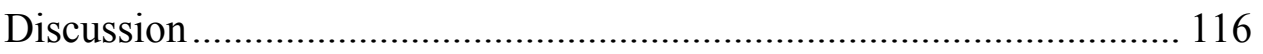

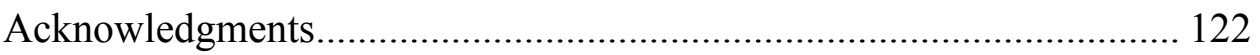

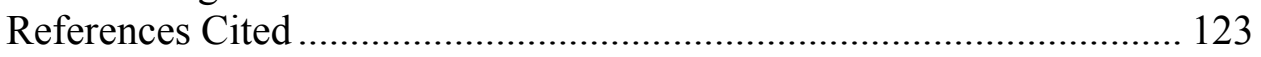

V. PREDATOR HUNTING MODE AND TIME OF DAY SHAPE THE RISK-REWARD TRADE-OFF IN FEEDING BEHAVIOR OF HERBIVOROUS FISHES ON A CORAL REEF ...................................... 143

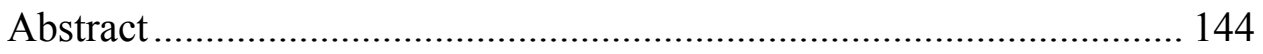

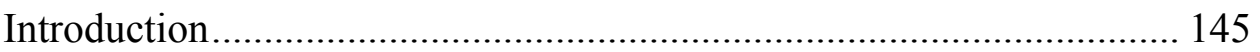




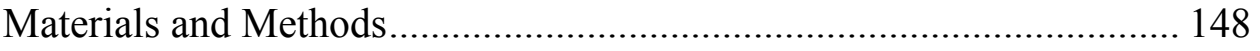

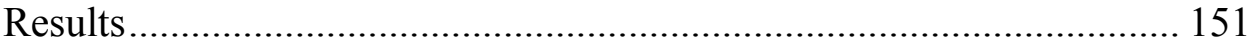

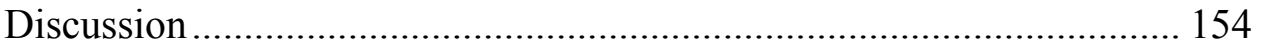

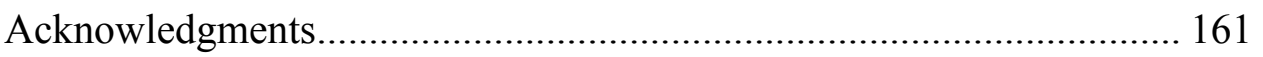

References Cited ..................................................................... 162

VI. CONCLUSION AND FUTURE DIRECTIONS .................................... 175

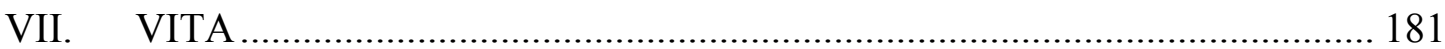




\section{LIST OF TABLES}

TABLE

PAGE

\section{CHAPTER II}

2.1 Study sites with GPS coordinates, protection status (Protected (P) or Not Protected (NP) and means of fish biomass, abundance, rugosity and benthic community $(\%$ cover $)$

2.2 Correlation between four principle components and seven site level predictors. Bold entries indicate significant correlations at the $\alpha=0.05$ level. Values in parentheses indicate percent of variance explained by each PC axis.

2.3 The effects ( $\beta$ (SE)) of PC1 (damselfish abundance), PC2 (competitor biomass), PC3 (Turf/algae/sediment (TAS) cover), PC4 (predator biomass) and fish total length on $\delta^{13} \mathrm{C}$ and $\delta^{15} \mathrm{~N}$ values for $S$. aurofrenatum and $A$. coeruleus based on hierarchical models with site as a random effect (intercept only). Conditional $\mathrm{R}^{2}$ values $\left(\mathrm{R}_{\text {LMM(c) }}^{2}\right)$ describe the variance explained by the entire mixed effects model, while marginal $\mathrm{R}^{2}$ values $\left(\mathrm{R}_{\mathrm{LMM}(\mathrm{m})}^{2}\right)$ describe variance explained by only fixed factors. Asterisks $(*)$ indicate significance for terms in the models.... 48

2.4 Diet components $(\% \pm \mathrm{SEM})$ of S. aurofrenatum based on behavioral follows and $A$. coeruleus based stomach contents. Minor components are listed in the text. Unidentified Organic Material (UOM) was not categorized for $S$.

aurofrenatum

\section{CHAPTER III}

3.1 Study sites with GPS coordinates, protection status (Protected (P) or Not Protected (NP) and means fish biomass, abundance, rugosity and benthic community ( $\%$ cover $)$.

3.2 Results from two-way ANOVAs for differences in (a) macroalgal cover, (b) $\mathrm{C}: \mathrm{N}$ ratios for Dictyota menstrualis and (c) rugosity with protection status (inside and outside of protected areas) and territory status (within and outside of territories).

3.3 Summary of ANCOVA models for the influence of male length and protection status on territory quality variables.

3.4 Summary of mixed-effects models for territory quality variables and site level predictors of predator and competitor biomass. 
3.5 Mean \pm SE of male size, female size and harem size among protected and unprotected sites.

3.6 Results from multiple regression models for relationships between (a) harem size and (b) average female size and territory quality metrics.

3.7 Summary of multiple logistic regression model for the probability of (a) engaging in aggressive interactions and (b) spawning, with territory quality variables, harem size, female size and reef protection status.

\section{CHAPTER IV}

4.1 Summary of two-way ANOVAs testing for effects of reef, predator treatment (i.e., grouper vs. control), rugosity (i.e., high vs. low) and their interaction on the percentage of seagrass consumed per minute based on seagrass measurements, and based on video observations: the bites on seagrass per minute, the bites on benthos per minute, individual feeding rates (bites/second) and forager size.

4.2 Summary of two-way ANOVAs testing for effects of rugosity (i.e., high vs. low), distance from grouper decoy (i.e., $1 / 2,1,2$, and $4 \mathrm{~m}$ ) and their interaction on percentage of seagrass consumed from assays (standardized by the length of each trial), bites on seagrass over time of video observation, feeding rates and forager size.

4.3 Summary of two-way ANOVAs testing for effects of rugosity (i.e., high vs. low), distance from grouper decoy (i.e., $1 / 2,1,2$, and $4 \mathrm{~m}$ ) and their interaction on bites on seagrass or benthos over time of video observation, individual feeding rates and forager size for (a) S. aurofrenatum and (b) A. coeruleus..... 131

\section{CHAPTER V}

5.1 Summary of two-way ANOVAs testing for effects of predator treatment (i.e., barracuda decoy, grouper decoy or control), time period (i.e., dawn, mid-day or dusk) and their interaction on the percentage of seagrass consumed, the total bites on seagrass or benthos, individual feeding rates and forager size. .... 167

5.2 Summary of ANCOVAs testing for effects of distance among three time periods (i.e., dawn, mid-day or dusk), and their interaction for two predator treatments (i.e., barracuda decoy, grouper decoy) on the percentage of seagrass consumed, the total bites on seagrass or benthos, individual feeding rates and forager size. 


\section{LIST OF FIGURES}

FIGURE

PAGE

\section{CHAPTER II}

2.1 Map of study sites in the northern reef tract of the Florida Keys National Marine Sanctuary (FKNMS)

2.2 Biplots of $\delta^{13} \mathrm{C}$ and $\delta^{15} \mathrm{~N}$ values $( \pm \mathrm{SD}$ ) for (a) S. aurofrenatum and (b) $A$. coeruleus with baseline corrected $\delta 13 \mathrm{C}$ values.

2.3 Partial regression plots for S. aurofrenatum showing the effect of (a) PC4 (predator biomass) and (b) PC1 (damselfish abundance) on Bayesian Standard Ellipse Area $\left(\mathrm{SEA}_{\mathrm{B}}\right)$. (c) Simple linear regression of PC1 (damselfish abundance) and $\mathrm{SEA}_{\mathrm{B}}$ for $A$. coeruleus. Note that because of the negative relationship between $\mathrm{PC} 1$ and damselfish abundance the $\mathrm{x}$-axis has been reversed in panel $\mathrm{b}$ and $\mathrm{c}$ to represent increasing damselfish abundance from left to right. Solid lines are fitted linear regressions

2.4 Predicted probability of occurrence of animal material and filamentous turf in stomachs of $A$. coeruleus as a function of fish length based on logistic regression model. Dashed lines represent $95 \%$ confidence intervals.

2.5 Regression plot for territorial damselfish abundance and ln-transformed predator biomass across sites. Line represents fitted linear regression.

\section{CHAPTER III}

3.1 Map of study sites sampled in the northern reef tract of the Florida Keys National Marine Sanctuary.

3.2 Territory areas $\left(\mathrm{m}^{2}\right)$ calculated every five minutes over the course of thirty minutes for four individual S. aurofrenatum.

3.3 Mean $( \pm \mathrm{SE})$ of territory sizes $\left(\mathrm{m}^{2}\right)$ in protected and unprotected areas.

Numbers above bars are the number of territories used to calculate means.

3.4 Map of 20 territories (polygons) and GPS tracks (triangles) at French Reef (a protected site).

3.5 Mean ( \pm SE) (a) Macroalgae cover, (b) C:N ratios of Dictyota menstrualis, and (c) Lidar-derived rugosity inside and outside territories at protected and unprotected reefs. Letters above bars represent differences among groups based on TukeyHSD post-hoc analysis. 
3.6 Male length and territory rugosity in (a) unprotected and (b) protected reefs. In panel (a), solid line represents fitted regression, shaded area represents $95 \%$ $\mathrm{CI}$ and points represent focal males observed.

3.7 Mean $( \pm$ SE) number of aggressive interactions by focal male with species of parrotfish. Letters above bars represent differences among species based on TukeyHSD post-hoc analysis.

\section{CHAPTER IV}

4.1 (a) Predator decoy of black grouper, Mycteroperca bonaci, anchored to the seafloor, (b) Sparisoma aurofrenatum biting standardized assay of Thalassia testudinum and (c) Mean \pm SE for percentage of seagrass consumed adjacent to predator decoy (fiberglass black grouper), decoy control (plastic carboy), or control (no carboy or decoy). Letters above bars represent differences among groups based on TukeyHSD post-hoc analysis.

4.2 Representative panoramic images of a (a) high and (b) low rugosity site.

4.3 Species distributions of foragers at different rugosity (HR: high rugosity, LR: low rugosity) and predator treatments (i.e., Grouper and Control)

4.4 Mean \pm SE (a) percentage of seagrass consumed/hour based on seagrass measurements, and based on video observations: (b) bites on seagrass/hour, (c) bites on benthos/hour, (d) individual feeding rates (bites/minute) and (e) forager size $(\mathrm{cm})$ at high and low rugosity sites and control and grouper treatments. Letters above bars in panel (e) represent differences among groups based on TukeyHSD post-hoc analysis.

4.5 Mean \pm SE (a) percentage of seagrass consumed/hour based on seagrass measurements, and based on video observations: (b) bites on seagrass/hour, (c) bites on benthos/hour, (d) individual feeding rates (bites/minute) and (e) forager size $(\mathrm{cm})$ at increasing distances from predator model. Asterisks $\left({ }^{*}\right)$ represent significant differences between rugosity treatments based on Tukey HSD post hoc comparisons.

4.6 Individual feeding rates (bites/second) at increasing distances from predator model for fishes $12-15 \mathrm{~cm}$. Asterisks (*) represent significant differences between rugosity treatments based on a TukeyHSD post hoc test.

4.7 Mean \pm SE (a) \& (b) bites/hour on seagrass or benthos, (c) \& (d) individual feeding rates (bites/minute) and (e) \& (f) forager size ( $\mathrm{cm}$ ) at increasing distances from predator model for $S$. aurofrenatum and A. bahianus. Asterisks 
(*) represent significant differences between rugosity treatments based on Tukey HSD post hoc comparisons.

4.8 Predicted probability of individual fishes taking multiple forays as a function of distance at (a) high and (b) low rugosity sites in grouper and control treatments based on logistic regression model. Dashed lines represent 95\% confidence intervals.

4.9 Size distributions of foragers near the predator model (at the 0.5 and 1 meter) at each predator (i.e., grouper and control) and rugosity (HR: High Rugosity and LR: Low Rugosity) treatment.

4.10 Plot of the nonmetric multidimensional scaling (NMDS) scores for the two most important axes for species abundance of herbivorous fishes. The red and black minimim convex polygons surround the grouper and control treatments, respectively. Squares and triangles represent high and low rugosity treatments, respectively. Species abbreviations are as follows: SA: S. aurofrenatum, AB: A. bahianus, SV: S. viride, AC: A. coeruleus, ScI: Sc. iserti, ST: Sc. taeniopterus, SR: S. rubripinne, SC: S. chrysopterum, ScV: Sc. vetula, ACh: A. chirurgus, ScCor: Sc. coeruleus, ScG: Sc. guacamaia, CH: Kyphosus sectatrix, ScC: Sc. coelestinus. Stress $=0.20$.

4.11 Predators observed per minute of video observation at four reefs in high and low rugosity sites.

\section{CHAPTER V}

5.1 (a) Predator decoys of a black grouper (Mycteroperca bonaci) and (b) a great barracuda (Sphyraena barracuda) anchored to the seafloor with a standardized assay of Thalassia testudinum in the foreground.

5.2 Mean $\pm \mathrm{SE}$ (a) percent seagrass consumed/hour, (b) total bites/hour, (c) individual feeding rates (bites/second) (square-root transformed) and (d) forager sizes amoung predator treatments (i.e., barracuda decoy, grouper decoy and control) and time periods (i.e., dawn, mid-day and dusk). Results of two way ANOVAs testing for the effects of predator and time period and their interaction $(\mathrm{P} \times \mathrm{T})$ on each feeding metric are indicated on each panel.

5.3 Histograms of average forager size from predator decoy trials at dawn, midday and dusk.

5.4 (a-b) The percent segrass consumed per hour, (c-d) total bites per hour and (e-f) forager size for grouper and barracuda treatments with increasing distance decoys. Solid lines represent fitted linear regressions for three time periods: dawn, mid-day and dusk. 
5.5 Plot of the nonmetric multidimensional scaling (NMDS) scores for the two most important axes for species abundance of herbivorous fishes. The red, black and green minimim convex polygons surround the barracuda, control and grouper treatments, respectively. Squares, triangles and diamonds represent dawn, dusk and mid-day treatments, respectively. Species abbreviations are as follows: SA: S. aurofrenatum, AB: A. bahianus, SV: $S$. viride, AC: A. coeruleus, SI: Sc. iserti, ST: Sc. taeniopterus, and ScV: Sc. vetula. Stress $=0.13$.

5.6 Mean \pm SE of the number of predators observed per hour among dawn, midday and dusk periods. Letters above bars indicate significance based on a Tukey HSD post hoc test. 
CHAPTER I

INTRODUCTION 
Predators act in diverse ways to have dramatic influences on ecological communities (Estes et al. 2011). By suppressing the abundance of their prey, predators can have important indirect effects on lower trophic levels. Trophic cascades develop as the effects of predators propagate down food webs and ultimately influence the distribution and abundance of primary producers (Paine 1980). Predators can also have indirect effects on lower trophic levels by altering prey behavior, resulting in behaviorally mediated trophic cascades (Dill et al. 2003). Multiple theoretical and empirical investigations from vastly different ecosystems demonstrate that predators can influence plant communities via behaviorally mediated pathways (Schmitz et al. 1997, Heithaus and Dill 2002, Werner and Peacor 2003, Creel et al. 2005, Stallings 2008, Gervasi et al. 2013). For example, following the reintroduction of wolves into Yellowstone National Park, elk (Cervus elaphus) reduced their use of preferred grassland foraging habitats and moved into the protective cover of wooded areas (Creel et al. 2005). Wolves initiated a behaviorally-mediated trophic cascade by deterring elk foraging behavior and therefore creating spatial refuges for woody browse species (Ripple and Beschta 2003). The ecological impact of sub-lethal or non-consumptive effects (NCEs) is often as strong or stronger than consumptive effects (Preisser et al. 2005). Despite the ubiquity and importance of NCEs, they have received relatively little attention in some ecosystems. In order to achieve a holistic understanding of how predators structure ecosystems it is essential to incorporate the role of NCEs.

Inherent in the idea of NCEs is that prey must make trade-offs to balance the conflicting demands of obtaining food and reproducing with staying safe. Prey must often reduce other fitness-enhancing activities in order to avoid predation. For instance, 
consumers will avoid resource rich habitats if they pose a significant risk (Gilliam \& Fraser 1987, Schmitz et al. 1997, Heithaus \& Dill 2002). Likewise, territory defense (Taylor 1988) and mating behaviors (Lima and Dill 1990) that can increase prey vulnerability to predation, diminish when predators are abundant (Sih 1994). We gain a mechanistic understanding of NCEs by examining the behaviors of animals and determining how they reconcile these conflicting demands.

An understanding of predator risk effects would be incomplete without considering variation across multiple contexts. Attributes of predators (e.g., hunting mode), the physical environment (e.g., light availability and habitat complexity) and prey (e.g., hunger state, size and vulnerability) can influence the magnitude and manner in which prey respond to risk. Thus, there are multiple contingencies which affect the strength and importance of NCEs in ecosystems. For example, hunger may drive prey to forage in potentially risky situations to avoid imminent starvation thereby decreasing the strength of NCEs (Heithaus et al. 2008). As a consequence, prey may exhibit seemingly maladaptive behaviors during high risk periods. Such contingencies are important for a developing a general understanding of NCEs, yet they are under-appreciated in many ecosystems.

Despite the relative importance of NCEs and the disproportionately large impact they may have on communities compared to consumptive effects (Werner and Peacor 2003, Schmitz et al. 2004), they have received relatively little empirical attention in coral reef ecosystems (but see Madin et al. 2010b, 2010a, Rizzari et al. 2014). Furthermore, no studies have examined how the importance of NCEs may change across a variety of ecological contexts (e.g., with variation in structural complexity or diel changes in light 
availability). Non-consumptive effects are predicted to be important in coral reef communities for a multitude of reasons. For instance, NCEs are more prevalent in ecosystems characterized by high structural complexity. Structural elements associated with complex habitats offer refugia, allowing predator and prey to overlap and interact in the same ecological domain. This structurally complex environment is ideal for the development of NCEs because it increases the ability of prey to respond behaviorally to predators (Grabowski 2004). Prey can switch among habitats and more effectively use tactical behaviors to manage risk and reward in heterogeneous habitats.

Predator-mediated changes to consumer foraging and reproductive behaviors have important conservation implications for coral reefs. Herbivorous fishes (e.g., parrotfishes and surgeonfishes) are functionally important for reefs because their grazing removes the majority of algal growth and facilitates coral settlement, growth and survivorship (Hughes et al. 2007, Mumby et al. 2007, Burkepile \& Hay 2008). By altering patterns of herbivory, predators could play an important role in the functioning of coral reef ecosystems via behaviorally mediated trophic cascades. Understanding the factors that shape their foraging decisions will be a key to knowing their impact on reef resilience and recovery in the face of global change.

For my dissertation research I combined a variety of approaches to examine the effect of predation risk on herbivore foraging and reproductive behaviors in a coral reef ecosystem. Each of my chapters furthers this goal in a different way. Two of my chapters are observational studies designed to take advantage of the anthropogenic-induced gradient in predator biomass across multiple reefs in the Florida Keys National Marine Sanctuary (FKNMS) created by variation in fishing pressure. In Chapter II, I examined 
diets of two common reef herbivores, Sparisoma aurofrenatum and Acanthurus coeruleus, across 12 sites of varying predator biomass. I used stable isotope analysis to understand the importance of predation risk relative to other known drivers of herbivore foraging decisions. In Chapter III, I investigated territoriality in a haremic, polygynous species of coral reef herbivore, S. aurofrenatum, across eight reefs that were either protected or unprotected from fishing of large predators. I examined how territory size and quality varied with reef protection status, competition, predation risk and male size. I then determined how territory size and quality influenced harem size and female size to understand the effect of territoriality on reproductive potential. These two chapters are unique in their scale and approach and among the first to specifically address the nonconsumptive effects of predators on behaviors of other reef fishes.

I used an experimental approach in the next two chapters to elucidate causal linkages between predation risk, herbivore foraging behavior and resource consumption and to identify sources of contingency affecting these linkages. In Chapter IV, I manipulated predation risk using model predator decoys to investigate how predation risk interacts with reef complexity to affect the foraging behavior and spatially-explicit impact of large herbivorous fishes (e.g., parrotfishes and surgeonfishes) across four coral reefs in the FKNMS. In Chapter V, I investigated how predator hunting mode affects foraging behavior of herbivorous fish within a temporally explicit context at Aquarius Research Base located on Conch Reef. I used two predator decoys of black grouper (Mycteroperca bonaci) (a sit-and-wait predator) and great barracuda (Sphyraena barracuda) (a sit-and-pursue predator) to manipulate predation risk over three times of day: dawn, mid-day and dusk. Together, Chapters IV and V develop a mechanistic 
understanding of NCEs on coral reefs by using a spatio-temporally explicit approach to link pattern to process.

Local and global anthropogenic impacts such as overfishing, global climate change and eutrophication have led to the world-wide decline in coral reef ecosystems (Gardner et al. 2003, Carpenter et al. 2008). The high economic, aesthetic, recreational and ecological value of coral reefs makes their continued persistence of great conservation concern. Reef herbivores have been recognized as important drivers in maintaining reefs in a state of coral dominance (Mumby 2006, Mumby et al. 2007b). By grazing macroalgae, which can otherwise overgrow and impede the recruitment and growth of corals, herbivores play a key role in the persistence and recovery of imperiled coral reef ecosystems. It is thus essential that we understand the factors, such as important species interactions, that promote or impede this key process on reefs. My dissertation work addresses predator-herbivore interactions and the influences they can have on the reef benthic community. The bulk of previous research investigating this interaction has focused on the consumptive role of predators. Yet, on the basis of current research in other systems, it is increasing clear that the non-consumptive role of predators can have important implications for the structure and function of ecosystems. It has been a challenge in ecological research to effectively address NCEs in a natural setting, and most investigations have scaled down to laboratory settings of limited duration. The results from work conducted in laboratory settings may not scale up to real world processes or capture complex interactions and natural variability inherent to natural systems. Using innovative methodology and new technologies, within a spatiotemporally explicit context, my work is among the first to specifically address the NCEs 
of predators on coral reefs. Thus, my research is both vital and timely because of the global threats to reefs, but also unique in its scale and approach. Specifically the power of my approach lies in: (1) the unique field-based methodology that allows examination of prey response's to the natural variability in predation risk; (2) the multi-factor design including both habitat structural complexity and diel patterns to explicitly model variation in predation risk across the reef landscape and with time; and (3) the three-tier level of questioning that ultimately links predation risk back to prey resource consumption. Ultimately, this dataset will make important connections between behavioral ecology and ecosystem structure and function and will be one of the first to track cascading effects of predators in reef ecosystems. The results of this research are crucial to fill serious gaps in our knowledge of the role of predators in imperiled coral reef ecosystems, and to add a realistic level of understanding necessary to further ecological theory of NCEs.

\section{References Cited}

Abrahams, M. V, and L. M. Dill. 1989. A determination of the energetic equivalence of the risk of predation. Ecology 70:999-1007.

Burkepile, D. E., and M. E. Hay. 2008. Herbivore species richness and feeding complementarity affect community structure and function on a coral reef. Proceedings of the National Academy of Sciences of the United States of America 105:16201-6.

Carpenter, K. E., M. Abrar, G. Aeby, R. B. Aronson, S. Banks, A. Bruckner, A. Chiriboga, J. Cortés, J. C. Delbeek, L. Devantier, G. J. Edgar, A. J. Edwards, D. Fenner, H. M. Guzmán, B. W. Hoeksema, G. Hodgson, O. Johan, W. Y. Licuanan, S. R. Livingstone, E. R. Lovell, J. a Moore, D. O. Obura, D. Ochavillo, B. a Polidoro, W. F. Precht, M. C. Quibilan, C. Reboton, Z. T. Richards, A. D. Rogers, J. Sanciangco, A. Sheppard, C. Sheppard, J. Smith, S. Stuart, E. Turak, J. E. N. Veron, 
C. Wallace, E. Weil, and E. Wood. 2008. One-third of reef-building corals face elevated extinction risk from climate change and local impacts. Science (New York, N.Y.) 321:560-3.

Creel, S., J. Winnie, B. Maxwell, K. Hamlin, and M. Creel. 2005. Elk Alter Habitat Selection As an Antipredator Response To Wolves. Ecology 86:3387-3397.

Dill, L., M. R. Heithaus, and C. Walters. 2003. Behaviorally mediated indirect interactions in marine communities and their conservation implications. Ecology $84: 1151-1157$.

Estes, J. a, J. Terborgh, J. S. Brashares, M. E. Power, J. Berger, W. J. Bond, S. R. Carpenter, T. E. Essington, R. D. Holt, J. B. C. Jackson, R. J. Marquis, L. Oksanen, T. Oksanen, R. T. Paine, E. K. Pikitch, W. J. Ripple, S. a Sandin, M. Scheffer, T. W. Schoener, J. B. Shurin, A. R. E. Sinclair, M. E. Soulé, R. Virtanen, and D. a Wardle. 2011. Trophic downgrading of planet Earth. Science (New York, N.Y.) 333:301-6.

Gardner, T. A., I. Cote, J. Gill, A. Grant, and A. R. Watkinson. 2003. Long-term regionwide declines in Caribbean corals. Science (New York, N.Y.) 301:958-960.

Gervasi, V., H. Sand, B. Zimmermann, J. Mattisson, P. Wabakken, and J. D. C. Linnell. 2013. Decomposing risk: landscape structure and wolf behavior generate different predation patterns in two sympatric ungulates. Ecological applications : a publication of the Ecological Society of America 23:1722-34.

Gilliam, J. F., and D. F. Fraser. 1987. Habitat Selection Under Predation Hazard : Test of a Model with Foraging Minnows. Ecology 68:1856-1862.

Grabowski, J. H. 2004. Habitat Complexity Disrupts Predator-Prey Interactions But Not the Trophic Cascade on Oyster Reefs. Ecology 85:995-1004.

Heithaus, M. R., and L. Dill. 2002. Food availability and tiger shark predation risk influence bottlenose dolphin habitat use. Ecology 83:480-491.

Heithaus, M. R., A. Frid, A. J. Wirsing, and B. Worm. 2008. Predicting ecological consequences of marine top predator declines. Trends in ecology $\&$ evolution 23:202-10.

Hughes, T. P., M. Rodrigues, D. R. Bellwood, D. M. Ceccarelli, O. Hoegh-Gudberg, L. J. Mccook, N. Moltschaniwskyj, M. Pratchett, R. S. Steneck, and B. Willis. 2007. Phase shifts, herbivory, and the resilience of coral reefs to climate change. Current Biology 17:360-365.

Lima, S. L., and L. M. Dill. 1990. Behavioral decisions made under the risk of predation: a review and prospectus. Canadian Journal of Zoology 68:619-640. 
Madin, E. M. P., S. D. Gaines, J. S. Madin, and R. R. Warner. 2010a. Fishing indirectly structures macroalgal assemblages by altering herbivore behavior. The American Naturalist 176:785-801.

Madin, E. M. P., S. D. Gaines, and R. R. Warner. 2010b. Field evidence for pervasive indirect effects of fishing on prey foraging behavior. Ecology 91:3563-3571.

Mumby, P. J. 2006. The impact of exploiting grazers (Scaridae) on the dynamics of caribbean coral reefs. Ecological Applications 16:747-769.

Mumby, P. J., A. R. Harborne, J. Williams, C. V Kappel, D. R. Brumbaugh, F. Micheli, K. E. Holmes, C. P. Dahlgren, C. B. Paris, and P. G. Blackwell. 2007a. Trophic cascade facilitates coral recruitment in a marine reserve. Proceedings of the National Academy of Sciences of the United States of America 104:8362-7.

Mumby, P. J., A. Hastings, and H. Edwards. 2007b. Thresholds and the resilience of Caribbean coral reefs. Nature 450:98-101.

Paine, R. T. 1980. Food Webs: Linkage, Interaction Strength and Community Infrastructure. The Journal of Animal Ecology 49:666.

Preisser, E. L., D. I. Bolnick, and M. E. Benard. 2005. Scared to death? The effects of intimidation and consumption in predator-prey interactions. Ecology 86:501-509.

Ripple, W. J., and R. L. Beschta. 2003. Wolf reintroduction, predation risk, and cottonwood recovery in Yellowstone National Park. Forest Ecology and Management 184:299-313.

Rizzari, J. R., A. J. Frisch, A. S. Hoey, and M. I. McCormick. 2014. Not worth the risk: apex predators suppress herbivory on coral reefs. Oikos:no-no.

Schmitz, O. J., A. P. Beckerman, and K. M. O’Brien. 1997. Behaviorally mediated trophic cascades : Effects of predation risk on food web interactions. Ecology 78:1388-1399.

Schmitz, O. J., V. Krivan, and O. Ovadia. 2004. Trophic cascades: the primacy of traitmediated indirect interactions. Ecology Letters 7:153-163.

Sih, A. 1994. Predation risk and the evolutionary ecology of reproductive behavior. Journal of Fish Biology 45:111-130.

Stallings, C. D. 2008. Indirect effects of an exploited predator on recruitment of coralreef fishes. Ecology 89:2090-2095. 
Taylor, R. J. 1988. Territory size and location in animals with refuges : influence of predation risk. Evolutionary Ecology 2:95-101.

Werner, E. E., and S. D. Peacor. 2003. A Review of Trait-Mediated Indirect Interactions in Ecological Communities. Ecology 84:1083-1100. 
CHAPTER II

PREDATION RISK, COMPETITION, AND TERRITORIAL DAMSELFISHES AS DRIVERS OF HERBIVORE FORAGING ON CARIBBEAN CORAL REEFS 
Abstract

Food availability, competition, habitat complexity, and territorial damselfish shape foraging decisions of herbivorous coral reef fishes. However, relatively little is known about how predators affect herbivore diet selection. We examined diets of two common reef herbivores, Sparisoma aurofrenatum and Acanthurus coeruleus in the Florida Keys, across sites of varying predator biomass. We used stable isotope analysis to understand the importance of predation risk relative to other known drivers of herbivore foraging decisions. For S. aurofrenatum we found that greater predator biomass was associated with an increase in the diversity of resources consumed within populations. In contrast, increasing densities of damselfishes, which aggressively defend resource-rich algal gardens, was associated with lower diet diversity. However, within A. coeruleus populations, diet diversity increased with damselfish abundance, but was unrelated to predator biomass. Stomach content analyses and direct observation of diet selection in the field corroborated the stable isotope analysis. Importantly, both predator and damselfish abundance impacted diet diversity in different ways for these two fishes, which may be linked to differences in sociality and group foraging. A. coeruleus is more likely to forage in schools potentially reducing predation risk and allowing them to overwhelm damselfishes and access their territories. Interestingly, damselfish abundance was positively correlated with predator biomass suggesting that predators may influence herbivore diets indirectly via altered densities or behavior of damselfishes. Our work argues for more emphasis on the role of predation risk in affecting herbivore foraging in order to understand the implications of human-mediated predator removal and recovery in coral reef ecosystems. 
Introduction

Animals often make trade-offs to balance the conflicting demands of obtaining energy required for growth and reproduction while avoiding competitors or predators (Lima and Dill 1990, Houston et al. 1993). For instance, herbivores often avoid resource rich but risky habitats in order to stay safe (Gilliam \& Fraser 1987, Schmitz et al. 1997, Heithaus \& Dill 2002). Tradeoffs like this are a fundamental organizing principle in ecological communities (Werner and Anholt 1993). Ultimately, it is important to understand the determinants of foraging behavior, even when the consequences of any single foraging decision are small, because the cumulative effects of foraging decisions can alter community dynamics and ecosystem processes (Schmitz 2008b).

Many abiotic and biotic factors determine the foraging behavior and diet of herbivorous fishes on coral reefs including resource availability and quality, inter- and intraspecific competition, and habitat complexity. For example, herbivores must acquire enough algae of sufficient nutritional quality while avoiding species that are chemically or morphologically defended (Hay 1991). Thus, where palatable algae are more abundant, they will likely be more abundant in the diets of fishes. Also, both inter- and intraspecific competitive interactions can alter foraging behavior (Muñoz and Motta 2000), as resource overlap is often high among large herbivorous fishes (e.g., parrotfishes and surgeonfishes) (Bellwood and Choat 1990). Therefore, when competition for the same limiting resources is intense, inferior competitors may be forced to consume less optimal resources (Milinski 1982). Interspecific competitors such as territorial damselfish can also affect how larger herbivorous fish forage (Foster 1985) by aggressively defending the algal gardens within their territories (Hixon and Brostoff 1983). Fishes that 
can invade defended algal gardens gain access to a greater diversity of algal resources (Klumpp and Polunin 1989). Finally, structural complexity (i.e., rugosity) can affect both algal cover (Graham and Nash 2013) and fish densities (Roberts \& Ormond 1987), which in turn can affect density-dependent competitive interactions (Carr et al. 2002). Thus, in structurally complex areas, where fish are more abundant and resources are often scarce, herbivorous fish may be forced to consume less optimal resources relative to those in low complexity areas, which are less preferred habitats and may have better quality food sources.

Predation risk is likely also an important factor affecting foraging by herbivorous fishes in reef ecosystems, however, it has received relatively little empirical attention (but see Madin et al. 2010a). Evidence from many different ecosystems shows important and ubiquitous effects of predators on foraging behavior of their prey (termed nonconsumptive effects; NCEs) (e.g., Schmitz et al. 1997, Heithaus \& Dill 2002, Preisser et al. 2005, Ripple \& Beschta 2007). In coral reefs, predators have an important consumptive role in affecting the size structure and abundance of their prey (McClanahan and Muthiga 1988, Mumby et al. 2006, 2012), however few studies have investigated the NCEs of reef predators on herbivorous fishes, especially the responses of multiple families of herbivores. In the central Pacific's remote northern Line Islands, Madin et al. (2010a) demonstrated that predation risk was associated with decreased excursion area of multiple prey fish species. This work suggests that NCEs may play an important but underappreciated role in consumer-prey interactions on coral reefs.

Large predatory fishes such as sharks and large grouper are rare on most modern reefs, except in relatively remote places (Sandin et al. 2008) or in well-established marine 
protected areas protected from fishing (Russ and Alcala 2010) due primarily to overexploitation (Myers and Worm 2003). Such drastic declines in predator abundance may have profoundly altered foraging behavior of reef herbivores. This may be especially true for long-lived, iteroparous species such as parrotfishes (Scaridae) and surgeonfishes (Acanthuridae) as their life-histories may select for responses that minimize predation risk (Heithaus et al. 2008). Additionally, these herbivores are very versatile in diet (Bellwood et al. 2006) and social organization (van Rooij et al. 1996) across local environmental conditions, suggesting that they may respond to changes in predator abundance with alterations in foraging behavior or diet. Understanding the drivers of foraging behavior for these herbivores is important to reef health as they are key for removing algae and facilitating coral settlement, growth, and survivorship (Hughes et al. 2007, Mumby et al. 2007a, Burkepile and Hay 2008).

The influence of predation risk on the diets of herbivorous fish depends on how individuals alter their foraging behavior in response to intimidation. Prey could potentially respond to risk by shifting habitats and foraging only in safer areas (Werner et al. 1983). Prey could also respond by staying in riskier areas but limiting their movement or reducing their excursion area (i.e., area they move over during a given time period) (Madin et al. 2010a). Both of these responses could potentially decrease individual diet diversity because algal resources are heterogeneously distributed on reefs (Hay 1991), and thus reduced foraging area would likely reduce the diversity of potential diet items that are encountered. However, individual diet diversity could also increase under this scenario. If fishes are constrained to foraging in risk-free areas, they may be forced to broaden their diet by consuming the resources that are most available, but typically low- 
preference. In contrast, individuals in areas with low predator abundance that are unconstrained in foraging area, would likely have a narrower diet consisting primarily of their preferred foods. Furthermore, the relationships between individual herbivorous fish foraging behavior and predation risk are likely species dependent. Factors such as body size, physiology, and social behavior will likely shape different trade-offs between food and safety across species (Wirsing et al. 2010, Preisser and Orrock 2012). For example, species that typically forage in groups may be less likely to change their behavior with increased predation risk due to the dilution of risk on individual foragers (Creel 2011).

The collective responses of individual-level foraging decisions to increased predation risk may be apparent at the population level (Araújo et al. 2011). For instance, in high risk areas, if individuals are forced to change their foraging behavior and expand their diets beyond targeting preferred resources, the population trophic niche (i.e., diet variation among individuals) would likely increase. Where predation risk is low and individual diets converge on preferred resources, the trophic niche of a population would likely remain small. However, not all individuals may respond the same way to risk. If only some individuals are risk averse and alter their foraging behavior while others do not (Coleman and Wilson 1998), it is plausible that the trophic niche of a population may not change much . Therefore, for a more complete understanding of the influence of predation risk, it is important to consider both individual and population responses.

We investigated the relative importance of multiple factors including: (1) algal community structure, (2) territorial damselfish abundance, (3) competition with other herbivorous fishes, (4) habitat structural complexity, and (5) predation risk, in influencing the foraging behavior and diet selection of the blue tang (Acanthurus coeruleus) and 
redband parrotfish (Sparisoma aurofrenatum) across twelve reefs in the Florida Keys (USA). We used stable isotope analysis (SIA) (a time and space-integrated metric of diet) in conjunction with stomach content analysis and observations of foraging fishes (which represent recent diet choices) to investigate how resource use differed for each species across sites. We then investigated the effect of site characteristics (e.g., predator biomass, damselfish abundance, algal cover) on individual diet selection and on diet diversity within populations. We hypothesized that increasing competitive interactions (i.e., with other large herbivorous fishes) and/or predation risk would restrict access to preferred food resources and force herbivores to consume a broader diet of less preferred foods, thereby increasing diet diversity within populations. Additionally, we hypothesized that abundant territorial damselfishes would increase diet diversity within populations by increasing the diversity of resources available but only for those herbivores that can gain access to these resources.

Materials and Methods

Site Description

The Florida Keys reef tract is a large bank reef ecosystem located approximately $8 \mathrm{~km}$ offshore of the Florida Keys, USA. Fishing pressure in the region is high with both commercial and recreational fisheries heavily exploiting carnivorous fishes (e.g., snapper, grouper, and barracuda) (Bohnsack et al. 2009). However, in 1997, 23 no-take zones were designated within the Florida Keys National Marine Sanctuary (FKNMS) to eliminate all fishing activity within those areas (Bohnsack et al. 2009). Within these protected areas piscivorous fishes have increased in size and abundance (Bohnsack et al. 
2009, Smith et al. 2011). Unlike most piscivores, herbivorous fishes (e.g., parrotfish, surgeonfish, etc.) are protected across the entirety of the FKNMS (i.e., in both protected and unprotected zones), and their populations are robust in the FKNMS relative to most other reefs in the wider Caribbean (Burkepile et al. 2013a). FKNMS is an ideal region to test hypotheses about the functional impact of predators on herbivorous fish as it does not confound predator effects (e.g. protected vs. unprotected areas) with vast differences in herbivore abundance across reefs as herbivores are protected everywhere.

From June-August of 2011 we sampled twelve forereef sites between 6-8 m depths along the northern reef tract off of Key Largo (Table 2.1, Fig. 2.1). We chose reefs that were similar in physical parameters (e.g., depth and structure) and that were separated by at least $700 \mathrm{~m}$ to assure independence. With the exception of large, mobile predators such as jacks, most reef fishes are unlikely to move among reefs over such distances, particularly when separated by open areas (i.e., large expanses of sand or rubble) (Chapman and Kramer 2000), as was the case with the sites used in this study. Sites included eight protected and four unprotected areas. At each site we sampled fishes for dietary analyses and conducted benthic and fish community surveys either on the same day or within a few days of each other. All surveys and sampling were conducted over the same time period (10:00 - 14:00 h) using SCUBA.

\section{Characterizing Fish and Benthic Communities}

To quantify fish abundance and benthic cover at each site we conducted surveys along eight $25 \mathrm{~m}$ transects that were laid out parallel to the main reef formation. On the initial pass, we identified and visually estimated the fork length of all fishes, with the 
exception of territorial damselfish species, within a $4 \mathrm{~m}$ wide window. We used $1 \mathrm{~m}$ long PVC T-bars to help estimate lengths to the nearest $\mathrm{cm}$. We counted individuals of territorial damselfish species (i.e., Stegastes and Microspathodon spp.) within a $2 \mathrm{~m}$ wide window on the second transect pass, because they have high site fidelity and are generally tolerant to diver presence. We used published length:weight relationships to convert fish lengths to biomass (Bohnsack \& Harper 1988). The urchin, Diadema antillarum, once a dominant reef herbivore, has remained rare since the mass mortality throughout the Caribbean in the early 1980's and were not quantified (Lessios 1988, Chiappone et al. 2002). On a third pass over each transect, photographs of the benthos were taken every meter to produce $50 \mathrm{~cm} \times 50 \mathrm{~cm}$ photo-quadrats $(\mathrm{n}=25$ per transect). These photographs were analyzed for cover of benthic organisms using Coral Point Count V4.1 (Kohler and Gill 2006). Categories were created for: (1) crustose coralline algae, short algal turf (algal filaments $<0.5 \mathrm{~cm}$ tall) and bare space (abbreviated CTB 'crustose, turf, bare'), (2) turf algae (algal filaments $>0.5 \mathrm{~cm}$ tall) and sediment (abbreviated TAS - 'turf algae, sediment'), (3) sponges, (4) gorgonians and (5) zoanthids. Macroalgae were classified to genus and scleractinian corals to species.

Structural complexity (i.e., rugosity) of each reef was calculated for each site using a Lidar (Light Detection and Ranging)-derived bathymetric data set provided by the U.S. Geological Survey (USGS) (available online http://pubs.usgs.gov/of/2007/1395/start.html). We used this dataset to create a raster of benthic rugosity (1 $\mathrm{m} \times 1 \mathrm{~m}$ resolution) with the Benthic Terrain Modeler (a collection of ESRI ArcGIS-based tools available online http://www.csc.noaa.gov/digitalcoast/tools/btm/index.html). We used benthic habitat 
maps available from the FKNMS (http://flkeysbenthicmaps.noaa.gov/) to distinguish reef from non-reef habitats (e.g., seagrass, sand, rubble). We then used the ArcGIS zonal statistics tool to calculated average rugosity of reef habitat within a $250 \mathrm{~m}$ radius of where fish were captured at each reef (see below).

Fish Collection and Processing for Stable Isotope Analysis

We focused our research on the parrotfish Sparisoma aurofrenatum and surgeonfish Acanthurus coeruleus because they are often numerically dominant on reefs in the Caribbean (Lewis \& Wainwright 1985) and are similar in size. While both species are known to feed on turf algae and macroalgae, they vary in their adaptations for herbivory. S. aurofrenatum possesses grinding dentition which enables this species to target leathery algal forms and scrape calcareous sediment, whereas A. coeruleus has relatively weak mouth parts, a complex alimentary architecture and symbiotic microbes for fermentative digestion (Choat 1998). Additionally, these species vary in their social organization. Adult S. aurofrenatum are generally solitary or move in small groups (Mumby \& Wabnitz 2002), whereas A. coeruleus are often aggregate and forage in large schools (Morgan and Kramer 2005).

We collected fifteen individuals of adult size class for S. aurofrenatum (mean: 20 $\mathrm{cm}$, range $15-27 \mathrm{~cm}$ both terminal and initial phase) and A. coeruleus (mean: $18 \mathrm{~cm}$, range: $12-27 \mathrm{~cm}$ ) at each site using barrier and hand nets. We measured the total length (TL) and weight for each specimen. We then clipped a small portion of dorsal fin tissue, which was immediately frozen for later analysis. S. aurofrenatum individuals were released back onto the reef after fin sample collection, and A. coeruleus were euthanized 
with $95 \%$ eugenol, placed on ice, and transported back to the lab where they were frozen for later stomach content analysis. Variation in isotopic composition among consumers could reflect variation in the isotopic composition of their algal diets (Post 2002). Therefore, to account for potential differences in isotopic baselines we collected portions ( $n=8$ per species where possible) of two commonly consumed species of algae, Halimeda tuna and Dictyota menstrualis at each site.

All fin and algal samples were dried at $60^{\circ} \mathrm{C}$, ground to a fine powder with a mortar and pestle, and weighed into tin capsules for SIA of $\delta^{13} \mathrm{C}$ and $\delta^{15} \mathrm{~N}$. Prior to analysis of $\delta^{13} \mathrm{C}$, ground samples of $H$. tuna (a highly calcified species) were washed in a $10 \% \mathrm{HCl}$ solution, rinsed with deionized water, re-dried and ground in order to remove inorganic carbon. All isotopic analyses were measured using a standard elemental analyzer isotope ratio mass spectrometer (EA-IRMS) procedures. Isotopic ratios (R) are reported in the standard delta notation $(\%): \delta(\%)=\left[\left(\mathrm{R}_{\text {sample }} / \mathrm{R}_{\text {standard }}\right)-1\right] * 1000$. These results are presented with respect to the international standards of atmospheric nitrogen (AIR, $\mathrm{N}_{2}$ ) and Vienna Pee Dee belemnite (V- PDB) for carbon.

\section{Characterizing Fish Diets}

SIA of carbon and nitrogen was used to estimate individual trophic level and basal resource use, and population trophic niche. Trophic level (e.g., first order or second order consumer) can be estimated from the ratio of ${ }^{15} \mathrm{~N}$ to ${ }^{14} \mathrm{~N}\left(\right.$ expressed as $\left.\delta^{15} \mathrm{~N}\right)$ because ${ }^{15} \mathrm{~N}$ becomes enriched in the tissues of organisms with each trophic step (Peterson \& Fry 1987). The basal source of carbon can be estimated by comparing the ratio of ${ }^{13} \mathrm{C}$ to ${ }^{12} \mathrm{C}$ (expressed as $\delta^{13} \mathrm{C}$ ) in consumers and potential diet items because $\delta^{13} \mathrm{C}$ 
changes very little with each trophic step (Peterson \& Fry 1987). Therefore, by examining isotopic signatures separately we can test hypotheses about the source of diet variation among individuals. We can infer if differences in diet are the result of differences in basal resource use and/or trophic level.

$\delta^{15} \mathrm{~N}$ and $\delta^{13} \mathrm{C}$ values provide two dimensions of resource use that can be used in concert to assess the isotopic or trophic niche of a population (Newsome et al. 2007). At sites where individuals have a broader range of items in their diets there would be greater isotopic variance (greater spread in $\delta^{15} \mathrm{~N}$ and $\delta^{13} \mathrm{C}$ values) within those populations. Therefore, those populations would have increased diet diversity or a larger trophic niche. Contrarily, at sites where individuals have similar diets, the population as a whole would have a smaller trophic niche. Therefore, by examining variation in trophic niche we can test hypotheses about differences in diet diversity among populations.

In addition to SIA, we analyzed stomach contents of $A$. coeruleus and feeding behavior of S. aurofrenatum. These two metrics give a snapshot of recent diet decisions that we could compare with isotope data which provides a metric of foraging decisions that is integrated over larger spatial and temporal scales (Heady and Moore 2013). The grinding of food by the pharyngeal mill of S. aurofrenatum makes identification of stomach contents challenging, even under high magnification. Therefore, we used field observations of feeding behavior rather than gut contents to determine diet composition for this species. Alternately, field observations of A. coeruleus feeding behavior would have been challenging because of their high feeding rates. We used alternate methods for both species because we were not comparing these metrics between species, but rather we were using them to compare with and support inferences from SIA data. 
A. coeruleus specimens were kept frozen until they were dissected in the laboratory. Their alimentary tract and associated viscera were dissected and materials from the stomach were preserved in $10 \%$ buffered formalin and stored in a $70 \%$ ethanol solution. Contents were sorted under 4 x 10 magnification and categorized as thallate red algae (e.g., Laurencia, Hypnea, Botryocladia), thallate green algae (e.g., Ulva, Halimeda), thallate brown algae (e.g., Dictyota, Sargassum), filamentous turf (e.g., Polysiphonia, Cladophora), calcareous sediment, animal material or unidentifiable organic material (i.e., organic contents that lacked any structural form and could not be distinguished). After sorting, we dried samples at $60^{\circ} \mathrm{C}$ and weighed them to the nearest milligram. In cases where filamentous turf or organic material could not be physically separated from calcareous sediment, these samples were ashed at $500^{\circ} \mathrm{C}$ for 24 hours and the ash-free dry weight was subtracted from dried weight to determine the dry weight of turf or organic material. From these data, we calculated the percentage of the overall stomach contents that each diet category represented.

At each site, $30 \mathrm{~S}$. aurofrenatum of adult size class (>15 cm TL), including terminal and initial phases, were followed on SCUBA by one diver for a total of six minutes and observations of feeding behavior began after a one-minute acclimation period. Divers maintained a distance of at least $1 \mathrm{~m}$ behind and $1 \mathrm{~m}$ above the focal fish to limit diver influence on fish behavior. Bites were recorded as filamentous turf, macroalgae, coral, crustose coralline algae (CCA), sponge, and other. Macroalgae were identified to species level where possible or to genus otherwise. From these data, we calculated the proportion of bites each fish took from each diet category. 


\section{Statistical Analyses}

All statistical analyses were conducted using $\mathrm{R}$ version 3.0.1. Parametric assumptions of normality and homoscedasticity were verified using plots of the residuals. In one of our analyses, for a simple linear regression between predator biomass and damselfish abundance, predator biomass was ln-transformed to meet normality assumptions. Biomass of large predators and competitors were used as proxies for the level of predation risk and the degree of competition, respectively. We chose biomass because it incorporates both fish size and abundance and has been shown to be meaningful for detecting the direct and indirect effects of fishing on coral reefs (Madin et al. 2010a). We defined competitor biomass as the combined biomass of Acanthuridae and Scaridae. We estimated large predator biomass by summing all primarily piscivorous fishes of the families Carangidae, Lutjanidae, Serranidae and Sphyraenidae that were > $30 \mathrm{~cm}$ and known to consume adult parrotfishes and surgeonfishes (based on Randall 1967). We tested for the effect of protection status on predator biomass using a Welsh Two-sample t-test.

Because of the large number of predictors we wanted to incorporate in the analysis relative to the limited number of sample reefs, we performed a principle component analysis (PCA) on site-level predictors (including: rugosity, cover of Halimeda spp., cover of Dictyota spp., cover of TAS, territorial damselfish abundance, large predator biomass, and herbivorous fish biomass) to create uncorrelated principle components that described the different reefs (Graham 2003). We standardized each variable prior to the PCA by centering and scaling (i.e., subtracting each observation by the group mean and dividing by the standard deviation). We used scores of principle 
components in subsequent analyses and made interpretations based on correlations between principle component axes and original variables (Husson et al. 2010). We investigated how fish diet (based on isotopic data and observational/stomach content data) varied along principle component axes for each species. It is important to note that although certain reef characteristics (e.g., predator biomass, damselfish abundance) were correlated more or less strongly with the PCA axes, the axes represent composite variables that are loaded on more than one of the original variables. Thus, multiple reef characteristics likely influence the correlations between PCA axes and our metrics of fish diets, even if only a limited subset of these characteristics strongly influenced the PCA.

Prior to analyzing fish isotopic data we tested and corrected for differences in isotopic baselines. We used analysis of variance (ANOVA) to test for differences in $\delta^{15} \mathrm{~N}$ and $\delta^{13} \mathrm{C}$ among sites using two species of algae, $H$. tuna and $D$. menstrualis. We did not find a significant difference among sites in $\delta^{15} \mathrm{~N}$ values of $H$. tuna (ANOVA, $\mathrm{F}_{11,39}=$ $1.39, \mathrm{p}=0.21$ ) or D. menstrualis (ANOVA, $\mathrm{F}_{11,56}=1.68, \mathrm{p}=0.11$ ). Therefore, we attributed variation in consumer $\delta^{15} \mathrm{~N}$ values to differences in diet, not differences in baselines. We did find significant differences in $\delta^{13} \mathrm{C}$ values of $H$. tuna (ANOVA, $\mathrm{F}_{11,39}=$ 4.64, $\mathrm{p}<0.001$ ) and $D$. menstrualis (ANOVA, $\mathrm{F}_{11,56}=2.06, \mathrm{p}=0.04$ ) among sites. We used a simple linear regression to investigate the relationship between $\delta^{13} \mathrm{C}$ values for both algal species and found them to be significantly positively related $\left(p<0.001, R^{2}=0.76\right)$ suggesting that these were true differences in isotopic baselines among reefs. Therefore, we used the relationship between these two algal resources to develop a baseline relationship across all sites and then corrected consumer $\delta^{13} \mathrm{C}$ values accordingly $\left(\delta^{13} \mathrm{C}[\right.$ corrected $]=\delta^{13} \mathrm{C}[$ consumer $]-\delta^{13} \mathrm{C}[$ baseline $\left.]\right)$ (VanderZanden et al. 2003). 
To test the hypothesis about the effect site characteristics (e.g., large predator biomass) on the diets of individuals we used a hierarchical modeling framework (Gelman \& Hill 2007). This approach allowed us to partition variance in isotopic metrics among individual-level predictors (e.g., fish size) and site-level predictors (e.g., large predator biomass). To understand if differences in diet were the result of differences in basal resource use and/or trophic level we created two hierarchical models for each species to analyze $\delta^{13} \mathrm{C}$ and $\delta^{15} \mathrm{~N}$ separately. We assessed the relative importance of each site characteristic's influence on each isotope signature based on values of parameter estimates. To assess model performance, we calculated conditional and marginal $\mathrm{R}^{2}$ values. Conditional $\mathrm{R}^{2}$ values $\left(\mathrm{R}_{\text {LMM(c) }}^{2}\right)$ describe the variance explained by the entire mixed effects model (including fixed (i.e., fish size, large predator biomass, etc.) and random (i.e., Site) factors), while marginal $\mathrm{R}^{2}$ values $\left(\mathrm{R}_{\mathrm{LMM}(\mathrm{m})}^{2}\right)$ describe variance explained by only fixed factors (Nakagawa \& Schielzeth 2013).

Next, we tested the hypothesis that site characteristics affect trophic niche within populations (i.e., the similarity in resource use among individuals at a site). For each herbivore, we calculated Bayesian standard ellipse area $\left(\mathrm{SEA}_{\mathrm{B}}\right)$ for each site. $\mathrm{SEA}_{\mathrm{B}}$ is a metric similar to convex hull area (Layman et al. 2007), which uses the area encompassed by isotope data points to estimate the extent of diet diversity among individuals of a population. To calculate $S E A_{B}$ metrics that were unbiased by unequal size distributions of fishes captured among sites we used residuals from each site's relationship between isotope values and fish length. Residuals were added to the intercepts from each regression and used to calculate $\mathrm{SEA}_{\mathrm{B}}$. We used linear regressions to evaluate 
relationships between $\mathrm{SEA}_{\mathrm{B}}$ and the principal component scores. The R package SIAR was used to calculate $\mathrm{SEA}_{\mathrm{B}}$ (Parnell and Jackson 2011).

Finally, we tested the hypothesis that acute differences in diet diversity among individuals (i.e., measured from stomach content and behavioral data) correlated with chronic differences in trophic niche (i.e., measured from isotope data). To calculate diversity indices at each site we used the exponential of the Shannon-Wiener diversity index $\left[\exp \left(\mathrm{H}^{\prime}\right)\right]$ using the proportions of diet items consumed (from stomach data for $A$. coeruleus and behavioral data from S. aurofrenatum). We used Spearman rank correlation to determine if there was a relationship between site diversity indices $\left[\exp \left(\mathrm{H}^{\prime}\right)\right]$ and site trophic niche measurements $\left(\mathrm{SEA}_{\mathrm{B}}\right)$. Positive correlation would indicate that trophic niche inferred from isotopes reflected true differences in feeding choices within populations.

Because isotope data suggested strong ontogenetic shifts in $\operatorname{diet}$ for $A$. coeruleus (see Results), we used simple linear regressions to assess relationships between proportions of major individual stomach components and total length. We also performed logistic regressions on several diet components to assess their probability of occurrence with fish size, and evaluated model fit using Hosmer-Lemeshow goodness-of-fit test. These analyses helped confirm that the differences across size classes in the isotopic data reflected true differences in diet. Although fish length was strongly related to isotopic composition for S. aurofrenatum, we did not perform these same analyses because we did not have diet data on the same individuals from which we also had stable isotope data.

Finally, because we found that damselfish abundance was significantly related to diet composition (see Results), we assessed if an increase in large predators may be 
influencing damselfish abundance, as others have shown (Harborne et al. 2008, Mumby et al. 2012). We used simple linear regression to examine the relationships between biomass of large predators and mesopredators known to consume damselfish (e.g., Cephalopholis fulvus, C. cruentatus and Epinephelus guttatus) and between large predator biomass and damselfish abundance.

Results

Overall, benthic communities of sites were characterized by high macroalgal cover $(34.9 \pm 3.9 \%$, mean \pm SEM), dominated by Dictyota spp. $(29.9 \pm 3.9 \%)$, and low coral cover $(1.5 \pm 0.4 \%)$ (Table 2.1). Mean Scarid and Acanthurid biomass was $10.9 \pm$ $1.6 \mathrm{~g} / \mathrm{m}^{2}$ and $4.2 \pm 0.4 \mathrm{~g} / \mathrm{m}^{2}$, respectively. The mean biomass of large predators $(>30 \mathrm{~cm}$ TL) known to consume adult surgeonfishes and parrotfishes (based on Randall 1967) was $10.7 \pm 5.1 \mathrm{~g} / \mathrm{m}^{2}$ (range: $0.2-108.6$ ) and included: Caranx ruber, C. bartholomaei, Lutjanus jocu, L. griseus, L. apodus, Sphyraena barracuda, Epinephelus morio and Mycteroperca bonaci. Protected sites had higher large predator biomass $\left(14.3 \pm 7.3 \mathrm{~g} / \mathrm{m}^{2}\right)$ relative to unprotected sites $\left(3.6 \pm 3.1 \mathrm{~g} / \mathrm{m}^{2}\right)$; however, this difference was not statistically significant ( $\mathrm{t}$-test, $\mathrm{t}=1.34, \mathrm{p}=0.21$ ). Territorial damselfishes averaged $0.33 \pm 0.05$ individuals per $\mathrm{m}^{2}$, with Stegastes partitus being the most abundant damselfish (representing $88 \%$ of all observations).

From the PCA on site level predictors we retained four uncorrelated principle components that explained $88 \%$ of the total variance. Although the principle component axes are composites of all of the original variables they each correlated most strongly with a single individual variable. Damselfish abundance, competitor biomass, TAS cover 
and large predator biomass were correlated more strongly with principle component axes 1 through 4, respectively, relative to the other original variables (Table 2.2).

Isotope values for both fish species were consistent with herbivores in this system based on algae isotope values (not shown) (See Fig. 2.2 for species biplots of $\delta^{13} \mathrm{C}$ and $\delta^{15} \mathrm{~N}$ ). Hierarchical models showed that $\delta^{13} \mathrm{C}$ values (an index of basal resource use) for S. aurofrenatum were positively related to total length and PC4 (large predator biomass) and negatively related to PC2 (competitor biomass) (Table 2.1). Therefore, larger $S$. aurofrenatum and those at sites with more abundant large predators and fewer competitors chose diets that were less depleted in $\delta^{13} \mathrm{C} . \delta^{15} \mathrm{~N}$ values (an index of trophic level) for both $A$. coeruleus and S. aurofrenatum were positively related to total length and negatively related to PC1 (damselfish abundance) (Table 2.3). Therefore, larger fish at sites with numerous damselfish occupied higher trophic levels. For A. coeruleus, total length was positively related to $\delta^{13} \mathrm{C}$ (Table 2.3). We did not include protection status (MPA vs. non-MPA) in these models because it explained $<0.01 \%$ of the variance in $\delta^{13} \mathrm{C}$ and $\delta^{15} \mathrm{~N}$ for both species based on null hierarchical models (i.e., intercept only models).

For S. aurofrenatum, PC4 (large predator biomass $)(\beta=0.11, \mathrm{p}=0.001)$ and PC1 (damselfish abundance) $(\beta=0.04, p=0.03)$ were positively related to trophic niche area $\left(\mathrm{SEA}_{\mathrm{B}}\right)$ in a multiple regression model $\left(\mathrm{p}=0.002, \mathrm{R}^{2}=0.68\right.$, Fig. $\left.2.3 \mathrm{a} \& \mathrm{~b}\right)$. This indicates a greater degree of diet diversity within populations where large predators were abundant and damselfish were not. For A. coeruleus, $\mathrm{SEA}_{\mathrm{B}}$ was negatively related to $\mathrm{PC} 1$ (and hence positively related to damselfish abundance) $(\beta=0.11)$ in a simple linear regression model $\left(p=0.02, R^{2}=0.42\right.$, Fig. $\left.2.3 c\right)$. This indicates greater diet diversity within 
populations where damselfish were abundant. Other PC axes were unrelated to trophic niche and were therefore not included in these models.

Based on follows of 293 individuals, the major diet components of $S$. aurofrenatum were turf/algae/sediment and macroalgae (Table 2.4). Brown thallate species included Dictyota spp. $(27.8 \pm 1.5 \%)$ and Stypopodium spp. $(2.5 \pm 0.4 \%)$ and green thallate was comprised exclusively of Halimeda spp. Minor categories that comprised an average of $<1 \%$ of diet included: crustose coralline algae, scleractinian corals, sponges, Millepora spp., fecal material, and zoanthids. Diet diversity based on proportions of diet items consumed $\left[\exp \left(\mathrm{H}^{\prime}\right)\right]$ at each site was positively correlated with isotopic measurements of trophic niche $\left(\mathrm{SEA}_{\mathrm{B}}\right)$ at each site (Spearman rank correlation; $\mathrm{r}=0.76, \mathrm{p}=0.006)$. Based on the analysis of 157 A. coeruleus stomachs, we found the average gut to include primarily filamentous turf algae and macroalgae (Table 2.4). Animal material comprised a small proportion of diet $(<1 \%)$. Diet diversity based on proportions of average stomach contents $\left[\exp \left(\mathrm{H}^{\prime}\right)\right]$ at each site was positively correlated with isotopic measurements of trophic niche $\left(\mathrm{SEA}_{\mathrm{B}}\right)$ (Spearman rank correlation; $\mathrm{r}=0.64$, $\mathrm{p}=0.04)$

We found significant, but relatively weak, positive relationships using simple linear regressions between $A$. coeruleus length and the proportions of macroalgae (red $\left(\mathrm{p}<0.001, \mathrm{R}^{2}=0.06\right)$, green $\left(\mathrm{p}<0.001, \mathrm{R}^{2}=0.11\right)$ and brown $\left(\mathrm{p}<0.001, \mathrm{R}^{2}=0.08\right)$ thallate species) and the proportion of calcareous sediment $\left(\mathrm{p}<0.001, \mathrm{R}^{2}=0.24\right)$ in stomachs. There was a strong negative relationship between fish length and the proportion of turf algae $\left(\mathrm{p}<0.001, \mathrm{R}^{2}=0.40\right)$ in stomachs. Additionally, using logistic regression we found a significant decrease in the probability of occurrence of filamentous $\operatorname{turf}(\beta=-0.34$, 
$\mathrm{SE}=0.09, \mathrm{p}<0.001)$ that coincided with a significant increase in the probability of occurrence of animal material ( $\beta=0.24, \mathrm{SE}=0.09, \mathrm{p}<0.05)$ as fish size increased (Fig. 2.4). A Hosmer-Lemeshow test for goodness of fit showed a good fit for both logistic regression models (Turf Algae: $\chi^{2}=12.18, \mathrm{p}=0.16$, Animal: $\chi 2=11.71, \mathrm{p}=0.20$ ).

Finally, when we examined how large predators might impact damselfish abundance, we showed a significant positive relationship between large predator biomass and damselfish abundance across sites $\left(\mathrm{p}=0.05, \mathrm{R}^{2}=0.25\right.$, Fig. 2.5$)$. We did not find a relationship between large predator and mesopredator biomass $\left(\mathrm{p}=0.12, \mathrm{R}^{2}=0.13\right)$.

\section{Discussion}

On coral reefs, food availability (Muñoz and Motta 2000), competition (Nash et al. 2012), habitat structural complexity (Hixon and Beets 1993), and territorial damselfish (Foster 1985) can influence foraging decisions of large mobile herbivorous fishes. However, much less is known about the influence that predators have on their diet selection. Using complimentary techniques including stable isotopes, behavioral observations, and stomach contents, we showed that the diets of two species of reef herbivores are influenced by different factors, likely depending on their susceptibility to predation and their ability to access defended food resources. For S. aurofrenatum we found the basal resource use (carbon isotope ratios) was positively related to predator biomass and negatively related to competitor biomass while trophic level (nitrogen isotope ratios) was negatively related to damselfish abundance. S. aurofrenatum's trophic niche was partially positively correlated with large predator biomass and negatively correlated with damselfish abundance. For A. coeruleus, trophic level and trophic niche 
were positively related to the abundance of territorial damselfish. Importantly, damselfish abundance influenced the diet of both herbivore species but in slightly different ways, likely dependent on how different foraging behaviors lead to differential access to damselfish territories. The effect of damselfish may have been influenced by large predator abundance as damselfish abundance showed a positive correlation with large predator biomass. Thus, abundant large predators may influence herbivore diets in a variety of direct and indirect mechanisms.

\section{Effect of site and individual characteristics on individual diets.}

We found that fish size as well as multiple site characteristics influenced individual diets. In particular, our isotopic data show a shift towards omnivory in larger fish, which is contrary to what other studies suggest for many herbivorous fishes (Cocheret de la Morinière et al. 2003). Our stomach content data support our isotopic data, suggesting our result represents a true ontogenetic shift. Specifically, A. coeruleus incorporated more animal material and macroalgae and less filamentous algae with increasing size suggesting that they may target more energetically rich animal material to meet their higher metabolic demands. However, they may simply be ingesting more animal material incidentally as they target more macroalgae, which may be fouled by epifauna more frequently than filamentous algae. Overall, the variation in isotopic values with fish length support the need for researchers to consider variation among individuals, and take appropriate steps to account for those differences as we have here, prior to making inferences about differences in isotopic composition among populations (Reum \& Marshall 2013). 
In addition to the strong effect of fish size, we found that certain site characteristics also correlated with individual diets but that the important site characteristics differed for the different herbivore species. For S. aurofrenatum, partial correlations with the principle component axes suggested that the biomass of competitors and large predators influenced the type of food resources consumed (i.e., $\delta^{13} \mathrm{C}$ ), whereas these factors were unrelated to diet for A. coeruleus. It is not surprising that competitive interactions could influence S. aurofrenatum diet because of the extensive overlap along multiple dimensions of diet (e.g., jaw morphology, feeding modes, microhabitat use) of the family Scaridae (Bellwood \& Choat 1990). Additionally, others have shown that aggression can be intense, particularly towards conspecifics, for S. aurofrenatum (Mumby \& Wabnitz 2002), suggesting strong inter- and intraspecific competition for food resources. In contrast, adult $A$. coeruleus rarely engage in aggressive interactions (Lawson et al. 1999), suggesting that interference competition may play a lesser role in influencing diet for this species as our data indicate. The effect of competition may also have been greater for S. aurofrenatum because parrotfishes, and thus potential competitors, were more abundant at our sites relative to surgeonfish.

Large predator biomass was also correlated with individual diets of $S$.

aurofrenatum, but was unrelated to A. coeruleus diet. This result supports the hypothesis that there are species-specific responses to predation risk (Creel 2011). The schooling behavior often observed for A. coeruleus may function to decrease their per capita susceptibility to predation via group vigilance or diluting per capita predation risk (Parrish and Edelstein-Keshet 1999). Additionally, A. coeruleus have a sharp scalpel on their caudal peduncle, which is presumably used in anti-predatory defense. Madin et al. 
(2010a) showed that Acanthurus nigricans, a congener of A. coeruleus, which also possesses a physical anti-predator defense and is known for its schooling behavior (Allen and Erdmann 2012), did not alter its foraging behavior in response to acute predation risk. These results together suggest that schooling Acanthuridae may be less likely to alter their behavior in response to higher risk of predation. In contrast, schooling is rarely observed for adult S. aurofrenatum nor do they have a physical anti-predatory defense potentially making them more likely to alter their behavior in areas with abundant predators. Patterns in social structure and group foraging often influence the vulnerability of different species to predation and predation risk (Wirsing et al. 2010) and could potentially explain the differences in diet between A. coeruleus and S. aurofrenatum.

The abundance of territorial damselfish influenced diets of both herbivores. It is unsurprising that damselfish had a strong influence on diet because on average, $34 \%$ of the reef was occupied by damselfish territories at our sites (calculated based on territory sizes from Hata \& Kato (2004) and references therein). As opposed to competitor and large predator biomass, which influenced the basal source of resources consumed (i.e., $\delta^{13} \mathrm{C}$ ), damselfish influenced the trophic level of resources consumed (i.e., $\left.\delta^{15} \mathrm{~N}\right)$. Many territorial damselfishes modify benthic communities by preventing fleshy macroalgae growth via weeding within their territories, which they defend vigorously from larger herbivorous fishes (Hixon and Brostoff 1983). Even though the most common species we observed, Stegastes partitus, is primarily planktivorous and not known to cultivate algae within its territories, it can still increase algal diversity by aggressively defending areas of the benthos (De Ruyter Van Steveninck 1984). Furthermore, the influence of 'farmer' species (i.e., Stegastes fuscus, S. diencaeus, S. planifrons, S. leucostictus and 
Microspathodon chrysurus) may be greater than would be expected based on their low abundance relative to S. partitus, because of the larger territory areas they defend (Hata and Kato 2004). Yet, it is unclear how territorial damselfish may alter the isotopic composition of food resources. Our data show that greater damselfish abundance was associated with lower $\delta^{15} \mathrm{~N}$ values of both fish species. By eliminating macroalgae (which is often fouled with epifauna) from their territories, damselfish may lower the overall $\delta^{15} \mathrm{~N}$ signal of resources in their territories. However, algal communities within damselfish territories vary among fish species, substrata, and localities (Hata and Kato 2004), making it difficult to isolate the specific mechanism to explain our result. However, it is clear that damselfish play an important role in influencing the individual diets of larger herbivores.

Ultimately, we showed that individual and site level factors influenced the isotopic signatures of individual herbivores. However, without isotopic information on a multitude of potential food resources, we cannot attribute specific changes in consumer isotopic signatures with specific changes in diet. This level of information, while useful, was not feasible for us to obtain considering the magnitude of sampling that would have been required over the large spatial scale of our study.

Effect of site characteristics on diet diversity within populations.

We found that diet diversity within populations varied among sites based on stable isotope analysis and other metrics of diet (i.e., stomach content analyses and observations of feeding behaviors). For S. aurofrenatum we found that greater predator biomass was positively associated with population trophic niches whereas damselfish abundance 
showed a negative relationship with trophic niche. However, for A. coeruleus the trophic niche of a population was positively correlated with damselfish abundance, but unrelated to large predator biomass. Thus, territorial damselfishes appeared to have the opposite effect on the trophic niche of A. coeruleus relative to S. aurofrenatum. Therefore, the diverse algal resources inside damselfish territories appear differentially available to $A$. coeruleus versus S. aurofrenatum. Schooling by A. coeruleus may allow them to overwhelm damselfish aggression and gain greater access to defended algal territories and therefore to a greater diversity of resources (Foster 1985). However, adult $S$. aurofrenatum are generally solitary or move in small groups that are likely too small to consistently overcome aggressive damselfishes (Mumby \& Wabnitz 2002).

For S. aurofrenatum, there was also a positive relationship between trophic niche and large predator biomass. This could indicate that herbivores at sites with fewer large predators, and hence less risk, have larger excursion areas in which to seek out their preferred foods resulting in similar diets. In contrast, herbivores at sites with more large predators may decrease their excursion area (Madin et al. 2010a) or decrease the time devoted to foraging by increasing vigilance (Lima \& Dill 1990), thereby restricting their access to preferred diet items. This could result in divergence of individual isotopic signatures and increase a population's trophic niche as our data suggest. Trophic niche was unrelated to large predator biomass for A. coeruleus. This supports our suggestion that this species is less susceptible to the behavioral impacts of predation risk, likely due to their schooling behavior and physical anti-predatory defense.

Our data also suggest that the effect of large predators on foraging may be mediated through their effect on damselfish abundance. As we show above, damselfishes 
were correlated with changes in diet metrics for both S. aurofrenatum and A. coeruleus. There was also a positive relationship between damselfish abundance and large predator biomass suggesting that predators may indirectly affect herbivore foraging via their positive effect on damselfish abundance. Yet, we did not find a relationship between the abundance of large predators and mesopredators, as would be expected if the effect of large predators on damselfishes was mediated via a reduction in mesopredator abundance (e.g. Harborne et al. 2008, Mumby et al. 2011). However, we may not have captured the full extent of mesopredator biomass from diurnal surveys because many predatory species are most active during crepuscular periods and at night (Holbrook and Schmitt 2002). Predation risk from large predators could also lower foraging efficiency of mesopredators, resulting in increased abundance or aggression of damselfish (Stallings 2008, Madin et al. 2010a) and more interference with larger herbivorous fishes. The abundance of large predators is likely not the only factor driving differences in damselfish abundance across sites as other factors such as available shelter (Holbrook and Schmitt 2002) and differences in recruitment (Sponaugle and Cowen 1996) could also play a role. However, our data suggest that the indirect effects of large predator abundance on territorial damselfishes may be a common, yet overlooked effect of predators on herbivore foraging.

\section{Conclusions}

Herbivorous fishes are functionally important to coral reef ecosystems because their grazing facilitates coral settlement, growth, and survivorship (Hughes et al. 2007, Mumby et al. 2007, Burkepile \& Hay 2008). Understanding the factors that shape their 
foraging decisions will be a key to knowing their impact on reef resilience and recovery in the face of global change. We demonstrated that multiple factors, from body size to large predator abundance, can have important species-specific influences on herbivore diets both at the individual and population scale. Furthermore, our research is among the first to specifically address the non-consumptive effects of predators on foraging of other reef fishes. Our data suggest that an increased abundance of large predators can alter herbivore diets directly by influencing foraging behavior via risk and indirectly by influencing food availability via positive indirect effects on damselfishes. A crucial question that remains is what cascading influences such predator-herbivore interactions can have on the reef community. Emerging evidence from other reef ecosystems suggests that increased predation risk lowers rates of herbivory and results in areas of increased macroalgal cover (Madin et al. 2010b). But it is yet unclear how this can, in turn, affect corals. It is increasingly clear that the non-consumptive effects of predators will be important for understanding the ecology of coral reefs in an era of human-mediated predator removal and recovery.

\section{Acknowledgments}

Funding for this work was provided by a PADI Foundation Grant to LBC and DEB, The Florida Sea Grant Scholar award to LBC, the College of Arts and Sciences at Florida International University, and a grant number 1130786 from the National Science Foundation, Biological Oceanography to DEB and R. Vega Thurber. We thank C. Pritchard, M. Kelley, R. Sarabia, T. Vaughn, R. McQueen, B. Gunn, B. Shirvani, R. Jamie, H. Gonzembach and M. Hernandez for assistance with field and laboratory work. 
We are indebted to W. Anderson and the SERC Stable Isotope Laboratory for contributing towards sample processing and C. Layman, J. Trexler, C. Catano, and N. Lemoine, for their time and advice with this project. This work was conducted with permission from the Florida Keys National Marine Sanctuary under permit no. FKNMS2011-081 and The Florida International University Institutional Animal Care and Use Committee (IACUC) Protocol \#A3096-01, 11-001.

\section{References Cited}

Abrahams, M. V, and L. M. Dill. 1989. A determination of the energetic equivalence of the risk of predation. Ecology 70:999-1007.

Allen, G. R., and M. V. Erdmann. 2012. Reef fishes of the East Indies. Page Volumes IIII. University of Hawai'i Press, Perth, Australia.

Araújo, M. S., D. I. Bolnick, and C. a Layman. 2011. The ecological causes of individual specialisation. Ecology letters 14:948-58.

Bellwood, D. R., and J. H. Choat. 1990. A functional analysis of grazing in parrotfishes (family Scaridae): the ecological implications. Environmental Biology of Fishes 28:189-214.

Bellwood, D. R., P. C. Wainwright, C. J. Fulton, and A. S. Hoey. 2006. Functional versatility supports coral reef biodiversity. Proceedings of the Royal Society B 273:101-107.

Bohnsack, J. A., and D. E. Harper. 1988. Length-weight relationships of selected marine reef fishes from the southeastern United States and the Caribbean. NOAA Technical Memorandum NMFS-SEFC-215:31p.

Bohnsack, J. A., D. E. Harper, D. B. Mcclellan, G. T. Kellison, N. Marine, F. Service, J. S. Ault, S. G. Smith, and N. Zurcher. 2009. Coral reef fish response to FKNMS management zones : the first ten years ( 1997-2007). Progress Report of the Florida Keys National Marine Sanctuary:1-29. 
Burkepile, D. E., J. E. Allgeier, A. a Shantz, C. E. Pritchard, N. P. Lemoine, L. H. Bhatti, and C. a Layman. 2013. Nutrient supply from fishes facilitates macroalgae and suppresses corals in a Caribbean coral reef ecosystem. Scientific reports 3:1493.

Burkepile, D. E., and M. E. Hay. 2008. Herbivore species richness and feeding complementarity affect community structure and function on a coral reef. Proceedings of the National Academy of Sciences of the United States of America 105:16201-6.

Carr, M. H., T. W. Anderson, and M. a Hixon. 2002. Biodiversity, population regulation, and the stability of coral-reef fish communities. Proceedings of the National Academy of Sciences of the United States of America 99:11241-5.

Chapman, M. R., and D. L. Kramer. 2000. Movements of fishes within and among fringing coral reefs in Barbados. Environmental Biology of Fishes 57:11-24.

Chiappone, M., D. . Swanson, and S. L. Miller. 2002. Density, spatial distribution and size structure of sea urchins in Florida Keys coral reef and hard-bottom habitats. Marine Ecology Progress Series 235:117-126.

Choat, J. H. 1998. Vertebrate herbivores in marine and terrestrial environments: A nutritional ecology perspective. Annual Review of Ecology and Systematics 29:375-403.

Cocheret de la Morinière, E., B. Pollux, I. Nagelkerken, M. Hemminga, A. Huiskes, and G. van der Velde. 2003. Ontogenetic dietary changes of coral reef fishes in the mangrove-seagrass-reef continuum: stable isotopes and gut-content analysis. Marine Ecology Progress Series 246:279-289.

Coleman, K., and D. Wilson. 1998. Shyness and boldness in pumpkinseed sunfish: individual differences are context-specific. Animal behaviour 56:927-936.

Creel, S. 2011. Toward a predictive theory of risk effects: hypotheses for prey attributes and compensatory mortality. Ecology 92:2190-2195.

Foster, S. A. 1985. Group foraging by a coral reef fish: a mechanism for gaining access to defended resources. Animal Behavior 33:782-792.

Gelman, A., and J. Hill. 2007. Data analysis using regression and multilevel/hierarchical models. Page 625. Cambridge University Press, Cambridge, UK.

Gilliam, J. F., and D. F. Fraser. 1987. Habitat Selection Under Predation Hazard : Test of a Model with Foraging Minnows. Ecology 68:1856-1862. 
Graham, M. H. 2003. Confronting multicollinearity in ecological multiple regression. Ecology 84:2809-2815.

Graham, N. a. J., and K. L. Nash. 2013. The importance of structural complexity in coral reef ecosystems. Coral Reefs 32:315-326.

Harborne, A. R., P. J. Mumby, C. V Kappel, C. P. Dahlgren, F. Micheli, K. E. Holmes, J. N. Sanchirico, K. Broad, I. A. Elliott, and D. R. Brumbaugh. 2008. Reserve effects and natural variation in coral reef communities. Journal of Applied Ecology 45:1010-1018.

Hata, H., and M. Kato. 2004. Monoculture and mixed-species algal farms on a coral reef are maintained through intensive and extensive management by damselfishes. Journal of Experimental Marine Biology and Ecology 313:285-296.

Hay, M. E. 1991. Fish-Seaweed Interactions on Coral Reefs : Effects of Herbivorous Fishes and Adaptations of Their Prey. Pages 96-119 in P. Sale, editor. The Ecology of Fishes on Coral Reefs. Academic Press, San Diego.

Heady, W. N., and J. W. Moore. 2013. Tissue turnover and stable isotope clocks to quantify resource shifts in anadromous rainbow trout. Oecologia 172:21-34.

Heithaus, M. R., and L. Dill. 2002. Food availability and tiger shark predation risk influence bottlenose dolphin habitat use. Ecology 83:480-491.

Heithaus, M. R., A. Frid, A. J. Wirsing, and B. Worm. 2008. Predicting ecological consequences of marine top predator declines. Trends in ecology \& evolution 23:202-10.

Hixon, M. A., and J. P. Beets. 1993. Predation, prey refuges, and the structure of coralreef fish assemblages. Ecological Monographs 63:77-101.

Hixon, M. A., and W. N. Brostoff. 1983. Damselfish as keystone species in reverse: Intermediate disturbance and diversity of reef algae. Science 220:511-513.

Holbrook, S. J., and R. J. Schmitt. 2002. Competition for shelter and space causes density-dependent predation mortality on damselfishes. Ecology 83:2855-2868.

Houston, A. I., J. M. McNamara, and J. M. C. Hutchinson. 1993. General results concerning the trade-off between gaining energy and avoiding predation. Philosophical Transactions of the Royal Society B: Biological Sciences 341:375397.

Hughes, T. P., M. Rodrigues, D. R. Bellwood, D. M. Ceccarelli, O. Hoegh-Gudberg, L. J. Mccook, N. Moltschaniwskyj, M. Pratchett, R. S. Steneck, and B. Willis. 2007. 
Phase shifts, herbivory, and the resilience of coral reefs to climate change. Current Biology 17:360-365.

Husson, F., S. Le, and J. Pages. 2010. Exploratory Multivariate Analysis by Example Using R. Pages 1-240. Chapman and Hall, London.

Klumpp, D. W., and N. V. C. Polunin. 1989. Partitioning among grazers of food resources within damselfish territories on a coral reef. Journal of Experimental Marine Biology and Ecology 125:145-169.

Kohler, K. E., and S. M. Gill. 2006. Coral Point Count with Excel extensions (CPCe): A Visual Basic program for the determination of coral and substrate coverage using random point count methodology. Computers \& Geosciences 32:1259-1269.

Lawson, G. L., D. L. Kramer, and W. Hunte. 1999. Size-related habitat use and schooling behavior in two species of surgeonfish (Acanthurus bahianus and A. coeruleus) on a fringing reef in Barbados, West Indies. Environmental Biology of Fishes 54:19-33.

Layman, C., D. A. Arrington, C. G. Montana, and D. M. Post. 2007. Can stable isotope ratios provide for community-wide measures of trophic structure? Ecology 88:4248.

Lessios, H. A. 1988. Mass mortality of Diadema antillarum in the Caribbean: What have we learned? Annual Review of Ecology and Systematics 19:371-93.

Lewis, S. M., and P. C. Wainwright. 1985. Herbivore abundance and grazing intensity on a Caribbean coral reef. Journal of Experimental Marine Biology and Ecology $87: 215-228$.

Lima, S. L., and L. M. Dill. 1990. Behavioral decisions made under the risk of predation: a review and prospectus. Canadian Journal of Zoology 68:619-640.

Madin, E. M. P., S. D. Gaines, J. S. Madin, and R. R. Warner. 2010a. Fishing indirectly structures macroalgal assemblages by altering herbivore behavior. The American Naturalist 176:785-801.

Madin, E. M. P., S. D. Gaines, and R. R. Warner. 2010b. Field evidence for pervasive indirect effects of fishing on prey foraging behavior. Ecology 91:3563-3571.

McClanahan, T. R., and N. A. Muthiga. 1988. Changes in Kenyan coral reef community structure and function due to exploitation. Hydrobiologia 166:269-276.

Milinski, M. 1982. Optimal Foraging : The Influence of Intraspecific Competition on Diet Selection. Behav. Ecol. Sociobiol 11:109-115. 
Morgan, I. E., and D. L. Kramer. 2005. Determinants of social organization in a coral reef fish, the blue tang, Acanthurus coeruleus. Environmental Biology of Fishes $72: 443-453$.

Mumby, P. J., C. P. Dahlgren, A. R. Harborne, C. V Kappel, F. Micheli, D. R. Brumbaugh, K. E. Holmes, J. M. Mendes, K. Broad, J. N. Sanchirico, K. Buch, S. Box, R. W. Stoffle, and A. B. Gill. 2006. Fishing, trophic cascades, and the process of grazing on coral reefs. Science (New York, N.Y.) 311:98-101.

Mumby, P. J., A. R. Harborne, J. Williams, C. V Kappel, D. R. Brumbaugh, F. Micheli, K. E. Holmes, C. P. Dahlgren, C. B. Paris, and P. G. Blackwell. 2007. Trophic cascade facilitates coral recruitment in a marine reserve. Proceedings of the National Academy of Sciences of the United States of America 104:8362-7.

Mumby, P. J., and C. C. C. Wabnitz. 2002. Spatial patterns of aggression, territory size, and harem size in five sympatric Caribbean parrot fish species. Environmental Biology of Fishes 63:265-279.

Mumby, P., R. Steneck, A. Edwards, R. Ferrari, J. Gibson, A. Harborne, and R. Coleman. 2012. Fishing down a Caribbean food web relaxes trophic cascades. Marine Ecology Progress Series 445:13-24.

Muñoz, R. C., and P. J. Motta. 2000. Interspecific aggression between two parrotfishes (Sparisoma, Scaridae) in the Florida Keys. Copeia 3:674-683.

Myers, R. a, and B. Worm. 2003. Rapid worldwide depletion of predatory fish communities. Nature 423:280-3.

Nakagawa, S., and H. Schielzeth. 2013. A general and simple method for obtaining R 2 from generalized linear mixed-effects models. Methods in Ecology and Evolution $4: 133-142$.

Nash, K., N. Graham, F. Januchowski-Hartley, and D. Bellwood. 2012. Influence of habitat condition and competition on foraging behaviour of parrotfishes. Marine Ecology Progress Series 457:113-124.

Newsome, S. D., C. M. Del Rio, S. Bearhop, and D. L. Phillips. 2007. A niche for isotopic ecology. Frontiers in Ecology and the Environment 5:429-236.

Overholtzer, K. L., and P. J. Motta. 1999. Comparative resource use by juvenile parrotfishes in the Florida Keys. Marine Ecology Progress Series 177:177-187.

Parnell, A., and A. Jackson. 2011. Package "siar", Stable isotope analysis in R. CRAN Repository. 
Parrish, J. K., and L. Edelstein-Keshet. 1999. Complexity, pattern, and evolutionary trade-offs in animal aggregation. Science 284:99-101.

Peterson, B. J., and B. Fry. 1987. Stable isotopes in ecosystem studies. Annual Review of Ecology and Systematics 18:293-320.

Post, D. M. 2002. Using stable isotopes to estimate trophic position: Models, methods, and assumptions. Ecology 83:703-718.

Preisser, E. L., D. I. Bolnick, and M. E. Benard. 2005. Scared to death? The effects of intimidation and consumption in predator-prey interactions. Ecology 86:501-509.

Preisser, E. L., and J. L. Orrock. 2012. The allometry of fear : interspecific relationships between body size and response to predation risk. Ecosphere 3:1-27.

Randall, J. E. 1967. Food habits of reef fishes of the West Indies. Studies in Tropical Oceanography 5:655-847.

Reum, J. C. P., and K. N. Marshall. 2013. Evaluating $\delta 15 \mathrm{~N}$-body size relationships across taxonomic levels using hierarchical models. Oecologia 173:1159-68.

Ripple, W., and R. Beschta. 2007. Restoring Yellowstone's aspen with wolves. Biological Conservation 138:514-519.

Roberts, C. M., and R. F. G. Ormond. 1987. Habitat complexity and coral reef fish diversity and abundance on Red Sea fringing reefs. Marine Ecology Progress Series 41:1-8.

Robertson, D. R., and S. D. Gaines. 1986. Interference competition structures habitat use in a local assemblage of coral reef surgeonfishes. Ecology 67:1372-1383.

Van Rooij, J. M., J. P. Kok, and J. J. Videler. 1996. Local variability in population structure and density of the protogynous reef herbivore Sparisoma viride. Environmental Biology of Fishes 47:65-80.

Russ, G. R., and A. C. Alcala. 2010. Decadal-scale rebuilding of predator biomass in Philippine marine reserves. Oecologia 163:1103-6.

De Ruyter Van Steveninck, E. 1984. The composition of algal vegetation in and outside damselfish territories on a Florida reef. Aquatic Botany 20:11-19.

Sandin, S. A., J. E. Smith, E. E. Demartini, E. A. Dinsdale, S. D. Donner, A. M. Friedlander, T. Konotchick, M. Malay, J. E. Maragos, D. Obura, O. Pantos, G. Paulay, M. Richie, F. Rohwer, R. E. Schroeder, S. Walsh, J. B. C. Jackson, N. 
Knowlton, and E. Sala. 2008. Baselines and degradation of coral reefs in the Northern Line Islands. Plos One 3:e1548.

Schmitz, O. J. 2008. Herbivory from individuals to ecosystems. Annual Review of Ecology, Evolution, and Systematics 39:133-152.

Schmitz, O. J., A. P. Beckerman, and K. M. O’Brien. 1997. Behaviorally mediated trophic cascades : Effects of predation risk on food web interactions. Ecology 78:1388-1399.

Smith, S. G., J. S. Ault, J. A. Bohnsack, D. E. Harper, J. Luo, and D. B. Mcclellan. 2011. Multispecies survey design for assessing reef-fish stocks, spatially explicit management performance, and ecosystem condition. Fisheries Research 109:25-41.

Sponaugle, S., and R. K. Cowen. 1996. Larval supply and patterns of recruitment for two Caribbean reef fishes, Stegastes partitus and Acanthurus bahianus. Marine and Freshwater Research 47:433-447.

Stallings, C. D. 2008. Indirect effects of an exploited predator on recruitment of coralreef fishes. Ecology 89:2090-2095.

VanderZanden, M. J., S. Chandra, B. C. Allen, J. E. Reuter, and C. R. Goldman. 2003. Historical food web structure and restoration of native aquatic communities in the Lake Tahoe (California-Nevada) Basin. Ecosystems 6:274-288.

Werner, E. E., and B. R. Anholt. 1993. Ecological consequences of the trade-off between growth and mortality rates mediated by foraging activity. The American Nautralist 142:242-272.

Werner, E. E., G. G. Mittelbach, D. J. Hall, and J. F. Gilliam. 1983. Experimental tests of optimal habitat use in fish: The role of relative habitat profitability. Ecology 64:1525-1539.

Wirsing, A. J., K. E. Cameron, and M. R. Heithaus. 2010. Spatial responses to predators vary with prey escape mode. Animal Behaviour 79:531-537. 
Table 2.1- Study sites with GPS coordinates, protection status (Protected (P) or Not Protected (NP) and means of fish biomass, abundance, rugosity and benthic community (\% cover).

\begin{tabular}{|c|c|c|c|c|c|c|c|c|c|}
\hline Site & Lat. & Long. & Status & $\begin{array}{l}\text { Macroalga } \\
\text { e ( } \% \text { cover })\end{array}$ & $\begin{array}{l}\text { Coral }(\% \\
\text { cover })\end{array}$ & $\begin{array}{l}\text { Competito } \\
\text { r Biomass } \\
\left(\mathrm{g} / \mathrm{m}^{2}\right)\end{array}$ & $\begin{array}{l}\text { Predator } \\
\text { Biomass } \\
\left(\mathrm{g} / \mathrm{m}^{2}\right)\end{array}$ & $\begin{array}{l}\text { Damselfish } \\
\left(\mathrm{ind} / \mathrm{m}^{2}\right)\end{array}$ & $\begin{array}{l}\text { Lidar- } \\
\text { derived } \\
\text { Rugosity }\end{array}$ \\
\hline Alligator & 24.97 & -80.71 & $\mathrm{P}$ & 40.1 & 0.49 & 15.5 & 108.6 & 0.81 & 3.59 \\
\hline Conch & 24.96 & -80.46 & $\mathrm{P}$ & 42.5 & 0.50 & 7.3 & 4.2 & 0.21 & 3.54 \\
\hline Davis & 24.93 & -80.51 & $\mathrm{P}$ & 24.5 & 0.54 & 16.0 & 14.4 & 0.32 & 3.46 \\
\hline $\begin{array}{l}\text { Dry } \\
\text { Rocks }\end{array}$ & 25.12 & -80.29 & $\mathrm{P}$ & 32.2 & 4.66 & 13.3 & 11.3 & 0.09 & 2.92 \\
\hline Elbow & 25.14 & -80.26 & $\mathrm{P}$ & 20.9 & 1.10 & 17.5 & 5.3 & 0.18 & 5.39 \\
\hline French & 25.04 & -80.36 & $\mathrm{P}$ & 37.0 & 3.27 & 16.3 & 6.3 & 0.23 & 3.66 \\
\hline Maitland & 25.19 & -80.23 & NP & 60.6 & 0.81 & 5.1 & 1.2 & 0.35 & 3.96 \\
\hline Molasses & 25.01 & -80.38 & $\mathrm{P}$ & 9.8 & 1.46 & 10.4 & 87.2 & 0.41 & 3.52 \\
\hline Pickles & 24.99 & -80.41 & NP & 26.3 & 1.10 & 21.3 & 3.4 & 0.36 & 3.42 \\
\hline Pinnacles & 24.99 & -80.41 & NP & 40.4 & 0.96 & 13.8 & 3.0 & 0.36 & 3.15 \\
\hline $\begin{array}{l}\text { South } \\
\text { Carysfort }\end{array}$ & 25.21 & -80.22 & $\mathrm{P}$ & 34.2 & 2.76 & 31.7 & 0.2 & 0.22 & 4.52 \\
\hline $\begin{array}{l}\text { Snapper } \\
\text { Ledge }\end{array}$ & 24.99 & -80.42 & NP & 50.2 & 1.02 & 13.6 & 35.0 & 0.44 & 2.84 \\
\hline
\end{tabular}


Table 2.2 - Correlation between four principle components and seven site level predictors. Bold entries indicate significant correlations at the $\alpha=0.05$ level. Values in parentheses indicate percent of variance explained by each PC axis.

\begin{tabular}{lccccccc}
\hline & Rugosity & $\begin{array}{c}\text { Dictyota } \\
\text { Cover }\end{array}$ & $\begin{array}{c}\text { Halimeda } \\
\text { Cover }\end{array}$ & $\begin{array}{c}\text { Turf/Algae/ } \\
\text { Sediment }\end{array}$ & $\begin{array}{c}\text { Competitor } \\
\text { Biomass }\end{array}$ & $\begin{array}{c}\text { Damselfish } \\
\text { Abundance }\end{array}$ & $\begin{array}{c}\text { Predator } \\
\text { Biomass }\end{array}$ \\
\hline PC1 (29\%) & 0.601 & -0.585 & 0.400 & -0.559 & -0.062 & $\mathbf{- 0 . 8 3 1}$ & -0.266 \\
PC2 (26\%) & 0.276 & 0.418 & 0.517 & 0.028 & $\mathbf{0 . 8 8 7}$ & 0.299 & -0.428 \\
PC3 (17\%) & -0.526 & 0.552 & 0.380 & $\mathbf{- 0 . 5 8 8}$ & -0.348 & -0.097 & 0.010 \\
PC4 (14\%) & 0.241 & -0.068 & 0.122 & -0.337 & 0.178 & 0.269 & $\mathbf{0 . 8 2 8}$ \\
\hline
\end{tabular}


Table 2.3 - The effects ( $\beta$ (SE)) of PC1 (damselfish abundance), PC2 (competitor biomass), PC3 (Turf/algae/sediment (TAS) cover), PC4 (predator biomass) and fish total length on $\delta^{13} \mathrm{C}$ and $\delta^{15} \mathrm{~N}$ values for $S$. aurofrenatum and $A$. coeruleus based on hierarchical models with site as a random effect (intercept only). Conditional $\mathrm{R}^{2}$ values $\left(\mathrm{R}_{\text {LMM(c) }}^{2}\right)$ describe the variance explained by the entire mixed effects model, while marginal $R^{2}$ values $\left(R_{\text {LMM }(m)}^{2}\right)$ describe variance explained by only fixed factors. Asterisks $(*)$ indicate significance for terms in the models.

\begin{tabular}{|c|c|c|c|c|}
\hline & \multicolumn{2}{|c|}{ S. aurofrenatum } & \multicolumn{2}{|l|}{ A. coeruleus } \\
\hline & $\delta^{13} \mathrm{C}$ & $\delta^{15} \mathrm{~N}$ & $\delta^{13} \mathrm{C}$ & $\delta^{15} \mathrm{~N}$ \\
\hline Parameter & & & & \\
\hline $\begin{array}{l}\text { PC1 (damselfish } \\
\text { abundance) }\end{array}$ & $0.18(0.07)$ & $-0.07(0.02)^{*}$ & $-0.08(0.10)$ & $-0.10(0.03)^{*}$ \\
\hline $\begin{array}{l}\text { PC2 (competitor } \\
\text { biomass) }\end{array}$ & $-0.24(0.08) *$ & $0.05(0.02)$ & $-0.13(0.11)$ & $0.04(0.03)$ \\
\hline PC3 (TAS cover) & $0.18(0.1)$ & $-0.02(0.03)$ & $0.01(0.13)$ & $-0.003(0.04)$ \\
\hline $\begin{array}{l}\text { PC4 (predator } \\
\text { biomass) }\end{array}$ & $\begin{array}{l}0.63 \\
(0.10)^{* * *}\end{array}$ & $0.03(0.03)$ & $-0.06(0.15)$ & $-0.11(0.04)$ \\
\hline Total Length & $\begin{array}{l}0.10 \\
(0.01)^{* * *}\end{array}$ & $\begin{array}{l}0.09 \\
(0.01)^{* * *}\end{array}$ & $0.03(0.01)^{* *}$ & $\begin{array}{l}0.09 \\
(0.01)^{* * *}\end{array}$ \\
\hline $\mathbf{R}_{\text {LMM(m) }}^{2}$ & 0.24 & 0.35 & 0.36 & 0.45 \\
\hline $\mathbf{R}_{\text {LMM(c) }}^{2}$ & 0.54 & 0.42 & 0.58 & 0.53 \\
\hline
\end{tabular}


Table 2.4 - Diet components $(\% \pm$ SEM) of S. aurofrenatum based on behavioral follows and A. coeruleus based stomach contents. Minor components are listed in the text. Unidentified Organic Material (UOM) was not categorized for S. aurofrenatum.

\begin{tabular}{lccccccc}
\hline & $\begin{array}{c}\text { Brown } \\
\text { Thallate }\end{array}$ & $\begin{array}{c}\text { Green } \\
\text { Thallate }\end{array}$ & $\begin{array}{c}\text { Red } \\
\text { Thallate }\end{array}$ & Turf Algae & $\begin{array}{c}\text { Sand/ } \\
\text { Sediment }\end{array}$ & Gorgonians & UOM \\
\hline S. aurofrenatum & $30.3(1.5)$ & $8.2(0.7)$ & $<1$ & $50.0(1.6)$ & $1.9(0.4)$ & $1.3(0.3)$ & N/A \\
A. coeruleus & $11.6(0.7)$ & $3.3(0.9)$ & $10.7(0.9)$ & $55.1(2.3)$ & $9.9(1.2)$ & $<1$ & $9.3(1.3)$ \\
\hline
\end{tabular}


Figure 2.1 - Map of study sites in the northern reef tract of the Florida Keys National Marine Sanctuary (FKNMS).

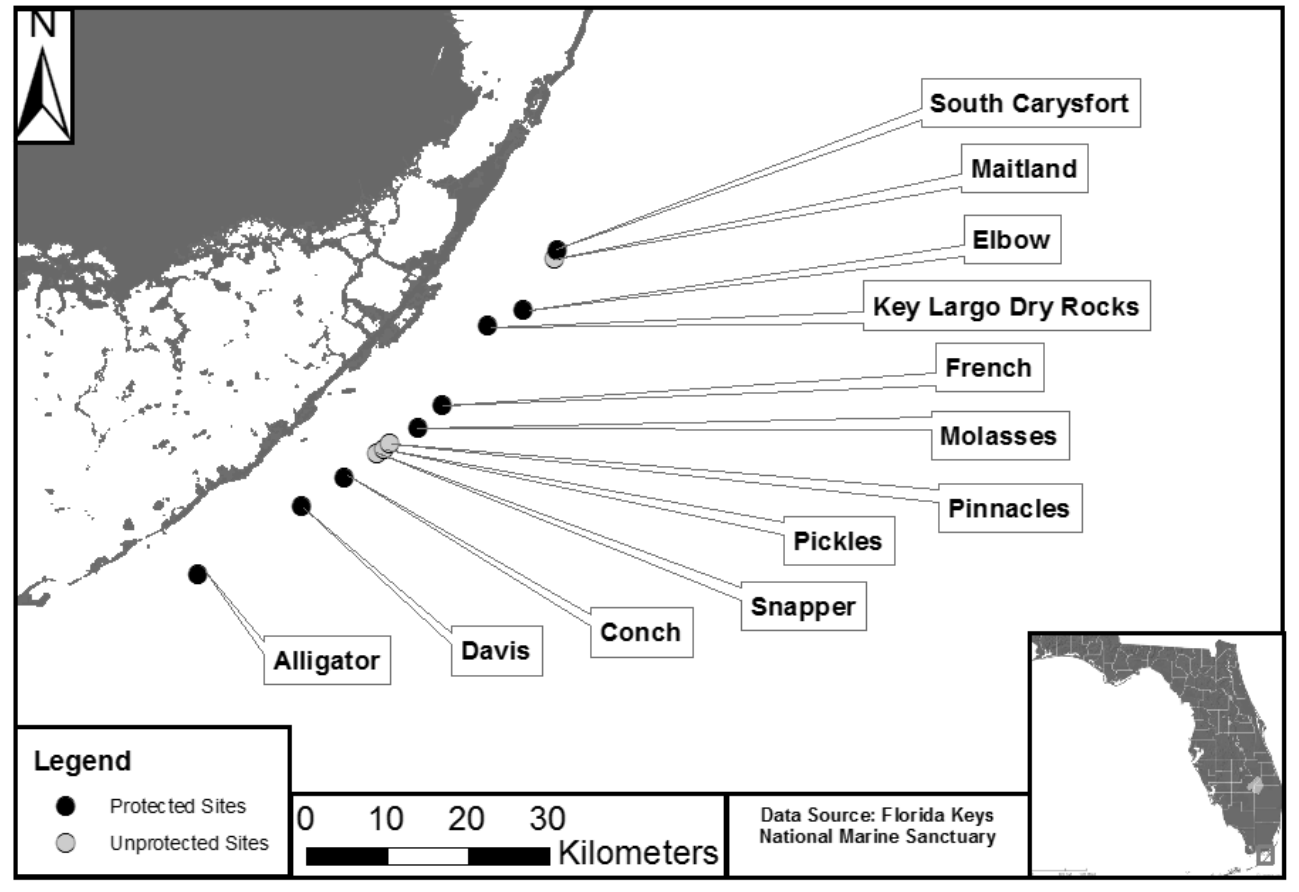


Figure 2.2 - Biplots of $\delta^{13} \mathrm{C}$ and $\delta^{15} \mathrm{~N}$ values ( $\pm \mathrm{SD}$ ) for (a) S. aurofrenatum and (b) A. coeruleus with baseline corrected $\delta 13 \mathrm{C}$ values.
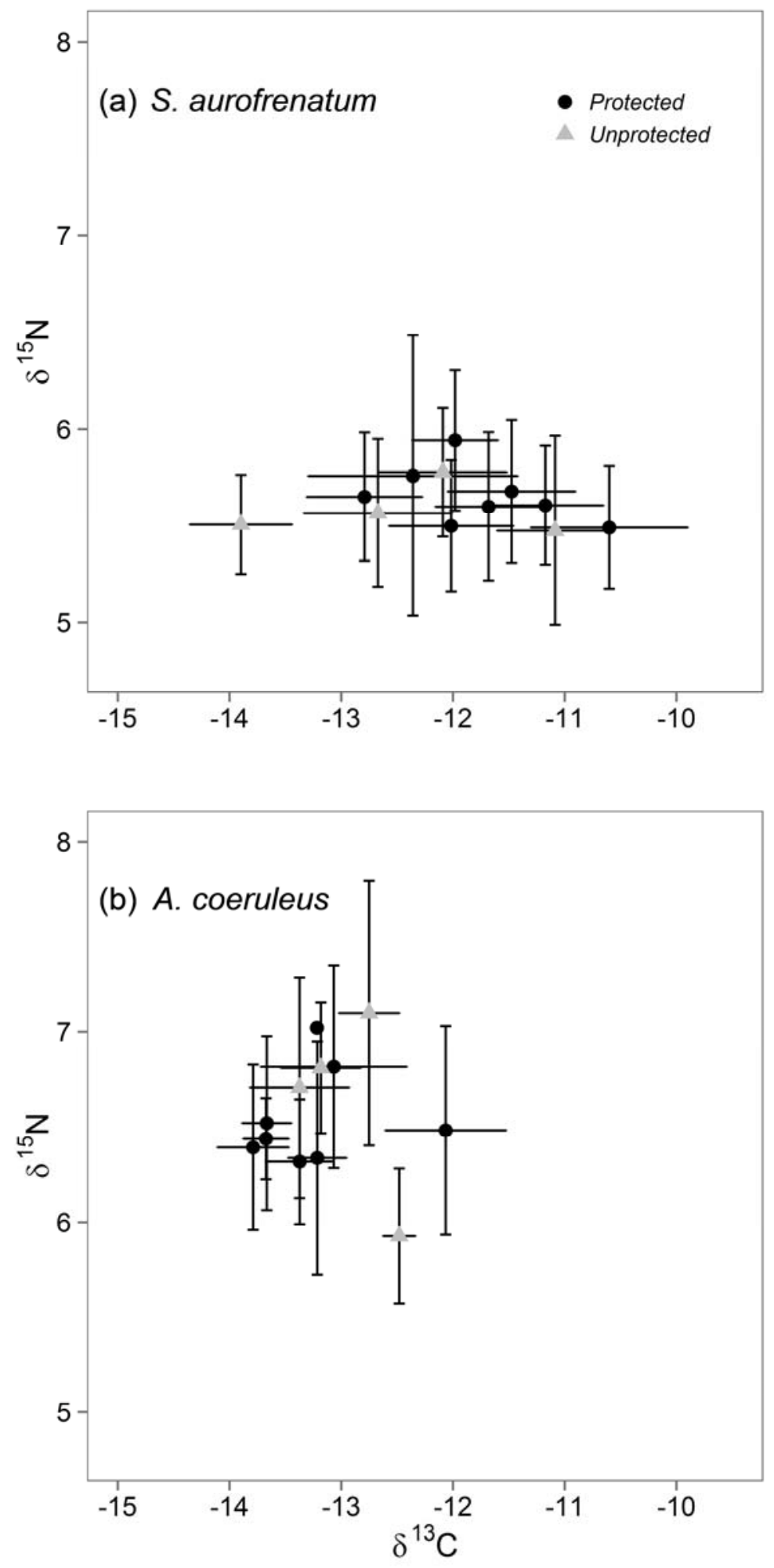
Figure 2.3 - Partial regression plots for S. aurofrenatum showing the effect of (a) PC4 (predator biomass) and (b) PC1 (damselfish abundance) on Bayesian Standard Ellipse Area $\left(\mathrm{SEA}_{\mathrm{B}}\right)$. (c) Simple linear regression of PC1 (damselfish abundance) and $\mathrm{SEA}_{\mathrm{B}}$ for A. coeruleus. Note that because of the negative relationship between $\mathrm{PC} 1$ and damselfish abundance the $\mathrm{x}$-axis has been reversed in panel $\mathrm{b}$ and $\mathrm{c}$ to represent increasing damselfish abundance from left to right. Solid lines are fitted linear regressions.
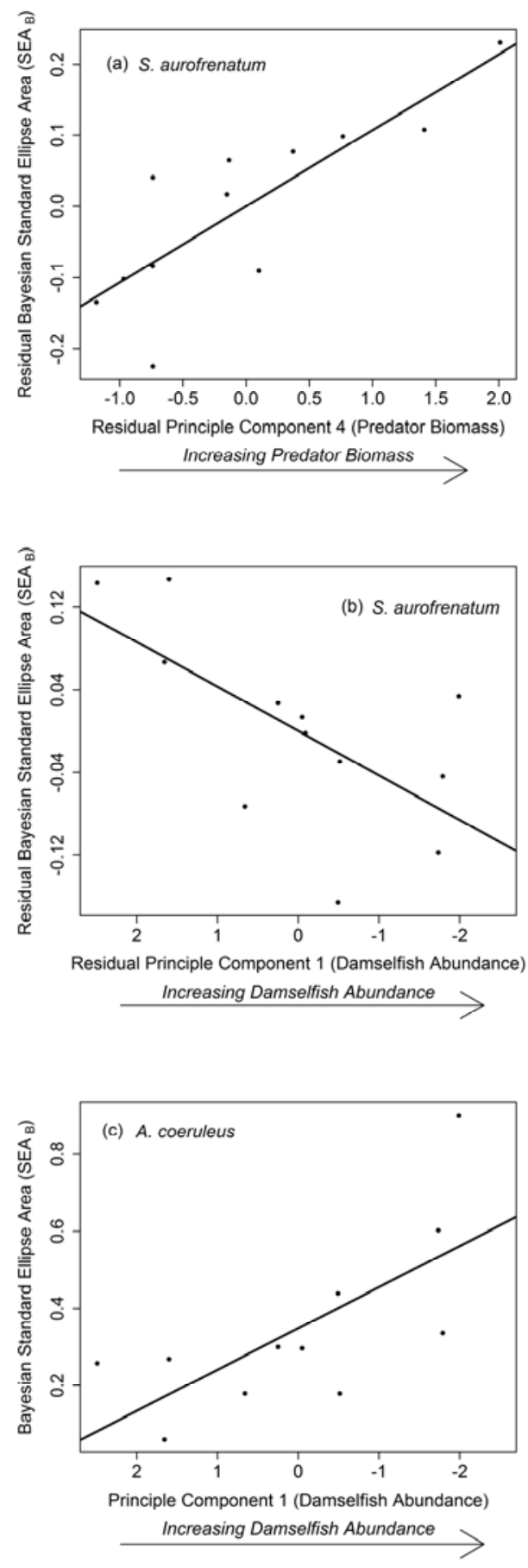
Figure 2.4 - Predicted probability of occurrence of animal material and filamentous turf in stomachs of $A$. coeruleus as a function of fish length based on logistic regression model. Dashed lines represent 95\% confidence intervals.

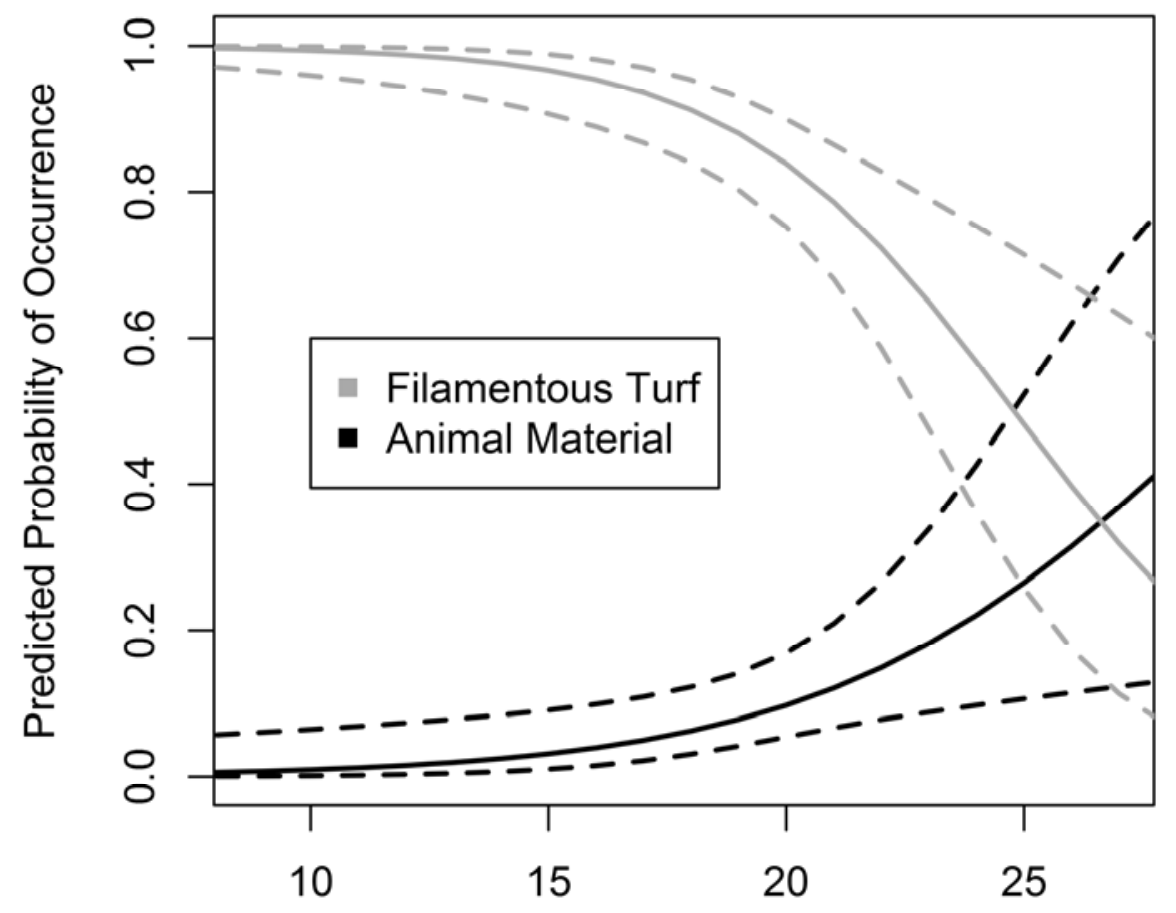

Fish Length $(\mathrm{cm})$ 
Figure 2.5 - Regression plot for territorial damselfish abundance and ln-transformed predator biomass across sites. Line represents fitted linear regression.

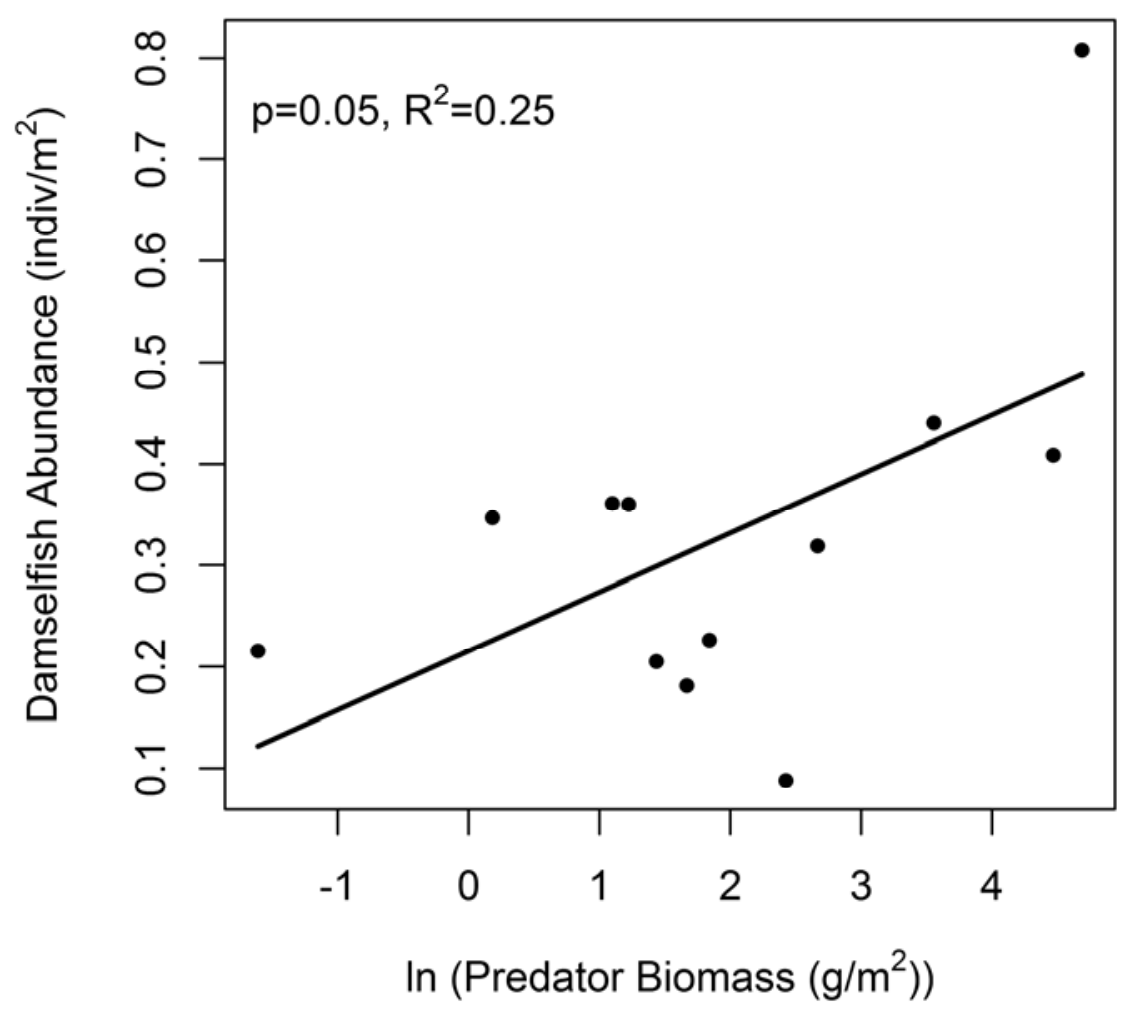




\section{CHAPTER III}

PREDATION RISK, RESOURCE QUALITY, AND REEF STRUCTURAL COMPLEXITY SHAPE TERRITORIALITY IN A CORAL REEF HERBIVORE 
Abstract

For many species securing territories is important for feeding and reproduction. Factors such as competition, habitat availability and male characteristics can influence an individual's ability to establish and maintain a territory. The risk of predation can have an important influence on feeding and reproduction; however, few have studied its effect on territoriality. We investigated territoriality in a haremic, polygynous species of coral reef herbivore, Sparisoma aurofrenatum (Redband Parrotfish), across eight reefs in the Florida Keys National Marine Sanctuary that were either protected or unprotected from fishing of large predators. We examined how territory size and quality varied with reef protection status, competition, predation risk and male size. We then determined how territory size and quality influenced harem size and female size to understand the effect of territoriality on reproductive potential. We found that in protected reefs, where predators are recovering, territories were smaller but had greater algal nutritional quality relative to unprotected reefs. Our data suggest that even though males in protected sites have smaller territories, which support fewer females, they may improve their reproductive potential by choosing nutritionally rich areas, which support larger females. Thus, reef protection appears to shape the trade-off reef herbivores make between territory size and quality. Furthermore, we provide evidence that males in unprotected sites choose territories with high structural complexity, suggesting the importance of this type of habitat for feeding and reproduction in S. aurofrenatum. Our work argues that coral loss and the resulting decline in structural complexity, as well as management efforts to protect reefs, could alter the territory dynamics and reproductive potential of important herbivore species. 
Introduction

Territories often serve as both feeding and breeding grounds that provide nutritional and reproductive benefits for male territory holders (Brown 1964). For haremic territorial species, territory size can influence a male's ability to attract and mate with females, ultimately affecting his reproductive success (Wade and Shulter 2004). Multiple factors can influence the size of territories including the density of competitors, traits of the territory holder such as body size, and predation risk. At high competitor densities, for example, territory holders must increase the time and energy spent defending borders and evicting intruders, often resulting in decreased territory size (Both and Visser 2000, Keeley 2000) except for the largest, competitively superior males (Candolin and Voigt 2001). Although a number of studies have investigated the influence of competition and male traits on territory dynamics, fewer have focused on the effects of predation risk, which is predicted to be an important cost of defending territories (Magnhagen 1991). Given the strong influence of predation risk on influencing foraging behavior (Gilliam and Fraser 1987, Schmitz et al. 1997, Heithaus and Dill 2002), one would expect similar impacts on territoriality. Large and/or high quality territories can enhance breeding success (Best 1977, Weatherhead and Robertson 1977, Both and Visser 2000, Vanpé et al. 2009) and thus can have a strong effect on regulating population densities (Hixon 1980, Adams 2001, López-Sepulcre and Kokko 2005). Therefore, to understand the population dynamics of territorial species it is essential to know the factors that influence territoriality.

On coral reefs, many families of fishes such as Pomacentridae (Hata and Kato 2004), Chaetodontidae (Roberts and Ormond 1992), and Labridae (Warner and Hoffman 
1980a) include species that exhibit conspicuous territorial behavior. For those species in the family Scaridae, known as parrotfishes, a group of harem females occupy the territory of a terminal phase male and breed with him (Barlow 1975, Robertson and Warner 1978, Van Rooij et al. 1996b, Mumby and Wabnitz 2002). Territoriality in this group provides both nutritional (Van Rooij et al. 1996a) and reproductive benefits (van Rooij et al. 1996, Mumby and Wabnitz 2002). For instance, by defending territories against individuals with the highest resource overlap, particularly conspecific males, territory holders gain exclusive access to food resources and spawning privileges with harem females within their territories (Van Rooij et al. 1996b, Mumby and Wabnitz 2002). One of the primary fitness costs of territoriality is aggressive defense against competitors, which decreases time available for foraging and mating. Thus, where competitors are abundant, territories are generally smaller (van Rooij et al. 1996).

An often overlooked cost of territoriality for parrotfishes is a potential increase in vulnerability to predation (Taylor 1988). Frequent and active defense of large territories against intruders may put territory holders at a high risk of predation. Mating behaviors may also increase predation risk (Lima and Dill 1990), resulting in a trade-off between mating behaviors and anti-predator behaviors when predators are abundant (Sih 1994). Indeed, evidence from multiple systems suggests that increasing predation risk alters mate choice (Forsgren 1992, Berglund 1993), male mating tactics (Clifton and Robertson 1993), the timing of mating (Endler 1987), and courtship (Fuller and Berglund 1996) (for review see: (Lima 1998)). However, relatively few studies have investigated the effect of predation risk on territoriality in fishes (Martel 1996, Candolin and Voigt 2001, LaManna and Eason 2007), despite its importance in mating success for many species. Given that 
the abundance of large predators will vary greatly depending on if coral reefs are protected or vulnerable to fishing pressure, it is important to consider how variable levels of predation risk impact the territoriality and reproductive success of parrotfishes. Large grouper, sharks, and barracuda are increasing in size and abundance inside many protected areas (Smith et al. 2011) which will likely increase the vulnerability of nontargeted species (i.e., parrotfishes) to predation risk and potentially alter their territorial and mating behaviors.

Territory selection and defense is a complex process that forces males to balance potentially conflicting forces of territory size, diet quality, structural complexity, competition and predation. For instance, increasing territory size may not improve resource availability for territory holders, particularly if the cost of aggressive defense is high, because resources are patchily distributed on reefs (Hay 1991) and vary in nutritional quality (Bruggemann et al. 1994). Furthermore, the associated costs and benefits of territory selection may require that organisms make trade-offs. For example, choosing a territory with high structural complexity may provide benefits including refuges from predation and greater resource diversity (Hixon and Beets 1993). However, such territories may come at a cost of higher competition because complex habitats likely attract increased densities of competitors (Graham and Nash 2013). Thus, understanding the drivers of territoriality requires using multiple metrics of territory quality to assess the costs and benefits of holding territories. However, many studies focus only on a limited subset of potential drivers, which may underestimate the potential tradeoffs of different mechanisms influencing territoriality. 
In this study we investigated the causes and consequences of territoriality in the herbivorous parrotfish, Sparisoma aurofrenatum, on coral reefs in the Florida Keys National Marine Sanctuary (FKNMS), an abundant herbivore across the Caribbean (Lewis and Wainwright 1985, Smith et al. 2011). Sparisoma aurofrenatum are protogynous with three distinct color phases; juvenile phase, initial phase and terminal phase. Terminal phase (TP) individuals are males which usually maintain permanent territories and spawn year-round with their harem of females (Robertson and Warner 1978). Spawning generally occurs daily during mid- to late-afternoon (Robertson and Warner 1978, Clavijo 1982). It is rare that TP males are seen together, except when involved in aggressive interactions along the borders of their territories (Muñoz and Motta 2000, Mumby and Wabnitz 2002). Initial phase (IP) individuals may be either females or males that have not yet transformed to TP male morphology. Female IP S. aurofrenatum are generally either solitary or move in small groups within a TP male's territory (pers. obs.). The diet of S. aurofrenatum consists of primarily macroalgae and algal turfs (Randall 1967, Catano et al. 2014).

We measured various characteristics of TP S. aurofrenatum territories and harems to test if: (1) reef protection status, competitor and predator biomass, and male size influenced territory size and quality, (2) territory size, territory quality, and male size influenced the size and number of harem females, and (3) territory and harem characteristics influenced the frequency of aggressive and reproductive interactions. We used multiple metrics to characterize territory quality including algal abundance, algal nutritional quality, and reef structural complexity. We expected territory size to decrease with increasing predator and competitor biomass because of the increased cost of 
territoriality. We also expected that larger males, that are likely competitively superior and at less risk of predation, would have larger territories. Further, we anticipated that territory size and territory quality would be inversely proportional and that large and/or high quality territories would be associated with large females and harems. Finally, we predicted that increasing predation risk would reduce the frequency of aggressive and reproductive interactions but that these interactions would be positively associated with harem size and territory quality and size.

Materials and Methods

Ethics Statement

This work was conducted with permission from the Florida Keys National Marine Sanctuary under permit no. FKNMS-2012-080 and the protocol for this study was approved by The Florida International University Institutional Animal Care and Use Committee (IACUC), (Protocol Approval \#12-015, FIU Animal Welfare Assurance Number \#A3096-01).

\section{Site Description}

The Florida Keys reef tract is a large bank reef system located approximately 8 $\mathrm{km}$ offshore of the Florida Keys, USA, parallel to the island chain. Carnivorous fishes (e.g., snapper, grouper, barracuda) are heavily exploited in the region by both commercial and recreational fisheries (Bohnsack et al. 1994, Ault et al. 2005). Fishing activity is restricted inside 23 no-take zones, which were established in 1997 within the Florida Keys National Marine Sanctuary (FKNMS) (Bohnsack et al. 2009). Piscivorous fishes 
including black grouper (Mycteroperca bonaci) and mutton snapper (Lutjanus analis) have increased in size and abundance within these protected areas (Bohnsack et al. 2009, Smith et al. 2011). Unlike most piscivores, herbivorous fishes (e.g., parrotfish, surgeonfish, etc.) are not heavily targeted by fishing across the entirety of the FKNMS (i.e., in both protected and unprotected zones) Although some regulated take of herbivores is allowed, their populations are robust in the FKNMS compared to most other reefs in the Caribbean (Burkepile et al. 2013). Voluntary compliance with sanctuary regulations restricting fishing is reported to be high based on opinion polls of boat users in the FKNMS, even though the sanctuary relies heavily on interpretive enforcement (i.e., enforcement primarily through education) (Keller and Donahue 2006). The FKNMS is an ideal region to test hypotheses about the functional impact of predators on herbivorous fish because it does not confound predator effects (e.g., protected vs. unprotected areas) with vast differences in herbivore abundance across reefs since herbivores are protected everywhere.

We sampled four protected (South Carysfort, Molasses, French and Conch) and four unprotected (Pickles, Pinnacles, Maitland and Snapper Ledge) forereef sites along the northern reef tract off of Key Largo (Figure 3.1, Table 3.1). Sites were similar in depth (6-8 m) and physical parameters (e.g., rugosity) and were separated by at least 700 $\mathrm{m}$ to assure independence. It is unlikely that most reef fishes, with the exception of large, mobile predators such as jacks, would move among reefs over such distances (Lindholm et al. 2005), particularly when separated by open areas (i.e., large expanses of sand or rubble) (Chapman and Kramer 2000), as was the case with the sites used in this study. 
Focal fish observations were made between June-July 2012 on the forereef at depths of 6$8 \mathrm{~m}$.

Territory Delineation and Behavioral Observations

At each site we delineated the territories of 20 TP males on SCUBA, using a towed surface float that was attached to a handheld GPS (Garmin eTrex 10, accurate to < 3 m; see (Nanami and Yamada 2008, Munoz et al. 2010) for similar methods). Divers located a TP male and maintained a position at least $1 \mathrm{~m}$ behind and $1 \mathrm{~m}$ above the focal fish during a 25-min behavioral follow while towing the surface float with GPS. Data collection began after 5-min to allow fish to acclimate to diver presence. We maintained the $1 \mathrm{~m}$ distance from focal males to limit diver influence on their behavior. Males generally acclimated well to diver presence, likely because $S$. aurofrenatum are not targeted by spear-fishing within the FKNMS and don't perceive divers as a threat (Feary et al. 2011). However, if males altered their activity in response to our presence (e.g., hiding or swimming rapidly away from the diver), we immediately stopped the observation and excluded these individuals from further study and analysis. On the basis of longer, 30-min observations, we determined that males patrolled the full extent of their territories several times in the first 20-min of each observation period (Figure 3.2). Therefore, we limited all data acquisition to 20 -min periods. We geo-referenced tracks from the GPS units using ESRI ArcGIS version 10.0 (Redlands, CA). We determined territory sizes by calculating minimum convex polygons of geo-referenced points for the total area covered from the entire observation. At each site, observations were performed over the same time period $(10: 00-16: 00 \mathrm{~h})$ because there are significant diurnal 
changes in activity for many parrotfishes (Sancho et al. 2000) and sites were sampled only on clear days with calm seas to obtain the most accurate GPS signals.

During the 20-min periods of data collection, we recorded aggressive interactions and spawning activities. Aggressive interactions included jaw fighting, parallel swimming, pectoral fin displays and rapid chasing that was initiated by or was directed towards the focal male. Spawning events are conspicuous and involve the focal male and a female swimming alongside each other and ultimately rushing towards the surface and releasing gametes into the water. We also recorded other focal male reproductive interactions with harem females that did not terminate with spawning [i.e., "looping", a down and up movement male performs near females to initiate courtship (Reinboth 1973, Clavijo 1982)]. We synchronized the watch of each diver with the GPS unit and recorded the time of behavioral observations. The geo-referenced tracks then allowed us to determine the exact position where each behavior occurred within the territory.

\section{Territory Metrics}

We estimated harem size by recording the number of females permitted within the territory by the focal male during the 20 -min territory survey. Immediately after the survey divers haphazardly swam the extent of each territory and counted females to verify counts made during the observation and to ensure that females were not counted more than once. Females tended to loosely aggregate in groups within territories, facilitating accurate counts of harem size. We designated individuals to be harem females if they exhibited IP coloring and were not chased by the TP male because TP males often chase both IP males and non-harem females from their territories (Robertson and Warner 
1978). The fork length of the focal TP male and the females within his territory were estimated visually. Prior to data collection, the observers were trained to estimate fish size by assessing the length of static objects underwater (i.e., sections of PVC pipe cut to various lengths) until they could reliably estimate length to the nearest $1 \mathrm{~cm}$. Accuracy was confirmed approximately every two weeks using this same methodology.

Following the 20-min focal follow, we assessed benthic community composition and collected samples for algal nutritional quality within each territory. We collected these metrics along four $5 \mathrm{~m}$ transects radiating from the territory center point in the north, south, east and west directions. We standardized transects to this length on the basis of the average territory diameter $(\sim 10 \mathrm{~m})$. We verified in situ estimations of territory centers with geo-referenced points. Along each transect, photographs were taken every meter to produce twenty $50 \mathrm{~cm} \times 50 \mathrm{~cm}$ photo-quadrats located on the benthos. To quantify benthic cover, 25 points were overlaid on these photographs in a $5 \times 5$ grid and analyzed for cover of benthic organisms using Coral Point Count V4.1 (Kohler and Gill 2006) to produce a total of 500 points per territory. Categories were created for: (1) crustose coralline algae, short algal turf (algal filaments $<0.5 \mathrm{~cm}$ tall) and bare space (abbreviated CTB - 'crustose, turf, bare'), (2) turf algae (algal filaments $>0.5 \mathrm{~cm}$ tall) and sediment (abbreviated TAS - 'turf algae, sediment'), (3) sponges, (4) gorgonians and (5) zoanthids. Macroalgae were classified to genus and scleractinian corals to species. Along each transect we collected portions ( $\mathrm{n}=4 /$ territory) of Dictyota menstrualis, a commonly consumed species of macroalgae (Catano et al. 2014), to analyze carbon and nitrogen content (a metric of resource quality). After collection, samples were immediately placed on ice and later transported back to the lab where they were kept 
frozen until dried at $60^{\circ} \mathrm{C}$. To obtain average $\mathrm{C}$ and $\mathrm{N}$ measurements for each territory, the four samples from each territory were combined and ground to a fine powder with a mortar and pestle, then weighed and processed using a CHN elemental analyzer.

We determined physical habitat characteristics including depth and rugosity (i.e., structural complexity) of each territory using a lidar (Light Detection and Ranging)derived bathymetric data set provided the U.S. Geological Survey (USGS) (available online http://pubs.usgs.gov/of/2007/1395/start.html). We used this dataset to create a raster of benthic rugosity ( $1 \mathrm{~m} \times 1 \mathrm{~m}$ resolution) with the Benthic Terrain Modeler (a collection of ESRI ArcGIS-based tools available online http://www.csc.noaa.gov/digitalcoast/tools/btm/index.html). Using the ArcGIS zonal statistics tool we calculated average depth and rugosity within each territory's minimum convex polygon. Lidar-derived rugosity measurements are often significantly positively correlated with traditional transect estimates of rugosity (Brock et al. 2006, Kuffner et al. 2007, Wedding et al. 2008). Furthermore, by using lidar data we obtained fine-grain $\left(1 \mathrm{~m}^{2}\right)$ metrics of rugosity that covered large extents (i.e., the entirety of each male's territory). Thus, we are likely capturing the grain and extent at which S. aurofrenatum makes foraging, sheltering and reproductive decisions - all of which are potentially important to consider when evaluating territory dynamics.

\section{Site Characteristics}

At each site, we also estimated benthic cover, algal nutritional quality, and rugosity outside of parrotfish territories so that we could compare them to those metrics measured inside territories. By doing so, we obtained reference metrics to determine if 
TP males selected territories with certain characteristics that differed from the surrounding reef. To obtain site-wide estimates of benthic cover and algal nutritional quality, we conducted eight $25 \mathrm{~m}$ transect surveys that were haphazardly laid out parallel to the main reef formation. We took photo-quadrats every meter and collected portions of D. menstrualis along each transect following the methodology described above for collection and processing of these data. We pooled the benthic data points from all eight transects and randomly resampled 500 points from the pooled data to calculate reference percent cover metrics. Repeating the procedure twenty times allowed us to obtain site estimates of benthic cover that were comparable to and estimated with the same precision as those inside territories (i.e., derived from 500 benthic data points). Performing the bootstrapping procedure was necessary because there was a limited area to conduct transects in surrounding reef without encountering S. aurofrenatum territories at smaller sites. Finally, to obtain site-wide estimates of rugosity comparable to the 20 territory estimates, we haphazardly placed twenty $100 \mathrm{~m}^{2}$ plots (the average size of the TP male territory) using ArcGIS that did not overlap with our measured S. aurofrenatum territories. We then calculated rugosity within plots derived from lidar data using the ArcGIS zonal statistics tool. We used benthic habitat maps available from the FKNMS (http://flkeysbenthicmaps.noaa.gov/) to distinguish reef from non-reef habitats (e.g., seagrass, sand, rubble).

To examine potential relationships between territory/harem size and competitor or predator abundance, we used fish abundance and biomass estimates from surveys done at each site. These data were collected from eight $25 \mathrm{~m}$ long transects along which we identified and visually estimated the fork length of all fishes within a $4 \mathrm{~m}$ wide window. 
We used published length:weight relationships to convert fish lengths to biomass (Bohnsack and Harper 1988).

Statistical Analysis

We first tested the hypothesis that protection status, competitor and predator biomass, and focal male length influenced territory metrics (i.e., territory size, rugosity, algal nutritional quality and algae percent cover). To test for differences in competitor biomass, predator biomass, and territory sizes between protected and unprotected sites we used Welch Two-Sample t-tests. We used two-way Analysis of Variance (ANOVA) followed by Tukey HSD post-hoc tests to examine the effect of protection status and territory status (i.e., reference vs. territory) to test if differences in territory quality variables (e.g., algal abundance and algal nutritional quality) were the result of protection status or were associated with the attributes of the reefs themselves. We used Analysis of Covariance (ANCOVA) to examine the effect of male size on territory quality variables among protected and unprotected sites. We investigated the effect of site-level variables including competitor and predator biomass on territory quality metrics using mixedeffects models with site and status modeled as random effects. We defined competitor biomass as the combined biomass of Sparisoma species because the overwhelming majority of aggressive interactions were with conspecifics and congeners (see Results). We estimated predator biomass, which in our prior work was shown to be a useful metric to estimate predation risk (Catano et al. 2014), by summing all primarily piscivorous fishes of the families Carangidae, Lutjanidae, Serranidae and Sphyraenidae that were > $30 \mathrm{~cm}$ and known to consume adult parrotfishes (using data from [Randall 1967]). 
Because larger males could have a differential ability to procure higher quality territories, we examined the effect of male size on territory quality metrics using simple linear regressions. Next, we tested the hypothesis that territory size, territory quality, and male size influenced the size and number of harem females. We used multiple linear regressions to examine how territory metrics (i.e., size, rugosity, algal nutritional quality and algal percent cover) and male length influenced both harem size and average female size.

Finally, we tested the hypothesis that territory and harem characteristics would influence the frequency of aggressive and reproductive interactions. We used multiple logistic regression to test the effects of these variables on the probability of occurrence of spawning and aggressive behaviors. To understand which fish species were the major targets of aggression, we tallied the aggressive interactions by species for each male and used a one-way ANOVA followed by Tukey HSD post-hoc tests to make comparisons. To understand how spawning events varied with protection status, we used a chi-square analysis to compare the proportion of males spawning in protected and unprotected areas. All statistical analyses were conducted using $R$ version 3.0.1. Parametric assumptions of normality and homoscedasticity were verified using plots of the residuals.

Results

Sparisoma aurofrenatum at protected sites had smaller territories $\left(91.7 \pm 5.8 \mathrm{~m}^{2}\right.$, mean $\pm \mathrm{SE}, \mathrm{n}=77)$ relative to those at unprotected sites $\left(131.45 \pm 8.9 \mathrm{~m}^{2}, \mathrm{n}=79\right)$ (Figure $3.3, \mathrm{t}=-3.77, \mathrm{df}=133.24, \mathrm{p}<0.001)$. At all sites, territories generally did not overlap (Figure 3.4). Predator biomass inside protected sites $(24.5 \pm 20.9 \mathrm{~g} \mathrm{~m}-2, \mathrm{n}=4)$ was 
statistically undistinguishable to unprotected sites $(10.7 \pm 8.1 \mathrm{~g} \mathrm{~m}-2, \mathrm{n}=4)(\mathrm{t}=0.62, \mathrm{df}=$ 3.88, $\mathrm{p}=0.57$ ). Competitor biomass (i.e., Sparisoma spp.) was similar inside protected sites $(16.4 \pm 5.4 \mathrm{~g} \mathrm{~m}-2, \mathrm{n}=4)$ and unprotected sites $(13.4 \pm 3.3 \mathrm{~g} \mathrm{~m}-2, \mathrm{n}=4)(\mathrm{t}=0.47, \mathrm{df}$ $=4.96, \mathrm{p}$-value $=0.66)$.

Metrics of territory quality (i.e., macroalgal cover, C:N of D. menstrualis and rugosity) varied with territory status (i.e., territory vs. reference) and protection status. Territories had less macroalgae relative to reference areas and, overall, protected sites had less macroalgal cover relative to unprotected sites (Table 3.2a, Figure 3.5a). Pairwise comparisons showed that territories in protected sites had less macroalgal cover relative to territories in unprotected sites. Dictyota menstrualis was most nutritious (lower C:N ratios) inside parrotfish territories and particularly inside territories of protected areas (Table 3.2b, Figure 3.5b). Territories in protected and unprotected areas were similar in terms of structural complexity. In unprotected sites territories tended to be more structurally complex relative to reference areas, whereas complexity was similar between territories and reference areas in protected sites (Table 3.2c, Figure 3.5c).

We did not find evidence that larger males occupied larger territories or that their territories had more algal resources in either protected or unprotected sites (Table 3.3). However larger males had more rugose territories, but only in unprotected areas where this relationship was relatively weak but significant $\left(R^{2}=0.05, p=0.03, \beta=0.41, S E=\right.$ 0.18 , Figure 3.6a\&b). Additionally, larger males controlled higher quality territories (lower C:N of D. menstrualis) $\left(\mathrm{R}^{2}=0.04, \mathrm{p}=0.02, \beta=-0.25, \mathrm{SE}=0.09\right.$, Figure 3.6c). We did not find evidence for any effect of predator biomass on territory size or quality, 
but competitor biomass was significantly positively associated with territory rugosity (Table 3.4).

Territory quality and male size had an influence on the number and size of females within territories (See Table 3.5 for summary statistics of male, female and harem sizes between protected and unprotected sites). Larger harems were associated with larger territories, but unrelated to male length, territory rugosity, algal quality or algal percent cover (Full model: F5,95 $=1.48, \mathrm{R}^{2}=0.02, \mathrm{p}=0.20$, Table 3.6a). Larger females were associated with larger males and with territories that had greater algal resource quality (lower $\mathrm{C}: \mathrm{N}$ ratios), but female size was unrelated to territory area, rugosity or algal percent cover (Full model: F5,92 $=10.39, \mathrm{R}^{2}=0.33, \mathrm{p}<0.001$, Table $3.6 b)$.

Of the aggressive interactions that focal males exhibited, most involved $(\%$, mean number per minute $\pm \mathrm{SE})$, rapid chases $(52 \%, 0.13 \pm 0.009)$ and fin-flares $(38 \%, 0.09 \pm$ 0.006), while fewer involved parallel swimming $(5 \%, 0.01 \pm 0.004)$ and jaw-fighting $(0.5 \%, 0.005 \pm 0.005)$. All such interactions occurred either within or along the borders of territories. The majority of aggressive interactions initiated by focal males were directed towards conspecifics $(\sim 77 \%)$. The remaining interactions were with heterospecifics including: S. rubripinne, S. chrysopterum, S. viride, S. taeniopterus, and Scarus iserti in order of decreasing frequency (Figure 3.7). There were significantly more aggressive interactions directed towards conspecifics than other parrotfish species (ANOVA: $\mathrm{F}_{9,996}=126.9, \mathrm{p}<0.001$ ). Additionally, based on pairwise comparisons, there were more aggressive interactions directed towards $S$. rubripinne relative to other heterospecifics. We found that the probability of engaging in aggressive interactions with 
other parrotfish was positively associated with harem size as we expected $(\beta=0.45 \pm$ $0.20, p=0.03)$. However, contrary to our expectations, the probability of engaging in in aggressive interactions was also positively associated with $\mathrm{C}: \mathrm{N}$ of $D$. menstrualis $(\beta=$ $0.25 \pm 0.13, p=0.05)$ (suggesting territories with lower quality algae were more aggressively defended), and unrelated to average female size or other territory quality metrics (i.e., territory size, rugosity, macroalgal cover) (Table 3.7a). A HosmerLemeshow test for goodness of fit showed a good fit for the logistic regression model $\left(\chi^{2}\right.$ $=157.42, \mathrm{p}=0.36)$.

All spawning we observed took place within the focal male's territory and occurred between the focal male and a female from his harem between 13:00 - 16:00 $\mathrm{h}$. We observed a total of 32 spawning events by 14 males. Thirty of these spawning events (by 12 males) were observed inside protected sites. Overall, there were a greater proportion of males spawning in protected sites relative to unprotected sites $\left(\mathrm{df}=1, \chi^{2}=\right.$ $6.93, \mathrm{p}=0.008)$. Spawning males inside protected sites had approximately twice as many spawning episodes relative to those in unprotected sites. We found that the probability of spawning decreased with territory size $(\beta=-0.03, \mathrm{SE}=0.01, \mathrm{p}=0.05)$, but was unrelated to other territory quality metrics or reef protection status (Table 3.7b). A Hosmer-Lemeshow test for goodness of fit showed a good fit for the logistic regression model $\left(\chi^{2}=13.05, \mathrm{p}=0.11\right)$.

\section{Discussion}

Our work elucidated multiple factors that influence territorial and reproductive behaviors for the parrotfish S. aurofrenatum on reefs in the Florida Keys. Reef protection 
status appeared to underlie some of the differences in quality metrics between territory and reference areas. For instance, there was a difference in algal nutritional quality between territories and surrounding areas (with territories having higher algal nitrogen content) and this difference was greater in protected sites. Reef protection status also influenced territory size, with territories inside protected areas being approximately $25 \%$ smaller than those inside unprotected areas. Although our data were consistent with the idea that increased predation risk decreased territory size, given smaller territories inside of protected areas, there was no direct correlation between predator biomass and smaller territory size. Our data suggest that it is beneficial for males to maintain large territories with high nutritional quality because they tended to support a greater number of large females. Furthermore, there may be a potential trade-off between territory size and quality as territories in protected sites were smaller but they had algae with higher nutritional quality. However, contrary to our expectations, we observed more spawning activity inside protected areas and in smaller territories. Overall, our work indicates that multiple metrics of both territory quality and male characteristics impact patterns in territoriality and spawning, which may have indirect consequences on the reproductive potential of male territory holders.

Mean territory sizes of S. aurofrenatum $\left(112 \mathrm{~m}^{2}\right)$, were in the range of those recorded in Belize (82 and $319 \mathrm{~m}^{2}$ ) (Mumby and Wabnitz 2002), Puerto Rico $\left(88 \mathrm{~m}^{2}\right.$ ) (Clavijo 1982), Barbados (142-215 m²) (Dubin 1981), and other areas in Florida (240 $\mathrm{m}^{2}$ ) (Muñoz and Motta 2000). Variation in territory sizes measured among these studies may be the result of differences in sampling methodology and/or the type of habitats sampled. Those studies done in Florida and Puerto Rico delineated territories based on 
locations of aggressive interactions. This method may be less accurate because territories can be maintained through mutual avoidance with or without aggression (Kaufmann 1983). Additionally, some of the sites used in the studies from Barbados and Florida were primarily patch reefs, which are likely different in resource distribution relative to contiguous reef structures. Prior studies have also relied on dropping physical markers to delineate territories, which may fail to capture the full extent of the territory and potentially have unintended effects on focal fish behavior. Our methodology using handheld GPSs attached to a float allowed us to more accurately estimate the full extent of male movements with minimal diver interference.

Protection from fishing, which increases the abundance of predators of $S$. aurofrenatum, could indirectly affect their territory size. Long-term monitoring of protected areas in the FKNMS has shown increases in absolute and relative predator abundances after reserve implementation as compared to reference areas (Smith et al. 2011). The fear of predation could decrease the area over which individuals venture as herbivorous fishes may reduce their excursion area (i.e., the distance or area that individuals move over a given time period) in the presence of increased predation risk (Madin et al. 2010). Unlike extensive surveys within the FKNMS (Smith et al. 2011), we did not find significantly greater predator biomass at protected sites compared to unprotected sites. The lack of significance, however, may be due to substantial variation in predator abundances across protected sites, relatively low sample size, or imperfect predator detection (Ward-Paige et al. 2010). Territories in protected areas were smaller, consistent with the hypothesis that increased predation risk results in an increased cost of holding larger territories. However, despite being supportive of our hypothesis, measured 
predator biomass did not directly relate to territory size or other territory quality metrics. As a consequence of having smaller territories, males likely have a more constrained foraging area and appear to compensate for smaller territories by choosing territories with greater food quality (i.e., lower C:N ratios).

A trade-off between territory size and quality may influence the number and size of harem females. Large territories, which require more surveillance over wide areas, likely put S. aurofrenatum at greater risk of predation, are energetically more expensive to defend and are more susceptible to incursions. The benefit of a large territory is in the greater foraging area it provides and in the greater number of harem females it can support. By choosing areas of the reef with higher algal quality, males may make up for their limited foraging area while still meeting their metabolic needs. Further, despite having fewer females, smaller territories with greater algal quality appear to support larger females with more spawning events. Thus, reef protection, which increases predator biomass (Smith et al. 2011), may influence the trade-off S. aurofrenatum makes between large territories with more feeding opportunities/abundant females and smaller territories with higher algal quality/larger females. Most studies investigating habitat use decisions based on a trade-off between food and safety have focused on either food quantity (Abramsky et al. 2002, Krause and Liesenjohann 2012) or food quality (McArthur et al. 2011, Pays et al. 2011, Brooker et al. 2013). Our work indicates that the resolution of this trade-off may be more dynamic, with each factor being valued differently depending on context (Festa-Bianchet 1988).

Despite the clear effect of protection on territory size, we cannot discount the alternative bottom-up explanation that higher algal quality inside territories of protected 
sites supported smaller territories. It may be more beneficial for males to defend a smaller area, even though there may be fewer potential feeding opportunities, because of the energetic costs to territory defense. Males in protected areas may be better able to realize this advantage because smaller territories tended to also have greater algal nutritional quality. Therefore, smaller territories which require less defense, may be all that is needed for these males to meet their metabolic needs. Less time spent defending a territory could provide males with more time for other activities such as spawning, which we observed more frequently inside protected areas. Thus, while our data clearly show smaller territories in protected zones, further work will be needed to determine the direction of causation for this relationship.

Structural complexity may also an important determinant of parrotfish territories. This was especially the case in unprotected areas where structurally complex habitat was more limited and males targeted high complexity areas with larger males securing the most sought-after and complex territories. Large males are likely superior competitors and potentially at less risk of predation, making them better able to secure quality territories (Candolin and Voigt 2001). These more complex areas may make better territories because more complexity typically attracts more fishes (Graham and Nash 2013), and fish aggregations may have an indirect positive effect on food resources by increasing nitrogen availability from fish excretion for macroalgae within those areas. In the Florida Keys fish excretion can supply up to 25 times more nitrogen to forereefs than all other biotic and abiotic sources combined (Burkepile et al. 2013). Further, higher biomass of fishes was associated with decreased algal C:N (higher algal nutritional quality) at the reef-wide scale (Burkepile et al. 2013). Thus, aggregations of fishes 
associating with highly complex regions inside territories, likely increase the nitrogen supply available to the benthos leading to higher algal nutritional quality inside territories. This would provide an added benefit for S. aurofrenatum in choosing high complexity regions to establish their territories. Thus, more complex areas are likely more desirable as a feeding and breeding habitat for S. aurofrenatum, as has been demonstrated in other reef fish (Gladstone 2007). As coral cover declines (Gardner et al. 2003) and reef complexity is lost (Alvarez-Filip et al. 2009), our data suggests that there also may be an associated loss of key habitat types for territorial species.

Contrary to what we expected, the probability of males engaging in aggressive interactions was not positively associated with metrics of territory quality. This may be due to the overall low probability of aggressive interactions or imperfect detection of aggression by observers. Territories can be maintained without overt aggression, but rather males may avoid potentially injurious interactions through mutual avoidance (Kaufmann 1983). Observers may have overlooked such subtle avoidance behaviors resulting in relationships that did not conform to hypotheses.

Our data also suggest that protection status may influence reproductive behaviors. Spawning was almost exclusively observed in protected sites, even though we consistently made observations during the same time periods at all sites (10:00 - 16:00 h). In particular, the two protected sites with the highest predator biomass (French Reef and Molasses Reef) also had the greatest proportion of males spawning (25\% and $11 \%$, respectively) relative to other sites. This was contrary to what we expected, as others have shown that the increased risk of predation suppresses courtship activity in fishes (e.g., (Endler 1987, Berglund 1993, Chivers et al. 1995, Fuller and Berglund 1996)). We 
suspect that $S$. aurofrenatum in protected sites may spawn mid-day to avoid crepuscular predators, as opposed to dusk when spawning activity general peaks (Robertson and Warner 1978, Clavijo 1982). This may explain why we did not observe spawning in unprotected sites during our mid-day surveys, but without dusk observations we can only speculate about peaks in spawning at unprotected sites. However, there are multiple, likely interacting, characteristics of protected sites that could also explain the increased likelihood of spawning. Inside protected areas there was greater structural complexity, territories were smaller and had food resources with greater nutritional quality relative to unprotected sites. For many coral reef fish, sites with high substratum rugosity are a preferred microhabitat for spawning aggregations (Gladstone 2007), although we could not detect a direct relationship between structural complexity and the frequency of spawning. Furthermore, males may be more likely to encounter and thus spawn with harem females in smaller territories, which we found in protected areas, and greater food quality, which we also found in territories in protected areas, may allow males to meet the energetically expensive demands of spawning. Additionally, there are other factors occurring at different spatial and temporal scales that we did not measure that can influence spawning activity of coral reef fish including reef size, the availability of suitable spawning sites, and the potential for successful transport of gametes (Johannes 1978, Warner 1984, Gladstone 2007). These factors likely varied among study sites, individual territories, and sampling days, making it challenging to identify the specific individual drivers of spawning activity.

Overall, our data support the idea that territoriality in S. aurofrenatum is at least partially linked to food resources which has consequences for reproduction. We show 
that males choose territories based on food resources because: (1) algal nutritional quality was greater inside territories, (2) aggression was primarily targeted towards individuals with the greatest resource overlap (i.e., conspecifics and congeners) (Lewis and Wainwright 1985, Van Rooij et al. 1996a), and (3) territories with the highest algal nutritional quality were defended by the largest, competitively superior males. The purpose for gaining exclusive access to food resources seemed to be to enhance reproductive potential because: (1) large territories were associated with larger harems and (2) high quality algae attracted large females. It has been demonstrated in multiple other species (i.e., great tits (Both and Visser 2000), field sparrows (Best 1977), redwinged blackbirds (Weatherhead and Robertson 1977) and European roe deer (Vanpé et al. 2009)) that territory size and quality influences breeding success, however data on reef fish is limited (Fricke 1980, Warner and Hoffman 1980b, Petersen 1995). Importantly, we show that multiple, interactive factors associated with protection status including, resource quality, and reef structural complexity as well as male characteristics, shape territoriality in S. aurofrenatum.

Along multiple reefs in the FKNMS, variability in territory size and quality of $S$. aurofrenatum between protected and unprotected sites, suggests a trade-off between the costs and benefits maintaining exclusive access to feeding and breeding grounds. Inside protected sites where predators are more abundant (Smith et al. 2011) and reefs are more structurally complex, territories are smaller and have higher resource quality. Whereas, inside unprotected sites with fewer predators and less complex reef structure, territories are larger but have lower resource quality and are equally as rugose as territories in protected sites. These differences suggest that greater resource quality offsets constraints 
in territory size which could be driven by increased predation risk. Although we did not find direct relationships between predator biomass and territory metrics, we demonstrate patterns associated with reef protection status that support this hypothesis. In recent decades the decline in coral abundance on coral reefs due to multiple global and local stressors (Hughes et al. 2003) have been associated with dramatic declines in reef structural complexity (Alvarez-Filip et al. 2009) and predator biomass (Pauly 1998). The indirect effects of coral reef declines, particularly on social and reproductive interactions of reef associated species, is yet unclear. However, our data suggest that the reduction in rugosity resulting from coral loss and changing predator abundances from overfishing could alter the territory dynamics of important herbivore species.

\section{Acknowledgments}

We thank C. Fuchs, R. McMinds, R. Sarabia, T. Vaughn, R. McQueen, and W. Sturrup for assistance with field and laboratory work. We are indebted M. Heithaus, A. Shantz and C. Catano, for their time and advice with this project.

\section{References Cited}

Abramsky, Z., M. L. Rosenzweig, and A. Subach. 2002. The Costs of Apprehensive Foraging. Ecology 83:1330.

Adams, E. S. 2001. Approaches to the study of territory size and shape. Annual Review of Ecology and Systematics 32:277-303.

Alvarez-Filip, L., N. K. Dulvy, J. a Gill, I. M. Côté, and A. R. Watkinson. 2009. Flattening of Caribbean coral reefs: region-wide declines in architectural complexity. Proceedings. Biological sciences / The Royal Society 276:3019-25. 
Ault, J. S., J. A. Bohnsack, S. G. Smith, and J. Luo. 2005. Towards sustainable multispecies fisheries in the Florida, USA and coral reef ecosystem. Bulletin of Marine Science 76:595-622.

Barlow, G. W. 1975. On the sociobiology of four puerto rican parrotfishes (Scaridae). Marine Biology 33:281-293.

Berglund, A. 1993. Risky sex: male pipefishes mate at random in the presence of a predator. Animal Behavior 46:169-175.

Best, L. B. 1977. Territory quality and mating success in the field sparrow (Spiella pusilla). The Condor 79:192-204.

Bohnsack, J. A., and D. E. Harper. 1988. Length-weight relationships of selected marine reef fishes from the southeastern United States and the Caribbean. NOAA Technical Memorandum NMFS-SEFC-215:31p.

Bohnsack, J. A., D. E. Harper, and D. B. Mcclellan. 1994. Fisheries trends from Monroe County, Florida. Bulletin of Marine Science 54:982-1018.

Bohnsack, J. A., D. E. Harper, D. B. Mcclellan, G. T. Kellison, N. Marine, F. Service, J. S. Ault, S. G. Smith, and N. Zurcher. 2009. Coral reef fish response to FKNMS management zones : the first ten years ( 1997-2007). Progress Report of the Florida Keys National Marine Sanctuary:1-29.

Both, C., and M. E. Visser. 2000. Breeding territory size affects fitness : an experimental study on competition at the individual level. Journal of Animal Ecology 69:10211030.

Brock, J., C. Wright, I. Kuffner, R. Hernandez, and P. Thompson. 2006. Airborne lidar sensing of massive stony coral colonies on patch reefs in the northern Florida reef tract. Remote Sensing of Environment 104:31-42.

Brooker, R. M., P. L. Munday, I. M. Mcleod, and G. P. Jones. 2013. Habitat preferences of a corallivorous reef fish: predation risk versus food quality. Coral Reefs 32:613622.

Brown, J. L. 1964. The evolution of diversity in avian territorial systems. Wilson Bulletin 76:160-169.

Bruggemann, J. H., M. J. H. Van Oppen, and A. M. Breeman. 1994. Foraging by the stoplight parrotfish Sparisoma viride. I. Food selection in different, socially determined habitats. Marine Ecology Progress Series 106:41-55. 
Burkepile, D. E., J. E. Allgeier, A. a Shantz, C. E. Pritchard, N. P. Lemoine, L. H. Bhatti, and C. a Layman. 2013. Nutrient supply from fishes facilitates macroalgae and suppresses corals in a Caribbean coral reef ecosystem. Scientific reports 3:1493.

Candolin, U., and H. Voigt. 2001. Correlation between male size and territory quality : consequence of male competition or predation susceptibility? Oikos 95:225-230.

Catano, L., A. Shantz, and D. Burkepile. 2014. Predation risk, competition, and territorial damselfishes as drivers of herbivore foraging on Caribbean coral reefs. Marine Ecology Progress Series 511:193-207.

Chapman, M. R., and D. L. Kramer. 2000. Movements of fishes within and among fringing coral reefs in Barbados. Environmental Biology of Fishes 57:11-24.

Chivers, D. P., B. D. Wisenden, and R. J. F. Smith. 1995. Predation risk influences reproductive behavior of Iowa darters, Etheostoma exile (Osteichthyes, Percidae). Ethology 99:278-285.

Clavijo, I. E. 1982. Distribution, reproductive biology and social structure of the Redband Parrotfish, Sparisoma aurofrenatum (Valenciennes). Ph. D. Thesis, University of Puerto Rico.

Clifton, K., and D. R. Robertson. 1993. Risks of alternative mating tactics. Nature 366:520.

Dubin, R. E. 1981. Social behaviour and ecology of some Caribbean parrotfish (Scaridae). Ph. D. Thesis, University of Alberta.

Endler, J. A. 1987. Predation, light intensity and courtship behavior in Poecilia reticulata (Pisces: Poeciliidae). Animal Behavior 35:1376-1385.

Feary, D. a, J. E. Cinner, N. a J. Graham, and F. a Januchowski-Hartley. 2011. Effects of customary marine closures on fish behavior, spear-fishing success, and underwater visual surveys. Conservation biology : the journal of the Society for Conservation Biology 25:341-9.

Festa-Bianchet, M. 1988. Seasonal range selection in bighorn sheep: conflicts between forage quality, forage quantity, and predator avoidance. Oecologia 75:580-586.

Forsgren, E. 1992. Predation risk affects mate choice in a gobiid fish. The American Nautralist 140:1041-1049.

Fricke, H. W. 1980. Control of different mating systems in a coral reef fish by one environmental factor. Animal Behavior 28:561-569. 
Fuller, R., and A. Berglund. 1996. Behavioral responses of a sex-role reversed pipefish to a gradient of perceived predation risk. Behavioral Ecology 7:69-75.

Gardner, T. A., I. Cote, J. Gill, A. Grant, and A. R. Watkinson. 2003. Long-term regionwide declines in Caribbean corals. Science. 301:958-960.

Gilliam, J. F., and D. F. Fraser. 1987. Habitat Selection Under Predation Hazard : Test of a Model with Foraging Minnows. Ecology 68:1856-1862.

Gladstone, W. 2007. Selection of a spawning aggregation site by Chromis hypsilepis (Pisces: Pomacentridae): habitat structure, transport potential, and food availability. Marine Ecology Progress Series 351:235-247.

Graham, N. a. J., and K. L. Nash. 2013. The importance of structural complexity in coral reef ecosystems. Coral Reefs 32:315-326.

Hata, H., and M. Kato. 2004. Monoculture and mixed-species algal farms on a coral reef are maintained through intensive and extensive management by damselfishes. Journal of Experimental Marine Biology and Ecology 313:285-296.

Hay, M. E. 1991. Fish-Seaweed Interactions on Coral Reefs : Effects of Herbivorous Fishes and Adaptations of Their Prey. Pages 96-119 in P. Sale, editor. The Ecology of Fishes on Coral Reefs. Academic Press, San Diego.

Heithaus, M. R., and L. Dill. 2002. Food availability and tiger shark predation risk influence bottlenose dolphin habitat use. Ecology 83:480-491.

Hixon, M. A. 1980. Food production and competitor density as the determinants of feeding territory size. The American Nautralist 115:510-530.

Hixon, M. A., and J. P. Beets. 1993. Predation, prey refuges, and the structure of coralreef fish assemblages. Ecological Monographs 63:77-101.

Hughes, T. P., A. H. Baird, D. R. Bellwood, M. Card, S. R. Connolly, C. Folke, R. Grosberg, O. Hoegh-Gudberg, J. B. C. Jackson, J. Kleypas, J. M. Lough, P. Marshall, M. Nystrom, S. R. Palumbi, J. M. Pandolfi, B. Rosen, and J. Roughgarden. 2003. Climate change, human impacts, and the resilience of coral reefs. Science. 301:929-933.

Johannes, R. E. 1978. Reproductive strategies of coastal marine fishes in the tropics. Environmental Biology of Fishes 3:65-84.

Kaufmann, J. 1983. On the definitions and functions of dominance and territoriality. Biological Reviews 58:1-20. 
Keeley, E. 2000. An experimental analysis of territory size in juvenile steelhead trout. Animal behaviour 59:477-490.

Keller, B. D., and S. Donahue. 2006. 2002-03 Sanctuary science report : An ecosystem report card after five years of marine zoning. U.S. Department of Commerce, National Oceanic and Atmospheric Administration, National Ocean Service, Office of National Marine Sanctuaries, Florida Keys Nation. U.S. Department of Commerce, NOAA, National Ocean Service, Office of National Marine Sanctuaries, Florida Keys National Marine Sanctuary, Marathon, FL.

Kohler, K. E., and S. M. Gill. 2006. Coral Point Count with Excel extensions (CPCe): A Visual Basic program for the determination of coral and substrate coverage using random point count methodology. Computers \& Geosciences 32:1259-1269.

Krause, E. T., and T. Liesenjohann. 2012. Predation pressure and food abundance during early life alter risk-taking behaviour and growth of guppies (Poecilia reticulata). Behaviour 149:1-14.

Kuffner, I. B., J. C. Brock, R. Grober-Dunsmore, V. E. Bonito, T. D. Hickey, and C. W. Wright. 2007. Relationships Between Reef Fish Communities and Remotely Sensed Rugosity Measurements in Biscayne National Park, Florida, USA. Environmental Biology of Fishes 78:71-82.

LaManna, J. R., and P. K. Eason. 2007. Effects of predator presence on territorial establishment. Behaviour 144:985-1001.

Lewis, S. M., and P. C. Wainwright. 1985. Herbivore abundance and grazing intensity on a Caribbean coral reef. Journal of Experimental Marine Biology and Ecology 87:215-228.

Lima, S. L. 1998. Stress and decision making under the risk of predation: recent developments from behavioral, reproductive and ecological perspectives. Advances in the Study of Behavior 27:215-290.

Lima, S. L., and L. M. Dill. 1990. Behavioral decisions made under the risk of predation: a review and prospectus. Canadian Journal of Zoology 68:619-640.

Lindholm, J., L. Kaufmann, S. Miller, A. Wagschal, and M. Newville. 2005. Movement of yellowtail snapper (Ocyurus chrysurus Block 1790 ) and black grouper ( Mycteroperca bonaci Poey 1860 ) in the northern Florida Keys National Marine Sanctuary as determined by acoustic telemetry. Page 17. Silver Spring, MD.

López-Sepulcre, A., and H. Kokko. 2005. Territorial defense, territory size, and population regulation. The American Naturalist 166:317-29. 
Madin, E. M. P., S. D. Gaines, and R. R. Warner. 2010. Field evidence for pervasive indirect effects of fishing on prey foraging behavior. Ecology 91:3563-3571.

Magnhagen, C. 1991. Predation risk as a cost of reproduction. Trends in Ecology and Evolution 6:183-186.

Martel, G. 1996. Growth rate and influence of predation risk on territoriality in juvenile coho salmon (Oncorhynchus kisutch). Canadian Journal of Fisheries and Aquatic Sciences 53:660-669.

McArthur, C., P. Orlando, P. B. Banks, and J. S. Brown. 2011. The foraging tightrope between predation risk and plant toxins: a matter of concentration. Functional Ecology 26:74-83.

Mumby, P. J., and C. C. C. Wabnitz. 2002. Spatial patterns of aggression, territory size, and harem size in five sympatric Caribbean parrot fish species. Environmental Biology of Fishes 63:265-279.

Munoz, R. C., M. L. Burton, K. J. Brennan, and R. O. J. Parker. 2010. Reproduction, habitat utilization, and movements of Hogfish (Lachnolaimus maximus) in the Florida Keys, U.S.A: Comparisions from fished versus unfished habitats. Bulletin of Marine Science 86:93-116.

Muñoz, R. C., and P. J. Motta. 2000. Interspecific aggression between two parrotfishes (Sparisoma, Scaridae) in the Florida Keys. Copeia 3:674-683.

Nanami, A., and H. Yamada. 2008. Size and spatial arrangement of home range of checkered snapper Lutjanus decussatus (Lutjanidae) in an Okinawan coral reef determined using a portable GPS receiver. Marine Biology 153:1103-1111.

Pauly, D. 1998. Fishing Down Marine Food Webs. Science. 279:860-863.

Pays, O., P. Blanchard, M. Valeix, S. Chamaillé-Jammes, P. Duncan, S. Périquet, M. Lombard, G. Ncube, T. Tarakini, E. Makuwe, and H. Fritz. 2011. Detecting predators and locating competitors while foraging: an experimental study of a medium-sized herbivore in an African savanna. Oecologia:419-430.

Petersen, C. W. 1995. Male mating success and female choice in permanently territorial damselfishes. Bulletin of Marine Science 57:690-704.

Randall, J. E. 1967. Food habits of reef fishes of the West Indies. Studies in Tropical Oceanography 5:655-847. 
Reinboth, R. 1973. Dualistic reproductive behavior in the protogynous wrasse Thalassoma bifasciatum and some observations on its day-night changeover*. Helgolader wiss. Meersunters 24:174-191.

Roberts, C. M., and R. F. G. Ormond. 1992. Butterflyfish social behaviour, with special reference to the incidence of territoriality: a review. Environmental Biology of Fishes 34:79-93.

Robertson, D. R., and R. R. Warner. 1978. Sexual Patterns in the Labroid Fishes of the Western Caribbean, II: The Parrotfishes (Scaridae). Smithsonian Contributions to Zoology 255:1-26.

Van Rooij, J. M., J. P. Kok, and J. J. Videler. 1996. Local variability in population structure and density of the protogynous reef herbivore Sparisoma viride. Environmental Biology of Fishes 47:65-80.

Van Rooij, J. M. Van, E. De Jong, F. Vaandrager, and J. J. Videler. 1996a. Resource and habitat sharing by the stoplight parrotfish, Sparisoma viride. Environmental Biology of Fishes 47:81-91.

Van Rooij, J. M. Van, F. J. Kroon, and J. J. Videler. 1996b. The social and mating system of the herbivorous reef fish Sparisoma viride: one-male versus multi-male groups. Environmental Biology of Fishes 47:353-378.

Sancho, G., A. Solow, and P. Lobel. 2000. Environmental influences on the diel timing of spawning in coral reef fishes. Marine Ecology Progress Series 206:193-212.

Schmitz, O. J., A. P. Beckerman, and K. M. O’Brien. 1997. Behaviorally mediated trophic cascades : Effects of predation risk on food web interactions. Ecology 78:1388-1399.

Sih, A. 1994. Predation risk and the evolutionary ecology of reproductive behavior. Journal of Fish Biology 45:111-130.

Smith, S. G., J. S. Ault, J. A. Bohnsack, D. E. Harper, J. Luo, and D. B. Mcclellan. 2011. Multispecies survey design for assessing reef-fish stocks, spatially explicit management performance, and ecosystem condition. Fisheries Research 109:25-41.

Taylor, R. J. 1988. Territory size and location in animals with refuges : influence of predation risk. Evolutionary Ecology 2:95-101.

Vanpé, C., N. Morellet, P. Kjellander, M. Goulard, O. Liberg, and a J. M. Hewison. 2009. Access to mates in a territorial ungulate is determined by the size of a male's territory, but not by its habitat quality. The Journal of Animal Ecology 78:42-51. 
Wade, M. J., and S. M. Shulter. 2004. Sexual selection: harem size and the variance in male reproductive success. The American Naturalist 164:E83-9.

Ward-Paige, C., J. Mills Flemming, and H. K. Lotze. 2010. Overestimating fish counts by non-instantaneous visual censuses: consequences for population and community descriptions. PloS one 5:e11722.

Warner, R. R. 1984. Mating behavior and hermaphroditism in coral reef fishes: the diverse forms of sexuality found among tropical marine fishes can be viewed as adaptations to their equally diverse mating systems. American Scientist 72:128-136.

Warner, R. R., and S. G. Hoffman. 1980a. Population density and the economics of territorial defense in a coral reef fish. Ecology 61:772-780.

Warner, R. R., and S. G. Hoffman. 1980b. Local population size as a determinant of mating system and sexual composition in two tropical marine fishes (Thallassoma spp.). Evolution 34:508-518.

Weatherhead, P. J., and J. Robertson. 1977. Harem size, territory quality, and reproductive success in the redwinged blackbird (Agelaius phoeniceus). Canadian Journal of Zoology 55:1261-1267.

Wedding, L. M., A. M. Friedlander, M. McGranaghan, R. S. Yost, and M. E. Monaco. 2008. Using bathymetric lidar to define nearshore benthic habitat complexity: Implications for management of reef fish assemblages in Hawaii. Remote Sensing of Environment 112:4159-4165. 
Table 3.1 - Study sites with GPS coordinates, protection status (Protected (P) or Not Protected (NP) and means fish biomass, abundance, rugosity and benthic community ( $\%$ cover).

\begin{tabular}{lllllllll}
\hline Site & Lat. & Long. & Status & $\begin{array}{l}\text { Macro- } \\
\text { algae }(\% \\
\text { cover })\end{array}$ & $\begin{array}{l}\text { Coral }(\% \\
\text { cover })\end{array}$ & $\begin{array}{l}\text { Competitor } \\
\text { Biomass } \\
\left(\mathrm{g} / \mathrm{m}^{2}\right)\end{array}$ & $\begin{array}{l}\text { Predator } \\
\text { Biomass } \\
\left(\mathrm{g} / \mathrm{m}^{2}\right)\end{array}$ & $\begin{array}{l}\text { Lidar- } \\
\text { derived } \\
\text { Rugosity }\end{array}$ \\
\hline Conch & 24.96 & -80.46 & $\mathrm{P}$ & 40.8 & 0.33 & 7.3 & 4.2 & 3.54 \\
French & 25.04 & -80.36 & $\mathrm{P}$ & 35.4 & 3.27 & 16.3 & 6.3 & 3.66 \\
S. Carysfort & 25.21 & -80.22 & $\mathrm{P}$ & 31.9 & 2.63 & 31.7 & 0.2 & 4.52 \\
Molasses & 25.01 & -80.38 & $\mathrm{P}$ & 8.8 & 1.30 & 10.4 & 87.2 & 3.52 \\
Pickles & 24.99 & -80.41 & $\mathrm{NP}$ & 25.2 & 1.33 & 21.3 & 3.4 & 3.42 \\
Pinnacles & 24.99 & -80.41 & $\mathrm{NP}$ & 39.3 & 1.00 & 13.8 & 3.0 & 3.15 \\
Maitland & 25.19 & -80.23 & $\mathrm{NP}$ & 55.3 & 1.48 & 5.1 & 1.2 & 3.96 \\
Snapper & 24.99 & -80.42 & $\mathrm{NP}$ & 47.3 & 0.95 & 13.6 & 35.0 & 2.84 \\
Ledge & & & & & & & &
\end{tabular}


Table 3.2 - Results from two-way ANOVAs for differences in (a) macroalgal cover, (b) $\mathrm{C}: \mathrm{N}$ ratios for Dictyota menstrualis and (c) rugosity with protection status (inside and outside of protected areas) and territory status (within and outside of territories).

\begin{tabular}{llcc}
\hline Response & Factor & F & p \\
\hline $\begin{array}{llcc}\text { (a) Macroalgae } \\
\text { Cover }\end{array}$ & Protection Status & $\mathbf{6 0 . 5 4}$ & $\mathbf{0 . 0 0 1}$ \\
& Territory Status & $\mathbf{3 2 . 9 1}$ & $\mathbf{0 . 0 0 1}$ \\
& Protection Status x Territory Status & 0.11 & 0.92 \\
\hline $\begin{array}{l}\text { (b) C:N of D. } \\
\text { menstrualis }\end{array}$ & Protection Status & $\mathbf{5 . 3 8}$ & $\mathbf{0 . 0 2}$ \\
& Territory Status & $\mathbf{1 2 3 . 4 6}$ & $\mathbf{0 . 0 0 1}$ \\
& Protection Status x Territory Status & $\mathbf{8 . 0 3}$ & $\mathbf{0 . 0 1}$ \\
\hline (c) Rugosity & Protection Status & $\mathbf{4 . 4 6}$ & $\mathbf{0 . 0 1}$ \\
& Territory Status & 0.78 & 0.38 \\
& Protection Status x Territory Status & $\mathbf{5 . 1 3}$ & $\mathbf{0 . 0 2}$ \\
\hline
\end{tabular}


Table 3.3 - Summary of ANCOVA models for the influence of male length and protection status on territory quality variables.

\begin{tabular}{|c|c|c|c|c|}
\hline $\begin{array}{l}\text { Territory } \\
\text { Quality } \\
\text { Variable }\end{array}$ & Factor & Estimate & SE & $\mathbf{p}$ \\
\hline \multirow[t]{3}{*}{ Area } & Male Length & 3.65 & 2.86 & 0.20 \\
\hline & Protection Status & 166.62 & 98.84 & 0.05 \\
\hline & $\begin{array}{l}\text { Male Length X } \\
\text { Protection Status }\end{array}$ & -5.29 & 4.23 & 0.21 \\
\hline \multirow[t]{3}{*}{ Rugosity } & Male Length & -0.11 & 0.08 & 0.18 \\
\hline & Protection Status & -6.17 & 2.81 & 0.03 \\
\hline & $\begin{array}{l}\text { Male Length X } \\
\text { Protection Status }\end{array}$ & 0.26 & 0.12 & 0.03 \\
\hline \multirow{3}{*}{$\begin{array}{l}\text { Macroalgae } \\
\text { Cover }\end{array}$} & Male Length & 0.30 & 0.67 & 0.66 \\
\hline & Protection Status & 24.94 & 23.22 & 0.29 \\
\hline & $\begin{array}{l}\text { Male Length X } \\
\text { Protection Status }\end{array}$ & -0.58 & 0.99 & 0.56 \\
\hline \multirow{3}{*}{$\begin{array}{l}\text { C:N D. } \\
\text { menstrualis }\end{array}$} & Male Length & -0.22 & 0.11 & 0.05 \\
\hline & Protection Status & -2.61 & 3.90 & 0.50 \\
\hline & $\begin{array}{l}\text { Male Length X } \\
\text { Protection Status }\end{array}$ & 0.15 & 0.17 & 0.35 \\
\hline
\end{tabular}


Table 3.4 - Summary of mixed-effects models for territory quality variables and site level predictors of predator and competitor biomass.

\begin{tabular}{llccc}
\hline $\begin{array}{l}\text { Territory Quality } \\
\text { Variable }\end{array}$ & Factor & Estimate & SE & p \\
\hline Area & Predator Biomass & 0.12 & 0.21 & 0.60 \\
& Competitor Biomass & -0.46 & 0.93 & 0.65 \\
& Predator Biomass & -0.00 & 0.01 & 0.86 \\
\hline Rugosity & Competitor Biomass & $\mathbf{0 . 1 5}$ & $\mathbf{0 . 0 5}$ & $\mathbf{0 . 0 4}$ \\
& Predator Biomass & -0.16 & 0.12 & 0.26 \\
\hline Macroalgae Cover & Competitor Biomass & 0.53 & 0.56 & 0.39 \\
& & & & \\
\hline C:N D. menstrualis & Predator Biomass & -0.00 & 0.01 & 0.76 \\
& Competitor Biomass & -0.07 & 0.05 & 0.22 \\
& & & & \\
\hline
\end{tabular}


Table 3.5 - Mean \pm SE of male size, female size and harem size among protected and unprotected sites.

\begin{tabular}{lcc}
\hline & Protected & Unprotected \\
\hline Male Size $(\mathrm{cm})$ & $23.92 \pm 0.31$ & $22.66 \pm 0.28$ \\
Female Size $(\mathrm{cm})$ & $15.59 \pm 0.18$ & $15.06 \pm 0.12$ \\
Harem Size (\# indiv) & $4.22 \pm 0.17$ & $4.09 \pm 0.15$ \\
\hline
\end{tabular}


Table 3.6 - Results from multiple regression models for relationships between (a) harem size and (b) average female size and territory quality metrics.

\begin{tabular}{llccc}
\hline Response & Territory Parameter & $\boldsymbol{\beta}$ & SE & $\mathbf{p}$ \\
\hline (a) Harem Size & Area & $\mathbf{0 . 9 6}$ & $\mathbf{0 . 4 7}$ & $\mathbf{0 . 0 5}$ \\
& Rugosity & -0.12 & 0.08 & 0.14 \\
& C:N Dictyota menstrualis & 0.03 & 0.07 & 0.63 \\
& Macroalgae Percent Cover & 0.004 & 0.05 & 0.68 \\
& Male Length & 0.03 & 0.05 & 0.63 \\
& Area & -0.001 & 0.002 & 0.40 \\
& Rugosity & -0.11 & 0.07 & 0.11 \\
& C:N Dictyota menstrualis & $\mathbf{- 0 . 1 2}$ & $\mathbf{0 . 0 6}$ & $\mathbf{0 . 0 5}$ \\
& Macroalgae Percent Cover & 0.009 & 0.007 & 0.22 \\
& Male Length & $\mathbf{0 . 2 5}$ & $\mathbf{0 . 0 4}$ & $<\mathbf{0 . 0 0 1}$ \\
& & & &
\end{tabular}


Table 3.7 - Summary of multiple logistic regression model for the probability of (a) engaging in aggressive interactions and (b) spawning, with territory quality variables, harem size, female size and reef protection status.

\begin{tabular}{|c|c|c|c|c|}
\hline Response & Factor & Estimate & SE & $\mathbf{p}$ \\
\hline \multirow{7}{*}{$\begin{array}{l}\text { (a) Aggressive } \\
\text { Interactions }\end{array}$} & Area & 0.00 & 0.00 & 0.21 \\
\hline & Rugosity & -0.21 & 0.16 & 0.19 \\
\hline & Macroalgal Cover & 0.01 & 0.02 & 0.51 \\
\hline & C:N D. menstrualis & 0.25 & 0.13 & 0.05 \\
\hline & Harem Size & 0.45 & 0.20 & 0.03 \\
\hline & Average Female Size & 0.11 & 0.19 & 0.55 \\
\hline & Reef Protection Status & 0.25 & 0.49 & 0.62 \\
\hline \multirow[t]{7}{*}{ (a) Spawning } & Area & -0.03 & 0.01 & 0.02 \\
\hline & Rugosity & 0.03 & 0.25 & 0.89 \\
\hline & Macroalgal Cover & 0.01 & 0.03 & 0.84 \\
\hline & C:N D.menstrualis & 0.08 & 0.25 & 0.74 \\
\hline & Harem Size & 0.39 & 0.39 & 0.31 \\
\hline & Average Female Size & -0.15 & 0.32 & 0.63 \\
\hline & Reef Protection Status & -19.0 & 2272.6 & 0.99 \\
\hline
\end{tabular}


Figure 3.1 - Map of study sites sampled in the northern reef tract of the Florida Keys National Marine Sanctuary.

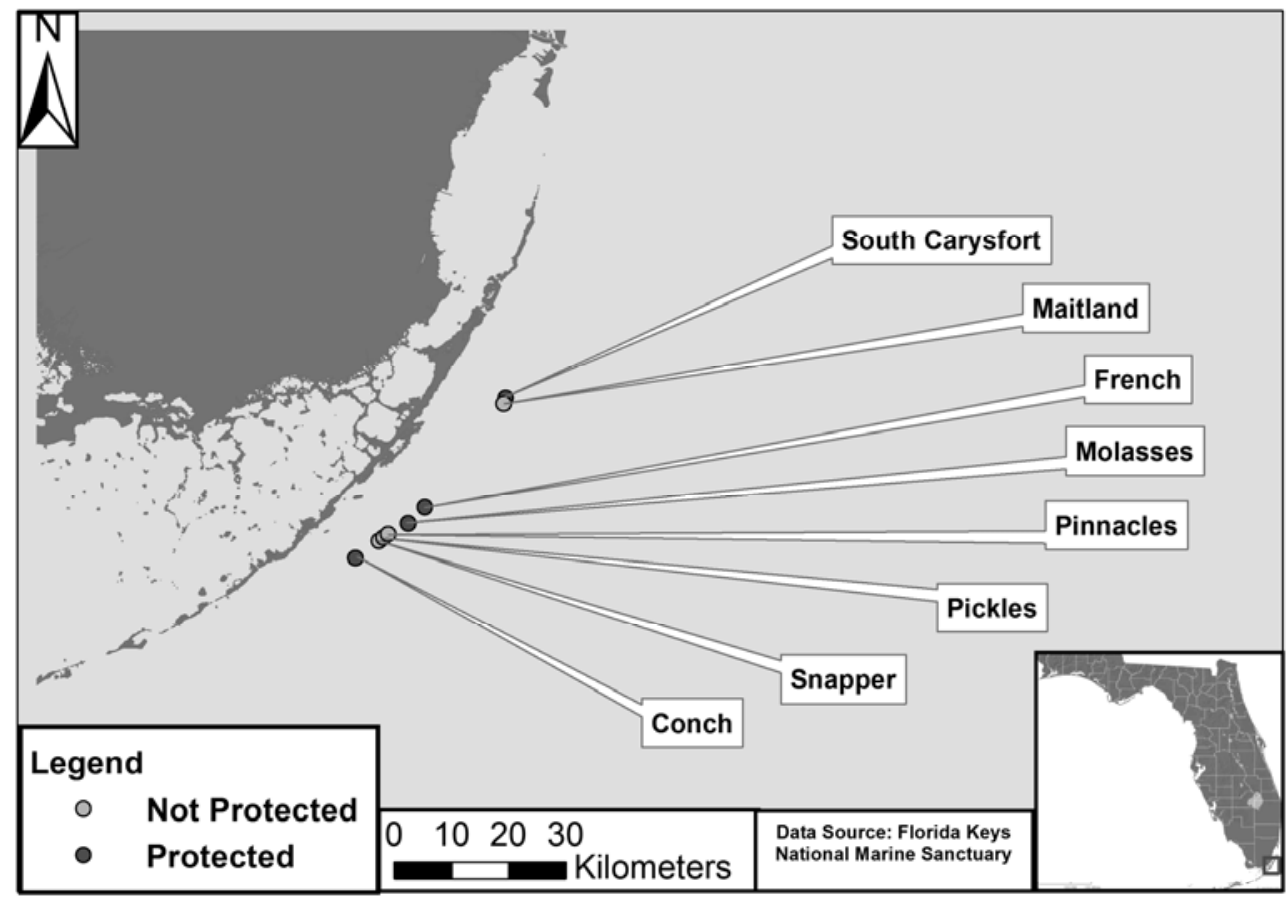


Figure 3.2 - Territory areas $\left(\mathrm{m}^{2}\right)$ calculated every five minutes over the course of thirty minutes for four individual $S$. aurofrenatum.

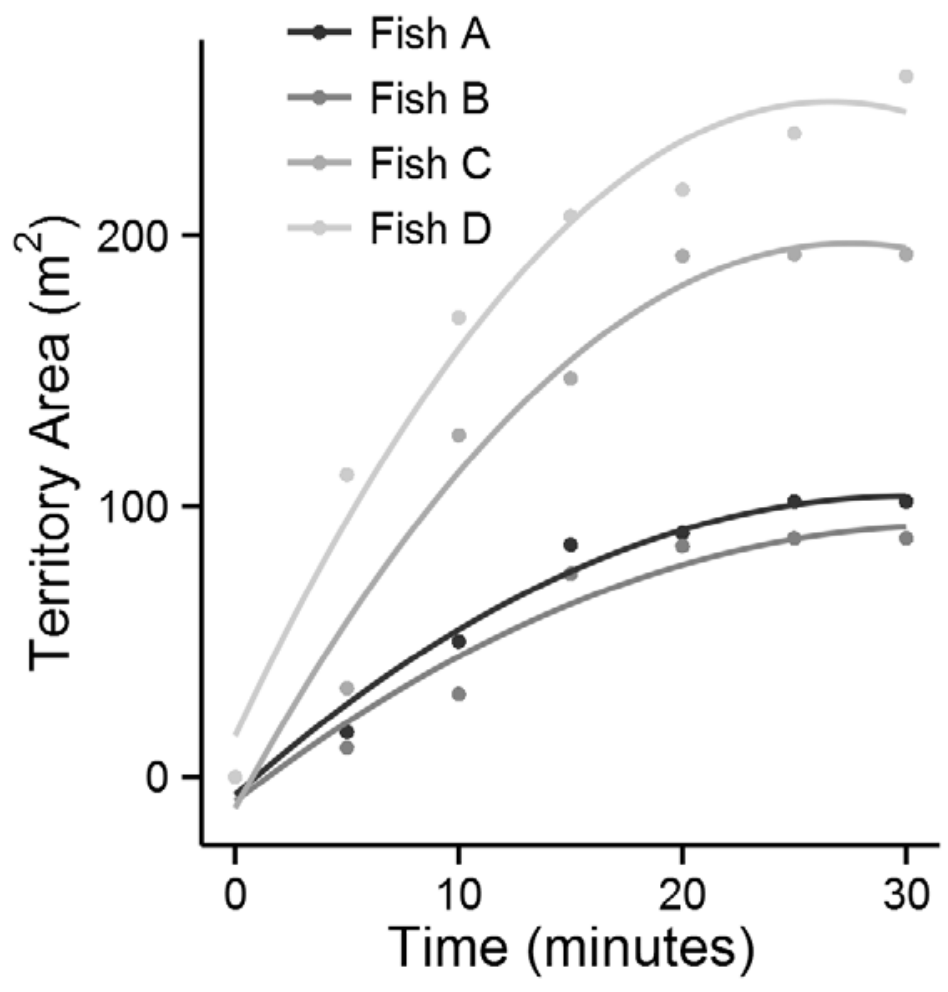


Figure $3.3-$ Mean $( \pm \mathrm{SE})$ of territory sizes $\left(\mathrm{m}^{2}\right)$ in protected and unprotected areas. Numbers above bars are the number of territories used to calculate means.

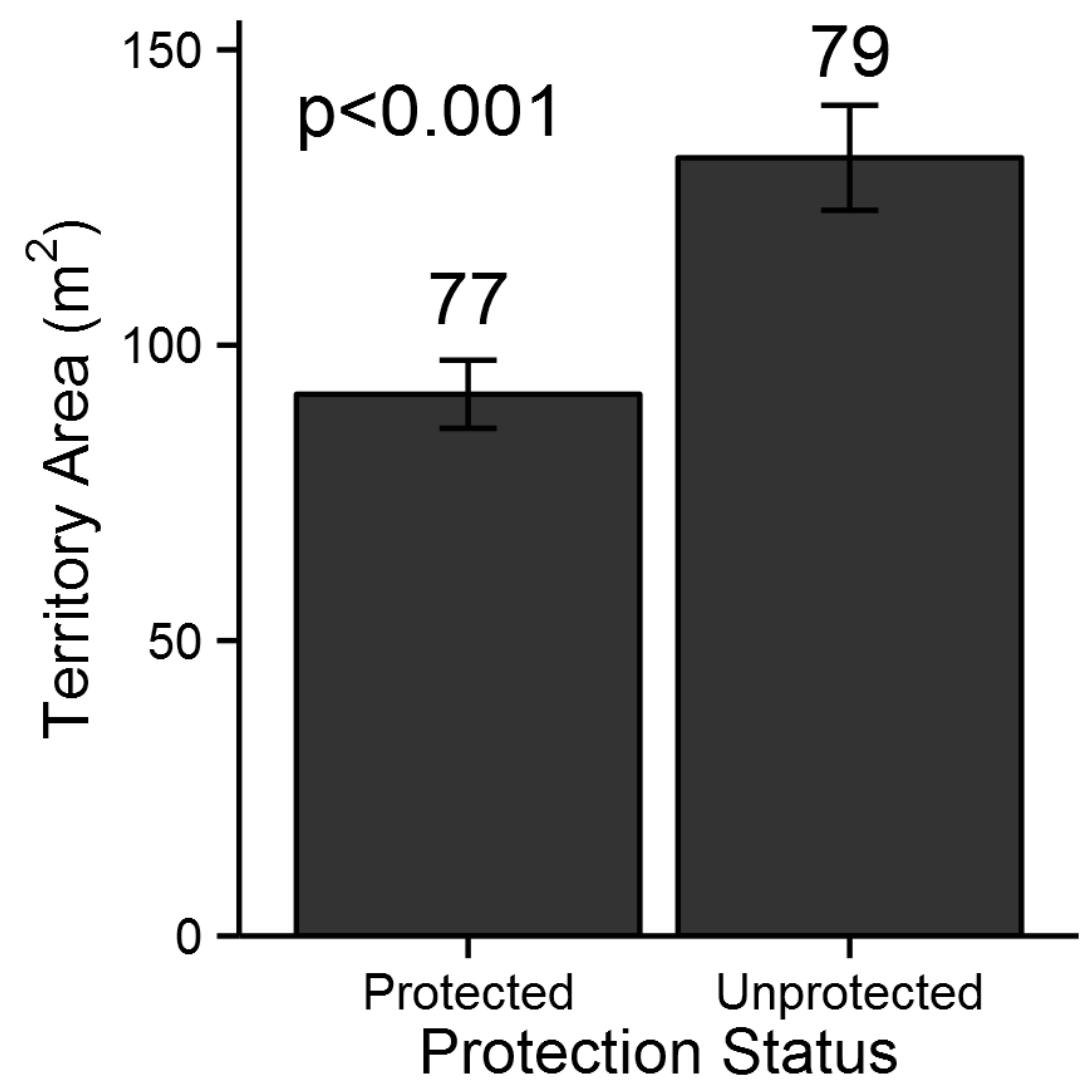


Figure 3.4 - Map of 20 territories (polygons) and GPS tracks (triangles) at French Reef (a protected site).

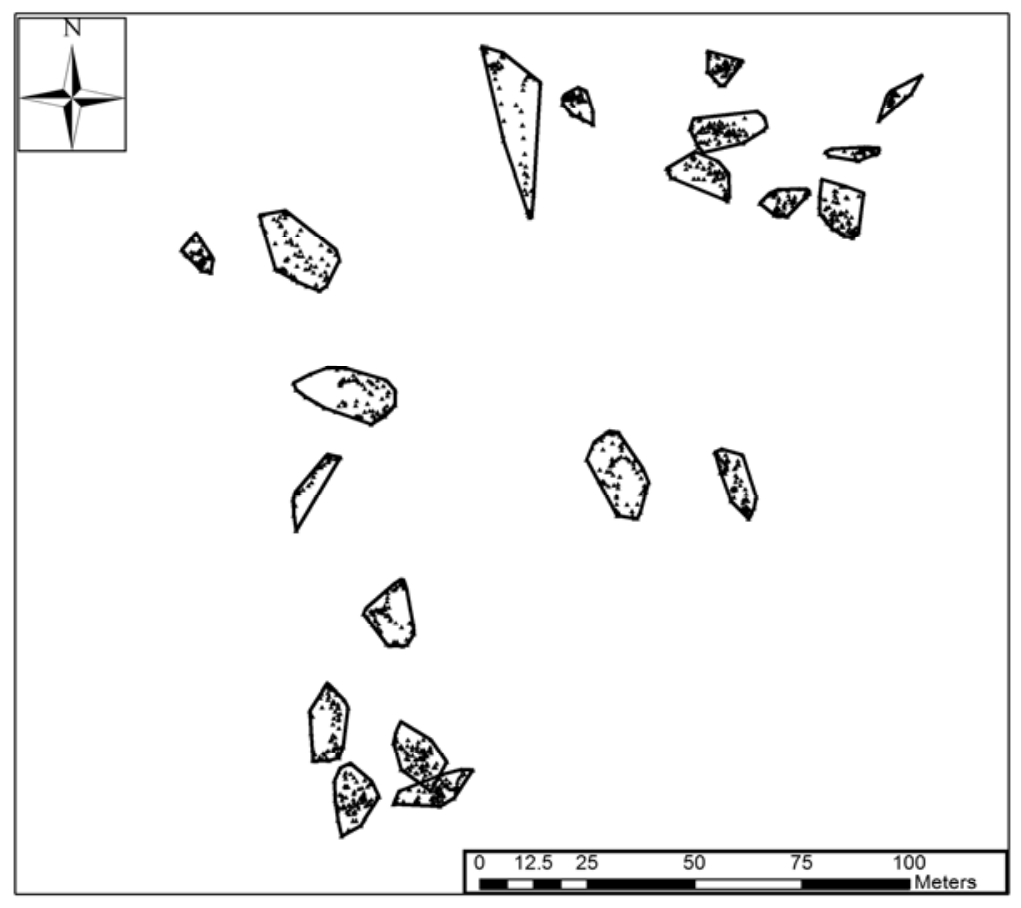

98 
Figure 3.5 - Mean ( \pm SE) (a) Macroalgae cover, (b) C:N ratios of Dictyota menstrualis, and (c) Lidar-derived rugosity inside and outside territories at protected and unprotected reefs. Letters above bars represent differences among groups based on TukeyHSD posthoc analysis.
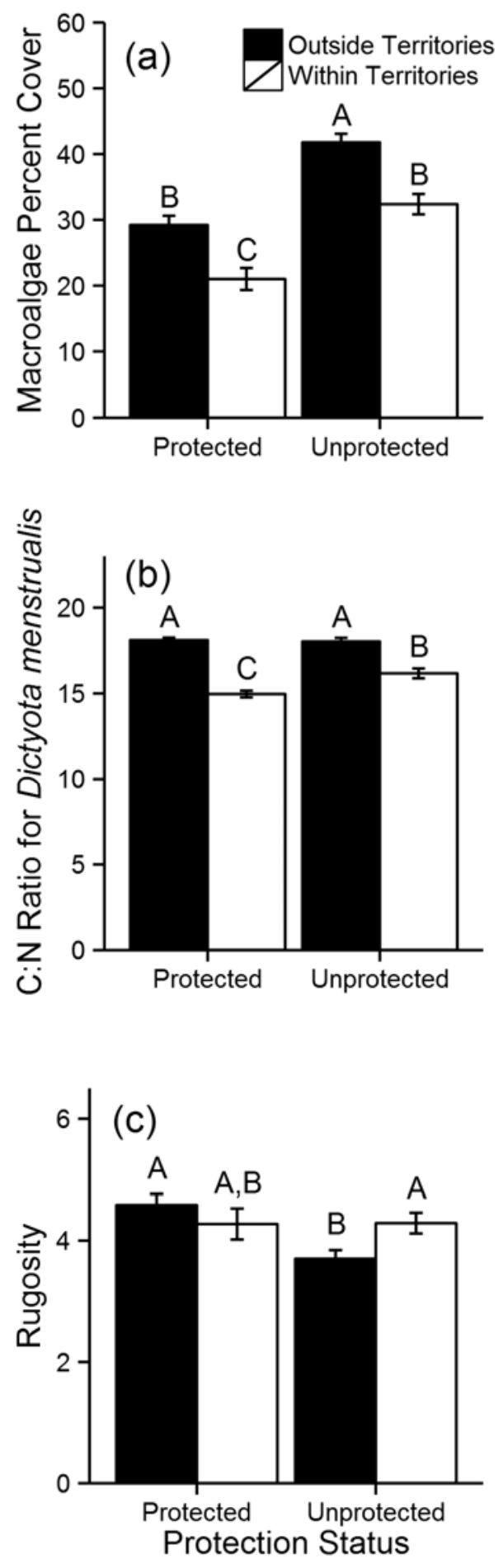
Figure 3.6 - Male length and territory rugosity in (a) unprotected and (b) protected reefs. In panel (a), solid line represents fitted regression, shaded area represents $95 \% \mathrm{CI}$ and points represent focal males observed.
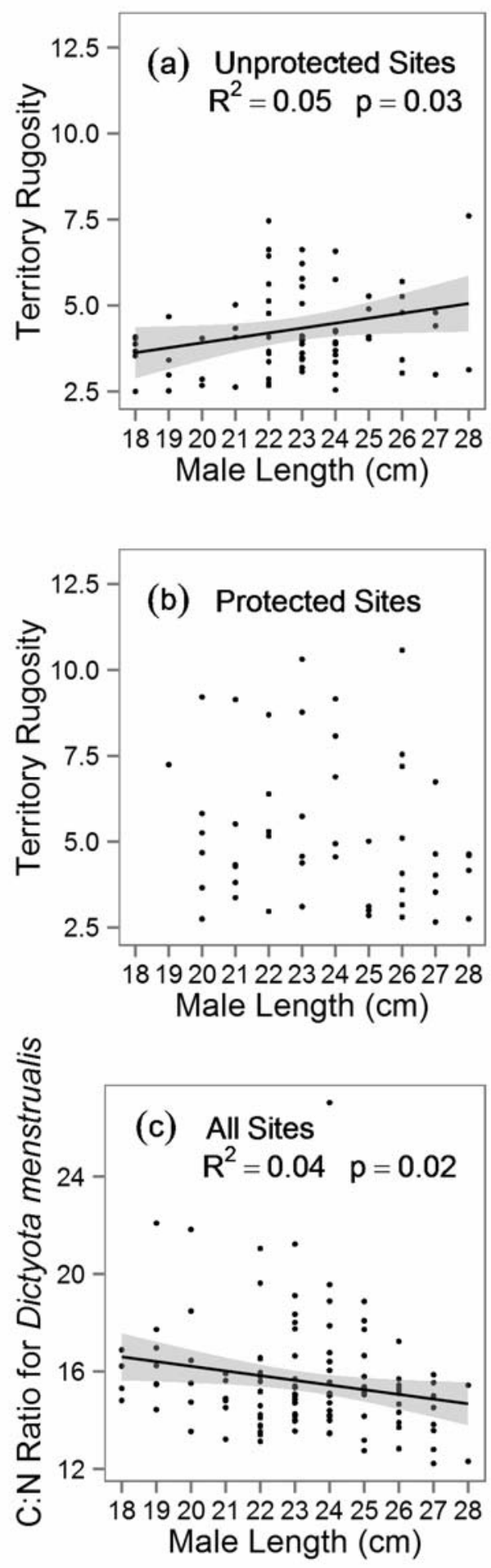
Figure 3.7 - Mean $( \pm \mathrm{SE})$ number of aggressive interactions by focal male with species of parrotfish. Letters above bars represent differences among species based on TukeyHSD post-hoc analysis.

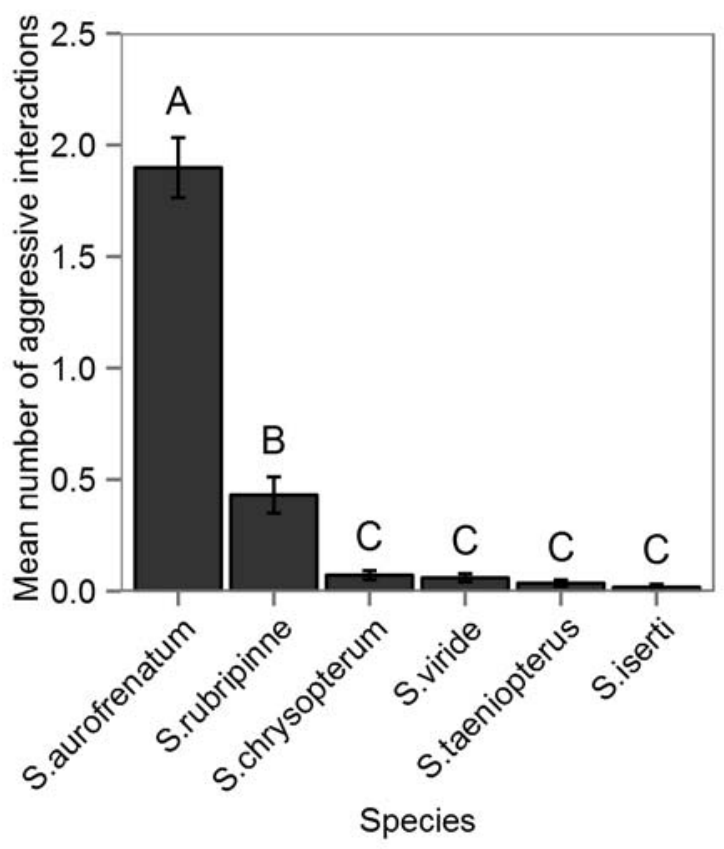




\section{CHAPTER IV}

REEFSCAPES OF FEAR: PREDATION RISK AND REEF HETEROGENEITY INTERACT TO SHAPE HERBIVORE FORAGING BEHAVIOR 
Abstract

Predators exert strong direct and indirect effects on ecological communities by intimidating their prey. The sub-lethal or non-consumptive effects (NCEs) of predators are often not uniform across landscapes or among species but can vary widely depending on context such as with varying habitat complexity and different prey escape tactics. These context-dependencies may be especially important for ecosystems such as coral reefs that vary widely in the complexity of habitat and have species rich predator and prey communities. With field experiments using predator decoys, we investigated how reef complexity interacts with predation risk to affect the foraging behavior and herbivory rates of large herbivorous fishes (e.g., parrotfishes and surgeonfishes) across four coral reefs in the Florida Keys (USA). We show that with increasing risk, herbivorous fishes make fewer feeding bouts and consume less food but feed at a faster rate when they do feed. Furthermore, we show that smaller individuals that are at less risk to larger predators show muted response to predation risk compared to their larger counterparts. Habitat heterogeneity mediated these risk effects differently for different species of herbivores, with predation risk more strongly impacting herbivore feeding in more complex areas and for more predator-prone species. Thus, predators appear to create a reefscape of fear that both changes the size structure of herbivores and decreases their feeding, potentially altering an ecosystem process critical for healthy coral reefs.

Introduction

Predators exert important top-down ecological forces by consuming their prey and impacting prey foraging behaviors and habitat use (Lima and Dill 1990, Werner and 
Peacor 2003). Research from multiple ecosystems shows the importance of sub-lethal or non-consumptive effects (NCEs) of predators, forcing prey to balance trade-offs between the benefits of obtaining food and the costs of avoiding predators (Schmitz et al. 1997, Heithaus \& Dill 2002, Preisser et al. 2005, Ripple \& Beschta 2007). Behaviorallymediated trophic cascades result when predation risk alters prey foraging behavior and thus impacts prey resources (Dill et al. 2003). Therefore, predators can have dramatic influences on the abundance and distribution of primary producers transmitted entirely through non-consumptive pathways (Preisser et al. 2005). Ecological context (e.g., habitat structure) can influence the nature and strength of NCEs and alter the outcome of predator intimidation (Preisser et al. 2007). It is clear that NCEs are common and potentially powerful structuring force among ecosystems (Preisser et al. 2005), however not incorporating the contextual variation in NCEs could impair the ability to understand their impact on community dynamics.

Habitat complexity can shape predator-prey interactions by influencing encounter rates between predators and prey, the likelihood of an attack, and the probability that prey will escape (Laundre et al. 2001). The resulting continuum of risky and safe areas within a prey's environment, the so called "landscape of fear", has been demonstrated in terrestrial (Kauffman et al. 2007, Gorini et al. 2012) and marine ecosystems (Wirsing et al. 2008, Matassa and Trussell 2011, Madin et al. 2011). Within this landscape of fear, prey alter their habitat use according to features of the terrain, often avoiding resource rich, but risky, habitats in order to stay safe (Gilliam \& Fraser 1987, Schmitz et al. 1997, Heithaus \& Dill 2002). For example, in African savannas, African buffalo (Syncerus caffer) avoided areas with the highest abundance of food resources because they 
overlapped with areas of high tree density where lions were more likely to prey on them (Burkepile et al. 2013b). Likewise, following the reintroduction of wolves into Yellowstone National Park, elk (Cervus elaphus) reduced their use of preferred grassland foraging habitats, where they were more susceptible to wolf predation, and moved into the protective cover of wooded areas (Creel et al. 2005). Wolves initiated a behaviorallymediated trophic cascade by deterring elk foraging behavior and therefore creating spatial refuges for the woody browse species that elk target (Ripple and Beschta 2003).

Predation risk clearly varies across landscapes which influences anti-predator responses of their prey with potential cascading effects on plant communities. Thus, the landscape of fear is a useful framework for developing a mechanistic, community-level understanding of predator-prey interactions (Schmitz 2005).

Despite the complex structural heterogeneity of coral reef ecosystems, the effect of landscape or "reefscape" elements (i.e., large coral mounds, sand channels, etc.) on predator-prey interactions of reef fishes is poorly understood. Living corals and the underlying matrices of dead coral skeletons form the major structural complexity (often termed 'rugosity') of coral reefs. Rugosity is often positively related to the diversity, abundance, and/or biomass of reef fishes (for a meta-analysis see: Graham and Nash 2012). The few studies examining the influence of structural complexity on reef fish predator-prey interactions suggest that it is likely context dependent. Structure can serve as refuge and increase survival in the presence of predators (Hixon and Beets 1993, Beukers and Jones 1997), but can also limit the visual field resulting in a more risky situation for prey (Rilov et al. 2007). Whether structure serves as a benefit or detriment to prey may depend on functional traits of the predator (e.g., hunting mode), behavioral 
attributes of the prey (e.g., escape tactics), and body size of both predator and prey (Heithaus et al. 2009, Wirsing et al. 2010, Gorini et al. 2012). For example, the complexity of highly branching corals can benefit certain taxa that are small enough to hide among its branches (Beukers and Jones 1997). Yet, for large-bodied species, high complexity areas could serve as an impediment to predator detection and escape, potentially increasing risk. While multiple studies have investigated the influence of structure on predation risk for small species such as damselfishes (Beukers and Jones 1997, Rilov et al. 2007), studies on larger taxa are lacking.

On coral reefs, herbivorous fishes (e.g., parrotfishes and surgeonfishes) are critical because their grazing removes the majority of algal growth and facilitates coral settlement, growth, and survivorship (Hughes et al. 2007, Mumby et al. 2007, Burkepile \& Hay 2008). Understanding the distribution of their grazing effort in a spatially explicit context is important to assess how their impact may vary across a reef landscape (Sandin and McNamara 2012). Recent research suggests that predation risk elicits strong behavioral responses in herbivores by altering foraging excursion areas (Madin et al. 2010b), bite rates (Rizzari et al. 2014) and the diversity of resources consumed (Catano et al. 2014). However, no studies have examined how herbivore foraging behavior changes across the range of riskiness prey may experience in nature while also integrating the role of landscape in mediating these effects. Knowing how herbivores respond to variation in risk and structural complexity will build a realistic level of understanding of risk effects in coral reef communities.

We investigated how reef complexity interacts with predation risk to affect the foraging behavior and spatially-explicit impact of large herbivorous fishes (e.g. 
parrotfishes and surgeonfishes) across four coral reefs in the Florida Keys (USA). In multiple controlled experiments, we used predator decoys of the black grouper (Mycteroperca bonaci) to manipulate predation risk in both high and low complexity areas of the reef. We measured how herbivory changed with increasing distance from the decoy to examine how herbivorous fishes reconcile the conflicting demands of avoiding predation vs. foraging within a reefscape context. We hypothesized that herbivory would diminish as predation risk increases (i.e., near predator decoys) and that high rugosity areas with more visual obstructions would be perceived as riskier, resulting in stronger suppression of herbivory when predator decoys were present.

\section{Material and Methods}

Site Description

The Florida Keys reef tract is a large bank reef system located approximately 8 $\mathrm{km}$ offshore of the Florida Keys, USA, parallel to the island chain. The reefs we sampled were characterized by shallow spur and groove topography and included (Lat., Long.): Molasses Reef (25.005, -80.378), French Reef (25.039, -80.355), South Carysfort (25.209, -80.219), and Pinnacles Reef (24.992, -80.409). Molasses, French and South Carysfort are no-take zones, established in 1997 within the Florida Keys National Marine Sanctuary (FKNMS), where fishing is restricted (Bohnsack et al. 2009), whereas Pinnacles Reef is open to fishing. The designation of no-take zones has led to increased predator biomass at some of these reefs (Smith et al. 2011). Herbivorous fishes (e.g., parrotfish, surgeonfish, etc.) are protected across the entirety of the FKNMS (i.e., in both take and no-take zones), and their populations are robust in the FKNMS relative to most 
other reefs in the wider Caribbean (Burkepile et al. 2013a). Sites were similar in depth (6-8 m) and physical parameters (e.g., rugosity). Trials were conducted during the day $(10: 00-14: 00 \mathrm{~h})$ between June-July 2013 on the forereef at depths of 6-8 $\mathrm{m}$.

\section{Experimental Design}

Prior to conducting our main experiments, we tested whether fishes would respond to fiberglass models of a black grouper (Mycteroperca bonaci) (approximately $90 \mathrm{~cm}$ in length) (Fig. 4.1a) either because the decoys represented a threat or simply because they were novel objects in the water column. At each reef, we tested fish responses to three treatments: (1) a grouper decoy, (2) a decoy control (a plastic carboy with similar dimensions to the grouper decoy), (3) and a control (no predator decoy or plastic carboy). We anchored grouper decoys and plastic carboys separated by at least 30 $\mathrm{m}$ to natural areas of the reef benthos using monofilament. At each reef, two trials were conducted for each of the three treatments producing a total of eight replicates per treatment. We assessed herbivore feeding using standardized assays of a palatable seagrass (Thalassia testudinum) placed one meter away from each treatment. Each assay consisted of five blades of seagrass cut to $10 \mathrm{~cm}$, scraped free of epiphytes, and clipped to wooden clothespins (Fig. 4.1b). Herbivores were allowed to feed on assays for two hours before we recollected them and measured each seagrass blade to calculate the percentage removed over the course of the trial.

To establish high and low rugosity sites at our four study reefs, we used in situ observations in conjunction with remotely-sensed rugosity measurements. A lidar (Light Detection and Ranging)-derived bathymetric data set provided by the U.S. Geological 
Survey (USGS) (available online http://pubs.usgs.gov/of/2007/1395/start.html) was used to create a raster of benthic rugosity ( $1 \mathrm{~m} \times 1 \mathrm{~m}$ resolution) with the Benthic Terrain Modeler (a collection of ESRI ArcGIS-based tools available online http://www.csc.noaa.gov/digitalcoast/tools/btm). Lidar-derived rugosity measurements accurately reflect rugosity as measured with traditional chain-transect methods (Kuffner et al. 2007). We chose sites with high (mean \pm SE: $5.5 \pm 0.1)$ and low $(3.9 \pm 0.1)$ lidarderived rugosity values that were also located along the reef tract (determined from benthic habitat maps available from the FKNMS (http://floridakeys.noaa.gov/fknms_map/maplibrary.html?s=about) to distinguish reef from non-reef habitats (e.g., seagrass, sand, rubble). We verified the complexity of these locations visually on SCUBA prior to running experiments. Our lidar selection criteria generated high rugosity sites that were structurally complex with large coral mounds (living or dead), ledges, and other potential visual obstructions and selected low rugosity sites that were considerably flatter (Fig. 4.2).

At each reef we used predator decoys to simulate predation risk in high and low complexity sites. We did not include decoy controls (plastic carboys) in these experiments because they did not affect herbivory versus controls with no carboys (See Results). At increasing distances from the decoy (1/2, 1, 2 and 4 meters) we secured seagrass assays as described and filmed them using GoPro Hero 3 cameras. Each trial lasted two hours, after which time all assays and predator decoys were collected and seagrass blades were measured to calculate percent removed. At each reef we conducted six trials (three in high rugosity areas and three in low rugosity) in the presence of the predator decoy and six control trials (three in high rugosity areas and three in low 
rugosity) where the predator decoy was not present producing a total of 12 replicates per treatment.

Many parrotfish species readily consume T. testudinum, however it is unlikely that surgeonfishes or juvenile parrotfishes would target it as a food source. Therefore, in addition to counting bites taken on the seagrass assays, we counted bites on the benthos from all herbivorous fishes that were within a $25 \mathrm{~cm}$ radius of the seagrass assay using video recordings. We estimated the sizes of fishes using markers of known length located in the field of view. To understand how predation risk and rugosity affected how fishes consumed resources, we also determined feeding rates and the incidence of multiple feeding bouts. We determined individual feeding rates by recording the time of a fish's first bite, how many bites they took, and the time of their last bite and then calculated bite rates. If the fish paused between bites longer than was necessary to reapply the jaws to the substratum, we considered this a separate feeding foray (Bellwood and Choat 1990). In order to understand other potential drivers of herbivore foraging behavior in our experiments, we also quantified territorial damselfishes and potential predators from our video observations. Territorial damselfish can affect how larger herbivorous fish forage by aggressively defending the algal gardens within their territories (Foster 1985). Therefore, we noted the number of territorial damselfish (Stegastes and Microspathodon spp.) that transected the $25 \mathrm{~cm}$ radius around the seagrass assay over the course of the two-hour video observation. The majority of the damselfish were always present in the video frame so most individuals were likely counted only once. Differences in the abundance of large predators both within and across reefs could also impact our feeding assays so we counted large predators that passed through the frame to estimate the level 
of background predation risk. We included only primarily piscivorous fishes of the families Carangidae, Lutjanidae, Serranidae and Sphyraenidae that are known to consume adult parrotfishes and surgeonfishes (based on Randall 1967). All counts were standardized by the time of each video observation.

\section{Statistical Methods}

All statistical analyses were conducted using R version 3.0.1. Parametric assumptions of normality and homoscedasticity were verified using plots of the residuals. To test the effect of the grouper decoy on seagrass consumption, we used one-factor analysis of variance (ANOVA) testing for differences among the grouper decoy, decoy control, and control. To examine variation in herbivory among reefs, we used ANOVAs to test for differences in five foraging metrics including: percentage seagrass consumed, the total number of bites on either seagrass or benthos standardized by observation time, size of foraging fishes, and individual feeding rates. We determined that the effect of reef was not significant for any of these metrics (see Results), therefore we pooled data from all reefs and used ANOVA to examine the main effects of treatment (i.e., grouper decoy vs. control) and rugosity (i.e., high and low rugosity) and their interaction on the five foraging metrics. For this analysis we pooled all distances to understand the overall effect of the decoy vs. the control. To understand how foraging changed with distance from the predator decoy, we used two factor ANOVA followed by a TukeyHSD post-hoc test to examine how the same foraging metrics varied across distance from the grouper decoy (i.e., $0.5,1,2$, and $4 \mathrm{~m}$ ) in both high and low rugosity areas. We did these analyses for all fishes and then for the two most frequently observed species, Sparisoma aurofrenatum 
and Acanthurus bahianus. Further, because smaller fishes typically have higher bite rates, which could drive the differences in feeding rates across distance, we also analyzed bite rate data after restricting that data set to fishes between $12-15 \mathrm{~cm}$. To determine the effect of distance on the probability of fishes taking multiple feeding bouts (i.e., forays), we performed logistic regressions for each rugosity/treatment combination, and evaluated model fits using Hosmer-Lemeshow goodness-of-fit test. To understand how potential background factors could influence foraging, we tested if damselfish and predator abundance observed from video captures varied among reefs and with rugosity (i.e., high and low rugosity) using a two factor ANOVA.

Given that the average size of fish was different across treatments (see Results), we tested to see if changes in forager size resulted from changes in fish species composition across treatments. We used non-metric multidimensional scaling (NMDS) with the metaMDS function in the vegan package in R using a Bray-Curtis dissimilarity matrix. We then examined changes in forager community composition across predator and rugosity treatments and with distance using the envfit function in vegan.

Results

Our initial experiments showed that herbivores responded to the perceived risk from the grouper decoy and not simply to the introduction of a novel object in the water column. The percentage of seagrass consumed adjacent to the decoy control (plastic carboy) and control (no carboy or grouper decoy) was significantly greater than the amount consumed adjacent to the grouper decoy (Fig. 4.1c, $\mathrm{F}_{2,33}=7.44, \mathrm{p}=0.002$ ). There was no statistical difference between the decoy control and the control. 
The species most frequently observed foraging based on video analyses were $S$.

aurofrenatum, A. bahianus, Sparisoma viride, Acanthurus coeruleus, Scarus iserti, and Sparisoma rubripinne (in order of decreasing frequency, Fig. 4.3). Sparisoma spp.

primarily targeted the seagrass, with $90 \%$ of the bites from S. aurofrenatum, followed by S. rubripinne (3\%), S. viride (3\%) and Sparisoma chrysopterum (2.6\%). Sparisoma, Scarus and Acanthurus spp. took bites on the benthos surrounding the seagrass, with the majority of bites being taken by S. aurofrenatum (37\%), A. bahianus (29\%), S. viride (10\%), A. coeruleus (8\%), Sc. iserti (5.6\%) and Scarus taeniopterus (4.8\%).

None of the foraging metrics [percentage of seagrass consumed per hour, bites on seagrass per hour, bites on benthos per hour, individual feeding rates (bites/second), and forager size] differed significantly among reefs (Table 4.1). However, the predator decoy had a significant influnce on multiple foraging metrics. The amount of seagrass consumed and the total number of bites of seagrass were lower when the grouper decoy was present and in the high rugosity areas (Fig. $4.4 \mathrm{a} \& \mathrm{~b}$ ). We did not find a significant effect of predator or rugosity on the number of bites taken from the benthos (Fig. 4.4c). Individual feeding rates were higher and fishes were smaller when the grouper was present (Fig. $4.4 \mathrm{~d} \&$ e). The interaction between predator and rugosity was significant for forager size, indicating that there was a more dramatic decline in forager size when the grouper was present in the high relative to low rugosity areas.

When we tested the spatial effects of the grouper decoy in different rugosities, fishes took fewer bites and removed less seagrass near the grouper decoy and in high rugosity areas (Table 4.2). Foraging on seagrass increased rapidly with distance from the decoy and plateaued at two and four meters (Fig. 4.5a \& b). There was an interaction 
between rugosity and distance for bites on seagrass with fishes taking fewer bites in high relative to low rugosity areas at distances farther from the predator. The number of bites on the benthos also increased with increasing distance but was not different between rugosities (Fig. 4.5c). Proximity to the grouper decoy also affected the size of fishes and their individual feeding rate (Fig. $4.5 \mathrm{~d} \&$ e). Feeding rate declined while forager size increased rapidly with increasing distance from the predator decoy. At $0.5 \mathrm{~m}$ and $1 \mathrm{~m}$, feeding rates were higher and forager sizes were smaller at the high relative to low rugosity areas. When we limited the analyses of bite rates to only fishes $12-15 \mathrm{~cm}$ in size to avoid confounding fish size with feeding rate, feeding rates declined with increasing distance from the decoy and were significantly higher in the high rugosity sites at $0.5 \mathrm{~m}$ (Fig. 4.6).

Individual feeding rates for the two most commonly observed species, $S$. aurofrenatum and A. bahianus, declined with increasing distance from the grouper decoy and were significantly greater in high relative to low rugosity sites at $0.5 \mathrm{~m}$ (Table 4.3 , Fig. $4.7 \mathrm{a} \& \mathrm{~b}$ ). Both fishes responded similarly to the grouper decoy, but showed different responses to rugosity in terms of total bites per hour and fish size (Fig. 4.4c-f). For both species these metrics increased with increasing distance from the decoy. However, for A. bahianus we did not find an effect of rugosity for either metric, whereas S. aurofrenatum were significantly smaller near the decoy, and took significantly fewer total bites per hour in the high relative to low rugosity sites.

The probability of fishes taking multiple forays increased with increasing distance from decoys in both rugosities (high rugosity: $\beta=0.66, \mathrm{SE}=0.26, \mathrm{p}=0.01$; low rugosity: $\beta=0.83, \mathrm{SE}=0.20, \mathrm{p}<0.001)$. A Hosmer-Lemeshow test showed a good fit 
for both logistic regression models (high rugosity: $\chi^{2}=2.9, p=0.41$, low rugosity: $\chi^{2}=$ $5.9, \mathrm{p}=0.11)$. In control trials the probability of multiple forays did not change with distance for either rugosity treatment (high rugosity: $p=0.33$; low rugosity: $p=0.60$ ) (Fig. 4.8).

Given that we saw significant effects of both predator decoy and rugosity on the mean size of foragers, we examined how the size distribution of fishes differed among predator and rugosity treatments at $0.5 \mathrm{~m}$ and $1 \mathrm{~m}$ distances and found a significant effect of both (Kolmogorov-Smirnov test, Predator: $\mathrm{D}=0.44, \mathrm{P}<0.001$, Rugosity: $\mathrm{D}=0.15, \mathrm{P}$ $<0.001$ ) (Fig. 4.9). In the presence of decoys and in high rugosity sites fish size distributions shifted towards smaller individuals. We found that differences in sizes of fishes was likely not due to changes in species composition because species composition did not vary with predator decoy $(\mathrm{p}=0.13)$, rugosity $(\mathrm{p}=0.10)$ or distance $(\mathrm{p}=0.85)$ (Fig. 4.10).

We did not find evidence for differences in damselfish abundance across reefs $\left(\mathrm{F}_{3,179}=0.92, \mathrm{p}=0.44\right)$ or between high and low rugosity treatments $\left(\mathrm{F}_{1,179}=1.09, \mathrm{p}=\right.$ 0.30). However, we found significant differences in the abundance of predators among reefs (Fig. 4.11, $\mathrm{F}_{3,179}=13.72, \mathrm{p}<0.001$ ). Based on Tukey HSD post-hoc tests, Molasses and French reef were not statistically different from one another in terms of number of predators observed $(\mathrm{p}=0.92)$, and neither were Pinnacles and South Carysfort $(\mathrm{p}=0.99)$. However, the former two reefs both had greater numbers of predators observed per minute than the latter two. At all reefs, fewer predators were observed in low relative to high rugosity sites $\left(\mathrm{F}_{1,179}=7.20, \mathrm{p}=0.008\right)$. 


\section{Discussion}

Across many disparate ecosystems, predators can exert strong influences on prey behavior and trophic interactions via intimidation (Preisser et al. 2005). However, the non-consumptive role on predators in coral reef ecosystems has received less attention (but see Madin et al. 2010, Rizzari et al. 2014). Even less is known about how risk effects change with reef habitat complexity. Our work suggests that the threat of predation alters both feeding behavior and impacts of herbivorous fishes. Specifically we show that with increasing risk, herbivorous fishes make fewer feeding bouts and consume less food but feed at a faster rate when they do feed. Furthermore, we show that smaller individuals that are at less risk to larger predators show muted response to predation risk compared to their larger counterparts. Importantly, habitat heterogeneity mediates these effects with predation risk more strongly impacting herbivore feeding in more complex areas. Thus, predators appear to create a reefscape of fear that both changes the size structure of herbivores and decreases their feeding, thereby altering the ecosystem process of grazing which is necessary for healthy coral reefs.

Our study reinforces the idea that reef herbivores display a threat-sensitive response to potential predators by trading off access to food in order to stay safe (Helfman 1989, Rizzari et al. 2014). Importantly, herbivorous fishes altered their feeding behavior in riskier areas (i.e., by consuming food faster and taking fewer feeding forays near predator decoys), thereby minimizing their time spent exposed to risk while still obtaining reward. Herbivory declined with increasing distance from simulated risk suggesting that herbivores respond to the magnitude of risk. Furthermore, the risk avoidance behaviors of fishes were remarkably similar across the four reefs that varied 
substantially in background levels of predation risk (i.e., reef-wide predator abundance). Large grouper such as the one depicted by our decoy are relatively rare across reefs in the FKNMS. At the two reefs where we detected the fewest predators, prey perceived the decoy as a potential threat and exhibited avoidance strategies similar to fishes at reefs where predators were more common. This suggests that visual predator detection recognition in reef herbivores are primarily based on unlearned predispositions (Kelley and Magurran 2003). Therefore, it is likely that prey will resume avoidance strategies, which will in turn alter their spatial impact on the benthos, as predators recover with the establishment of marine protected areas (Smith et al. 2011).

In terrestrial systems, landscape features (e.g., valleys, trees, etc.) can be important mediators of predation risk and anti-predator behavior (Laundre et al. 2001, Valeix et al. 2009). For example, in Yellowstone National Park, landscape attributes (e.g., slope, openness, proximity to roads and streams, etc.) strongly influence on patterns of wolf predation on ungulates (Kauffman et al. 2007). In particular, snow-covered areas close to streams and roads increased the hunting success of wolves by facilitating prey detection and limiting their escape. Fewer studies have investigated the role of landscape in affecting the predator-prey interactions in marine systems (but see Heithaus et al. 2009), particularly in coral reef ecosystems. Seascape structure can influence movement decisions of coral reef fishes because they are often hesitant to transverse structurally simple habitats (e.g., sand flats) both within (Turgeon 2010) and between reefs (Chapman and Kramer 2000), likely because it makes them more vulnerable to predators. Yet, how habitat features affect the trade-off between risk and reward is less understood. 
Our study suggests that structural complexity of reefs interacts with risk to determine the outcome of foraging decisions. We show that this interaction influences anti-predatory behavior differently depending on the size and identity of foragers. At close proximities to the predator decoy, fishes avoided foraging in both structurally complex and simple habitats. However, grazing remained low in complex areas even at further distances from predator decoys. Although these complex areas may offer places of escape for smaller fishes (Beukers and Jones 1997), most parrotfishes and surgeonfishes are too large to hide in the crevices of the reef or among the branches of a coral, and generally flee when threatened. For these fishes the large coral heads and complex reef structure characterizing high rugosity areas likely impede both detection of and escape from predators. Beyond the acute effect of the predator decoy, video analyses revealed higher predator abundances in complex areas, which may have driven the overall lower rates of herbivory in high rugosity areas regardless of the presence of the predator decoy. These results together suggest that the probability of encountering a predator is greater and the probability of escape is lower in high complexity areas, resulting in greatly altered patterns of large herbivore behavior in these areas. Thus, in a marine ecosystem we demonstrate responses of herbivores to landscape features that are not unlike those of elk in Yellowstone National Park (Kauffman et al. 2007), suggesting that across ecosystems, landscapes of fear provide a generalizable framework for predicting trophic interactions.

Our data suggests that landscape features have species-specific effects on antipredator responses of prey. We showed that the two most common species observed, $S$. aurofrenatum and A. bahianus, decreased foraging at close proximities to the predator 
decoy and individuals actually fed at faster rates in high complexity sites. However, rugosity appeared to influence the relationship between distance and total bites and size of foragers for S. aurofrenatum, whereas there was no difference in these relationships between rugosities for A. bahianus. S. aurofrenatum may have perceived high rugosity areas as more dangerous because foraging was more dominated by smaller, less predator prone individuals near the decoy and total bites remained lower at all distances compared to low rugosity areas. Landscape features may be more of a driver of anti-predatory behavior for S. aurofrenatum relative to A. bahianus because of differences in their escape modes or susceptibilities to predation (Lingle 2002, Wirsing et al. 2010). A. bahianus like other Acanthurids, possess a razor-like scalpel on their caudal peduncle, presumably used in anti-predatory defense, which may make them more likely to forage in potentially risky situations. Other studies have shown that similar acanthurid species do not alter their foraging behavior in response to chronic predation risk (i.e., risk integrated over space) (Madin et al. 2010b, Catano et al. 2014). In contrast, $S$. aurofrenatum do not have a physical anti-predatory defense and mostly rely on escape tactics, potentially making them more likely to avoid complex regions that could hinder their escape.

The vulnerability of prey to predation often differs depending on prey body size with smaller prey often being subject to more predators and greater predation rates (Sinclair et al. 2003, Preisser and Orrock 2012). On coral reefs protected from fishing, large-bodied parrotfishes escape predation from gape-limited predators, whereas smaller bodied species suffered greater predation rates (Mumby et al. 2006). Alternatively, small size could also be a refuge for prey if predators preferentially consume larger prey which 
provide more reward with less energy expenditure (Brooks and Dodson 1965). This idea is supported by other studies that show an increased wariness to predation with increasing body size for multiple species of reef fishes (Gotanda et al. 2009, Januchowski-Hartley et al. 2011). Our work showed a shift in the size distribution of herbivores towards smaller individuals where predation risk was higher (i.e., near the predator decoy), suggesting that larger bodied herbivores may be more vulnerable to predation from a grouper the size of our decoy $(\sim 90 \mathrm{~cm})$. This pattern was evident when we considered all herbivore species as well as when we considered patterns in body size within species (e.g. S. aurofrenatum). Smaller fishes may be at less risk since such a large grouper may not pursue prey smaller than $10 \mathrm{~cm}$. Additionally, our data suggests that the impact of rugosity was greater for large-sized fishes because they avoided foraging near the decoy more often in high complexity areas. Smaller fishes likely perceive landscape attributes of reefs differently than their larger counterparts because of their ability to seek refuge in the small crevices available in greater complexity areas. These body size-dependent differences in habitat use appear common across ecosystems because different sized herbivores often respond differently to the same habitat depending on how it either impedes or facilitates their escape from predation (Burkepile et al. 2013b).

When herbivores trade-off food for safety it can lead to complex indirect effects of predators on plant resources (Schmitz et al. 2004). The responses of herbivorous fishes to predation risk could have important implications for reef dynamics. Herbivory plays a key role in preventing algal overgrowth and facilitating coral recruitment, growth, and survivorship (Mumby 2006, Hughes et al. 2007). Therefore, predators could have indirect effects on benthic communities by reducing the abundance of herbivorous fishes or by 
altering herbivore behavior (Madin et al. 2010a). Specifically, our work suggests that predation risk may alter the spatial distribution of herbivory. On reefs where predators are abundant, herbivores may concentrate their feeding on areas of reef that have inherently less risk, potentially making these areas more suitable for the recruitment and establishment of coral species. On reefs where predators are rare, herbivores may be free to forage more widely thereby diluting herbivory on a reef wide scale and lessening the indirect positive impacts on corals. Recent models suggest that increasing the spatial concentration of herbivory is more likely to lead to increases in coral recruitment and coral cover relative to areas where the same amount of herbivory is spread across larger areas of reef (Sandin and McNamara 2012). Additionally, our data suggest that risk from predators results in herbivory that is dominated by smaller herbivores. This shift in the size structure of herbivores could affect the impact of herbivory on the benthos as smaller individuals often have fundamentally different effects on algal communities than do larger individuals (Bonaldo and Bellwood 2008, Plass-Johnson et al. 2012). It is important to note that our data show an immediate, localized response by herbivores to the imminent threat of predation. How this acute risk scales up to long-term changes to benthic communities is yet unclear. Evidence (e.g., 'grazing halos') from other reef ecosystems suggests that, indeed, behavioral responses to predators do translate to chronic alterations to herbivory and the benthos (Madin et al. 2010a, 2011). It is clear that much more work is needed to understand the community-level effects of predation risk on coral reefs.

Our work demonstrates that the threat of predation alters many aspects of herbivore foraging behavior, thereby influencing the key ecological process of grazing on 
coral reefs. Based on evidence from multiple disparate ecosystems, it is clear that predators have an important non-consumptive role and our work is among the first to reinforce this idea in coral reef ecosystems. Furthermore, our work supports the idea that habitat features and species-specific prey responses are crucial components to consider when assessing predator-prey interactions and risk effects. However, many coral reefs are undergoing rapid shifts, often driven by global change that may fundamentally alter the nature of these predator prey interactions. The intense fishing of predators worldwide (Myers and Worm 2003) may fundamentally affect the role that predation risk plays in influencing fish foraging behavior on reefs (Madin et al. 2010b, Rizzari et al. 2014, Catano et al. 2014). Further, global and local factors such as climate change, disease, and pollution have reduced the cover of living coral on reefs (Hoegh-Guldberg and Bruno 2010) resulting in a loss of structural complexity that has profoundly altered reef landscapes (Alvarez-Filip et al. 2009). Our data suggest that declines in predator abundance coupled with losses in structural complexity could alter the landscape of fear for reef herbivores thereby influencing the distribution and concentration of herbivory and the positive indirect effects on corals. Resolving the multiple drivers of contingency in anti-predator behavior will help improve our ability to predict the consequences for coral reefs of altering the landscape of predation risk in an era of global change.

\section{Acknowledgments}

This work was supported by a grant from the NOAA Coral Reef Conservation Program to DEB and facilitated by grant number OCE-1130786 from the National Science Foundation to DEB and R. Vega Thurber. We thank T. Vaughn, R. McQueen, E. Valle 
and T. Torres for assistance with video analysis. We are indebted to C. Catano for his time and advice with this project. This work was conducted with permission from the Florida Keys National Marine Sanctuary under permit no. FKNMS-2013-069.

\section{References Cited}

Abrahams, M. V, and L. M. Dill. 1989. A determination of the energetic equivalence of the risk of predation. Ecology 70:999-1007.

Alvarez-Filip, L., N. K. Dulvy, J. a Gill, I. M. Côté, and A. R. Watkinson. 2009. Flattening of Caribbean coral reefs: region-wide declines in architectural complexity. Proceedings. Biological sciences / The Royal Society 276:3019-25.

Bellwood, D. R., and J. H. Choat. 1990. A functional analysis of grazing in parrotfishes (family Scaridae): the ecological implications. Environmental Biology of Fishes 28:189-214.

Beukers, J. S., and G. P. Jones. 1997. Habitat complexity modifes the impact of piscivores on a coral reef fish population. Oecologia 114:50-59.

Bohnsack, J. A., D. E. Harper, D. B. Mcclellan, G. T. Kellison, N. Marine, F. Service, J. S. Ault, S. G. Smith, and N. Zurcher. 2009. Coral reef fish response to FKNMS management zones : the first ten years ( 1997-2007). Progress Report of the Florida Keys National Marine Sanctuary:1-29.

Bonaldo, R., and D. Bellwood. 2008. Size-dependent variation in the functional role of the parrotfish Scarus rivulatus on the Great Barrier Reef, Australia. Marine Ecology Progress Series 360:237-244.

Brooks, J. L., and S. I. Dodson. 1965. Predation, Body Size, and Composition of Plankton. Science (New York, N.Y.) 150:28-35.

Burkepile, D. E., J. E. Allgeier, A. a Shantz, C. E. Pritchard, N. P. Lemoine, L. H. Bhatti, and C. a Layman. 2013a. Nutrient supply from fishes facilitates macroalgae and suppresses corals in a Caribbean coral reef ecosystem. Scientific reports 3:1493.

Burkepile, D. E., C. E. Burns, C. J. Tambling, E. Amendola, G. M. Buis, N. Govender, V. Nelson, D. I. Thompson, A. D. Zinn, and M. D. Smith. 2013b. Habitat selection by large herbivores in a southern African savanna : the relative roles of bottom-up and top-down forces. Ecosphere 4:1-19. 
Burkepile, D. E., and M. E. Hay. 2008. Herbivore species richness and feeding complementarity affect community structure and function on a coral reef. Proceedings of the National Academy of Sciences of the United States of America 105:16201-6.

Catano, L., A. Shantz, and D. Burkepile. 2014. Predation risk, competition, and territorial damselfishes as drivers of herbivore foraging on Caribbean coral reefs. Marine Ecology Progress Series 511:193-207.

Chapman, M. R., and D. L. Kramer. 2000. Movements of fishes within and among fringing coral reefs in Barbados. Environmental Biology of Fishes 57:11-24.

Creel, S., J. Winnie, B. Maxwell, K. Hamlin, and M. Creel. 2005. Elk Alter Habitat Selection As an Antipredator Response To Wolves. Ecology 86:3387-3397.

Dill, L., M. R. Heithaus, and C. Walters. 2003. Behaviorally mediated indirect interactions in marine communities and their conservation implications. Ecology 84:1151-1157.

Foster, S. A. 1985. Group foraging by a coral reef fish: a mechanism for gaining access to defended resources. Animal Behavior 33:782-792.

Gilliam, J. F., and D. F. Fraser. 1987. Habitat Selection Under Predation Hazard : Test of a Model with Foraging Minnows. Ecology 68:1856-1862.

Gorini, L., J. D. C. Linnell, R. May, M. Panzacchi, L. Boitani, M. Odden, and E. B. Nilsen. 2012. Habitat heterogeneity and mammalian predator-prey interactions. Mammal Review 42:55-77.

Gotanda, K. M., K. Turgeon, and D. L. Kramer. 2009. Body size and reserve protection affect flight initiation distance in parrotfishes. Behavioral Ecology and Sociobiology 63:1563-1572.

Graham, N. a. J., and K. L. Nash. 2013. The importance of structural complexity in coral reef ecosystems. Coral Reefs 32:315-326.

Heithaus, M. R., and L. Dill. 2002. Food availability and tiger shark predation risk influence bottlenose dolphin habitat use. Ecology 83:480-491.

Heithaus, M. R., A. J. Wirsing, D. Burkholder, and J. Thomson. 2009. Towards a predictive framework for predator risk effects: the interaction of landscape features and prey escape tactics. Journal of Animal Ecology:556-562.

Helfman, G. S. 1989. Threat-sensitive predator avoidance in damselfish-trumpetfish interactions. Behavioral Ecology and Sociobiology 24:47-58. 
Hixon, M. A., and J. P. Beets. 1993. Predation, prey refuges, and the structure of coralreef fish assemblages. Ecological Monographs 63:77-101.

Hoegh-Guldberg, O., and J. F. Bruno. 2010. The impact of climate change on the world's marine ecosystems. Science (New York, N.Y.) 328:1523-8.

Hughes, T. P., M. Rodrigues, D. R. Bellwood, D. M. Ceccarelli, O. Hoegh-Gudberg, L. J. Mccook, N. Moltschaniwskyj, M. Pratchett, R. S. Steneck, and B. Willis. 2007. Phase shifts, herbivory, and the resilience of coral reefs to climate change. Current Biology 17:360-365.

Januchowski-Hartley, F. a, N. a J. Graham, D. a Feary, T. Morove, and J. E. Cinner. 2011. Fear of fishers: human predation explains behavioral changes in coral reef fishes. PloS one 6:e22761.

Kauffman, M. J., N. Varley, D. W. Smith, D. R. Stahler, D. R. MacNulty, and M. S. Boyce. 2007. Landscape heterogeneity shapes predation in a newly restored predator-prey system. Ecology letters 10:690-700.

Kelley, J. L., and A. E. Magurran. 2003. Learned predator recognition and antipredator responses in fishes. Fish and Fisheries 4:216-226.

Kuffner, I. B., J. C. Brock, R. Grober-Dunsmore, V. E. Bonito, T. D. Hickey, and C. W. Wright. 2007. Relationships Between Reef Fish Communities and Remotely Sensed Rugosity Measurements in Biscayne National Park, Florida, USA. Environmental Biology of Fishes 78:71-82.

Laundre, J., L. Hernandez, and K. B. Altendorf. 2001. Wolves, elk, and bison: reestablishing the "landscape of fear" in Yellowstone National Park, U.S.A. Canadian Journal of Zoology 79:1401-1409.

Lima, S. L., and L. M. Dill. 1990. Behavioral decisions made under the risk of predation: a review and prospectus. Canadian Journal of Zoology 68:619-640.

Lingle, S. 2002. Coyote predation and habitat segregation of white-tailed deer and mule deer. Ecology 83:2037-2048.

Madin, E. M. P., S. D. Gaines, J. S. Madin, and R. R. Warner. 2010a. Fishing indirectly structures macroalgal assemblages by altering herbivore behavior. The American Naturalist 176:785-801.

Madin, E. M. P., S. D. Gaines, and R. R. Warner. 2010b. Field evidence for pervasive indirect effects of fishing on prey foraging behavior. Ecology 91:3563-3571. 
Madin, E. M. P., J. S. Madin, and D. J. Booth. 2011. Landscape of fear visible from space. Scientific reports 1:14.

Matassa, C. M., and G. C. Trussell. 2011. Landscape of fear influences the relative importance of consumptive and nonconsumptive predator effects. Ecology 92:22582266.

Mumby, P. J. 2006. The impact of exploiting grazers (Scaridae) on the dynamics of caribbean coral reefs. Ecological Applications 16:747-769.

Mumby, P. J., C. P. Dahlgren, A. R. Harborne, C. V Kappel, F. Micheli, D. R. Brumbaugh, K. E. Holmes, J. M. Mendes, K. Broad, J. N. Sanchirico, K. Buch, S. Box, R. W. Stoffle, and A. B. Gill. 2006. Fishing, trophic cascades, and the process of grazing on coral reefs. Science (New York, N.Y.) 311:98-101.

Mumby, P. J., A. R. Harborne, J. Williams, C. V Kappel, D. R. Brumbaugh, F. Micheli, K. E. Holmes, C. P. Dahlgren, C. B. Paris, and P. G. Blackwell. 2007. Trophic cascade facilitates coral recruitment in a marine reserve. Proceedings of the National Academy of Sciences of the United States of America 104:8362-7.

Myers, R. a, and B. Worm. 2003. Rapid worldwide depletion of predatory fish communities. Nature 423:280-3.

Plass-Johnson, J. G., C. D. McQuaid, and J. M. Hill. 2012. Stable isotope analysis indicates a lack of inter- and intra-specific dietary redundancy among ecologically important coral reef fishes. Coral Reefs 32:429-440.

Preisser, E. L., D. I. Bolnick, and M. E. Benard. 2005. Scared to death? The effects of intimidation and consumption in predator-prey interactions. Ecology 86:501-509.

Preisser, E. L., and J. L. Orrock. 2012. The allometry of fear : interspecific relationships between body size and response to predation risk. Ecosphere 3:1-27.

Preisser, E. L., J. L. Orrock, and O. J. Schmitz. 2007. Predator hunting mode and habitat domain alter nonconsumptive effects in predator-prey interactions. Ecology $88: 2744-51$.

Randall, J. E. 1967. Food habits of reef fishes of the West Indies. Studies in Tropical Oceanography 5:655-847.

Rilov, G., W. Figueira, S. Lyman, and L. Crowder. 2007. Complex habitats may not always benefit prey: linking visual field with reef fish behavior and distribution. Marine Ecology Progress Series 329:225-238. 
Ripple, W., and R. Beschta. 2007. Restoring Yellowstone's aspen with wolves. Biological Conservation 138:514-519.

Ripple, W. J., and R. L. Beschta. 2003. Wolf reintroduction, predation risk, and cottonwood recovery in Yellowstone National Park. Forest Ecology and Management 184:299-313.

Rizzari, J. R., A. J. Frisch, A. S. Hoey, and M. I. McCormick. 2014. Not worth the risk: apex predators suppress herbivory on coral reefs. Oikos:no-no.

Sandin, S. a, and D. E. McNamara. 2012. Spatial dynamics of benthic competition on coral reefs. Oecologia 168:1079-90.

Schmitz, O. J. 2005. Scaling from plot experiments to landscapes: studying grasshoppers to inform forest ecosystem management. Oecologia 145:225-34.

Schmitz, O. J., A. P. Beckerman, and K. M. O’Brien. 1997. Behaviorally mediated trophic cascades : Effects of predation risk on food web interactions. Ecology 78:1388-1399.

Schmitz, O. J., V. Krivan, and O. Ovadia. 2004. Trophic cascades: the primacy of traitmediated indirect interactions. Ecology Letters 7:153-163.

Sinclair, A. R. E., S. Mduma, and J. S. Brashares. 2003. Patterns of predation in a diverse predator - prey system. Nature 425:288-290.

Smith, S. G., J. S. Ault, J. A. Bohnsack, D. E. Harper, J. Luo, and D. B. Mcclellan. 2011. Multispecies survey design for assessing reef-fish stocks, spatially explicit management performance, and ecosystem condition. Fisheries Research 109:25-41.

Turgeon, K. 2010. Functional Connectivity from a Reef Fish Perspective: Behavioral Tactics for Moving in a Fragmented Landscape. Ecology 91:100415162714010.

Valeix, M., A. J. Loveridge, S. Chamaillé-Jammes, Z. Davidson, F. Murindagomo, H. Fritz, and D. W. Macdonald. 2009. Behavioral adjustments of African herbivores to predation risk by lions: spatiotemporal variations influence habitat use. Ecology 90:23-30.

Werner, E. E., and S. D. Peacor. 2003. A Review of Trait-Mediated Indirect Interactions in Ecological Communities. Ecology 84:1083-1100.

Wirsing, A. J., K. E. Cameron, and M. R. Heithaus. 2010. Spatial responses to predators vary with prey escape mode. Animal Behaviour 79:531-537. 
Wirsing, A. J., M. R. Heithaus, A. Frid, and L. M. Dill. 2008. Seascapes of fear: evaluating sublethal predator effects experienced and generated by marine mammals. Marine Mammal Science 24:1-15. 
Table 4.1 - Summary of two-way ANOVAs testing for effects of reef, predator treatment (i.e., grouper vs. control), rugosity (i.e., high vs. low) and their interaction on the percentage of seagrass consumed per minute based on seagrass measurements, and based on video observations: the bites on seagrass per minute, the bites on benthos per minute, individual feeding rates (bites/second) and forager size.

\begin{tabular}{|c|c|c|c|c|c|c|c|c|c|c|}
\hline & \multicolumn{2}{|c|}{ \% Seagrass Consumed } & \multicolumn{2}{|c|}{$\begin{array}{l}\text { Bites on } \\
\text { Seagrass }\end{array}$} & \multicolumn{2}{|c|}{$\begin{array}{l}\text { Bites on } \\
\text { Benthos }\end{array}$} & \multicolumn{2}{|c|}{$\begin{array}{l}\text { Feeding } \\
\text { Rates }\end{array}$} & \multicolumn{2}{|c|}{ Forager Size } \\
\hline & $\mathbf{F}$ & $\mathbf{p}$ & $\mathbf{F}$ & $\mathbf{p}$ & $\mathbf{F}$ & $\mathbf{p}$ & $\mathbf{F}$ & $\mathbf{p}$ & $\mathbf{F}$ & $\mathbf{p}$ \\
\hline Reef & 0.39 & 0.76 & 0.14 & 0.94 & 0.68 & 0.57 & 1.64 & 0.18 & 2.00 & 0.17 \\
\hline Predator & 68.84 & $<0.001$ & 13.10 & $<0.001$ & 1.40 & 0.24 & 5.79 & 0.01 & 24.75 & $<0.001$ \\
\hline Rugosity & 5.11 & 0.02 & 13.67 & $<0.001$ & 0.01 & 0.94 & 1.03 & 0.31 & 0.002 & 0.97 \\
\hline Predator $x$ Rugosity & 1.12 & 0.29 & 1.36 & 0.25 & 1.89 & 0.17 & 1.49 & 0.22 & 0.18 & 0.67 \\
\hline
\end{tabular}


Table 4.2 - Summary of two-way ANOVAs testing for effects of rugosity (i.e., high vs. low), distance from grouper decoy (i.e., $1 / 2$, 1,2 , and $4 \mathrm{~m}$ ) and their interaction on percentage of seagrass consumed from assays (standardized by the length of each trial), bites on seagrass over time of video observation, feeding rates and forager size.

\begin{tabular}{|c|c|c|c|c|c|c|c|c|c|c|}
\hline \multirow[b]{2}{*}{ Source } & \multicolumn{2}{|c|}{ \% Seagrass Consumed } & \multicolumn{2}{|c|}{$\begin{array}{l}\text { Bites on } \\
\text { Seagrass }\end{array}$} & \multicolumn{2}{|c|}{$\begin{array}{l}\text { Bites on } \\
\text { Benthos }\end{array}$} & \multicolumn{2}{|c|}{ Feeding Rates } & \multicolumn{2}{|c|}{ Forager Size } \\
\hline & $\mathrm{F}$ & $\mathrm{p}$ & $\mathrm{F}$ & $\mathrm{p}$ & $\mathrm{F}$ & $\mathrm{p}$ & $\mathrm{F}$ & $\mathrm{P}$ & $\mathrm{F}$ & $\mathrm{P}$ \\
\hline Rugosity & 7.71 & 0.007 & 16.05 & $<0.001$ & 0.67 & 0.42 & 3.27 & 0.07 & 41.81 & $<0.001$ \\
\hline Distance & 33.53 & $<0.001$ & 19.45 & $<0.001$ & 3.85 & 0.01 & 28.81 & $<0.001$ & 79.67 & $<0.001$ \\
\hline Rugosity $x$ Distance & 0.56 & 0.64 & 4.77 & 0.004 & 1.23 & 0.31 & 10.02 & $<0.001$ & 7.93 & $<0.001$ \\
\hline
\end{tabular}


Table 4.3 - Summary of two-way ANOVAs testing for effects of rugosity (i.e., high vs. low), distance from grouper decoy (i.e., $1 / 2$, 1,2 , and $4 \mathrm{~m}$ ) and their interaction on bites on seagrass or benthos over time of video observation, individual feeding rates and forager size for (a) S. aurofrenatum and (b) A. coeruleus.

\begin{tabular}{|c|c|c|c|c|c|c|c|}
\hline & \multirow[b]{2}{*}{ Source } & \multicolumn{2}{|c|}{ Bites on Seagrass or Benthos } & \multicolumn{2}{|c|}{ Feeding Rates } & \multicolumn{2}{|c|}{ Forager Size } \\
\hline & & F & $\mathrm{p}$ & F & $\mathrm{p}$ & $\mathrm{F}$ & $\mathrm{p}$ \\
\hline \multirow[t]{3}{*}{ (a) S. aurofrenatum } & Rugosity & 14.88 & $<0.001$ & 0.23 & 0.63 & 3.86 & 0.05 \\
\hline & Distance & 13.44 & $<0.001$ & 13.81 & $<0.001$ & 41.87 & $<0.001$ \\
\hline & Rugosity $x$ Distance & 5.11 & $<0.01$ & 3.09 & 0.03 & 6.71 & $<0.001$ \\
\hline \multirow[t]{3}{*}{ (b) A. bahianus } & Rugosity & 1.74 & 0.19 & 0.10 & 0.75 & 0.68 & 0.41 \\
\hline & Distance & 0.466 & $<0.01$ & 3.48 & 0.02 & 28.32 & $<0.001$ \\
\hline & Rugosity $x$ Distance & 0.46 & 0.71 & 8.29 & $<0.001$ & 1.43 & 0.24 \\
\hline
\end{tabular}


Figure 4.1 - (a) Predator decoy of black grouper, Mycteroperca bonaci, anchored to the seafloor, (b) Sparisoma aurofrenatum biting standardized assay of Thalassia testudinum and (c) Mean \pm SE for percentage of seagrass consumed adjacent to predator decoy (fiberglass black grouper), decoy control (plastic carboy), or control (no carboy or decoy). Letters above bars represent differences among groups based on TukeyHSD posthoc analysis.
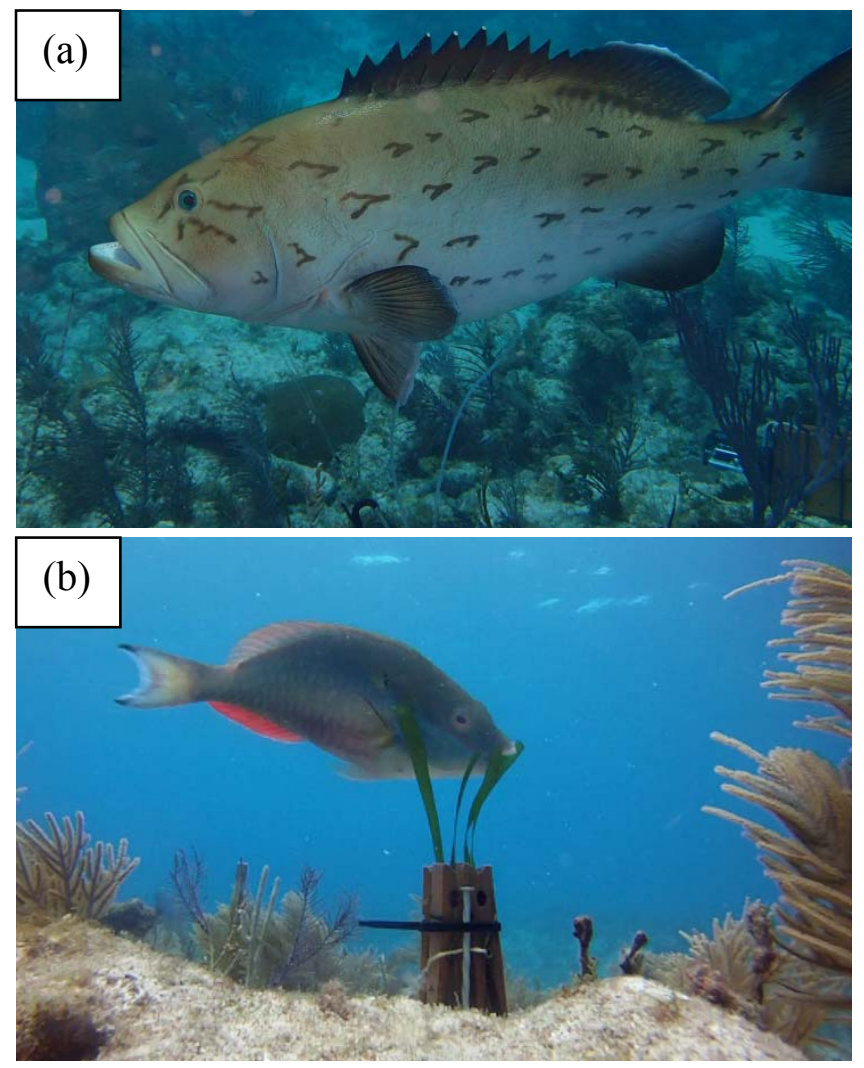

(c)

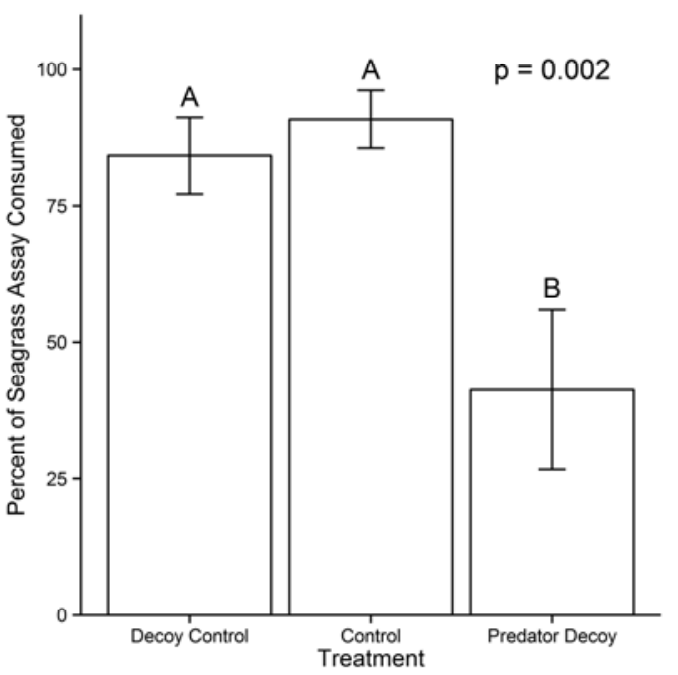


Figure 4.2 - Representative panoramic images of a (a) high and (b) low rugosity site.
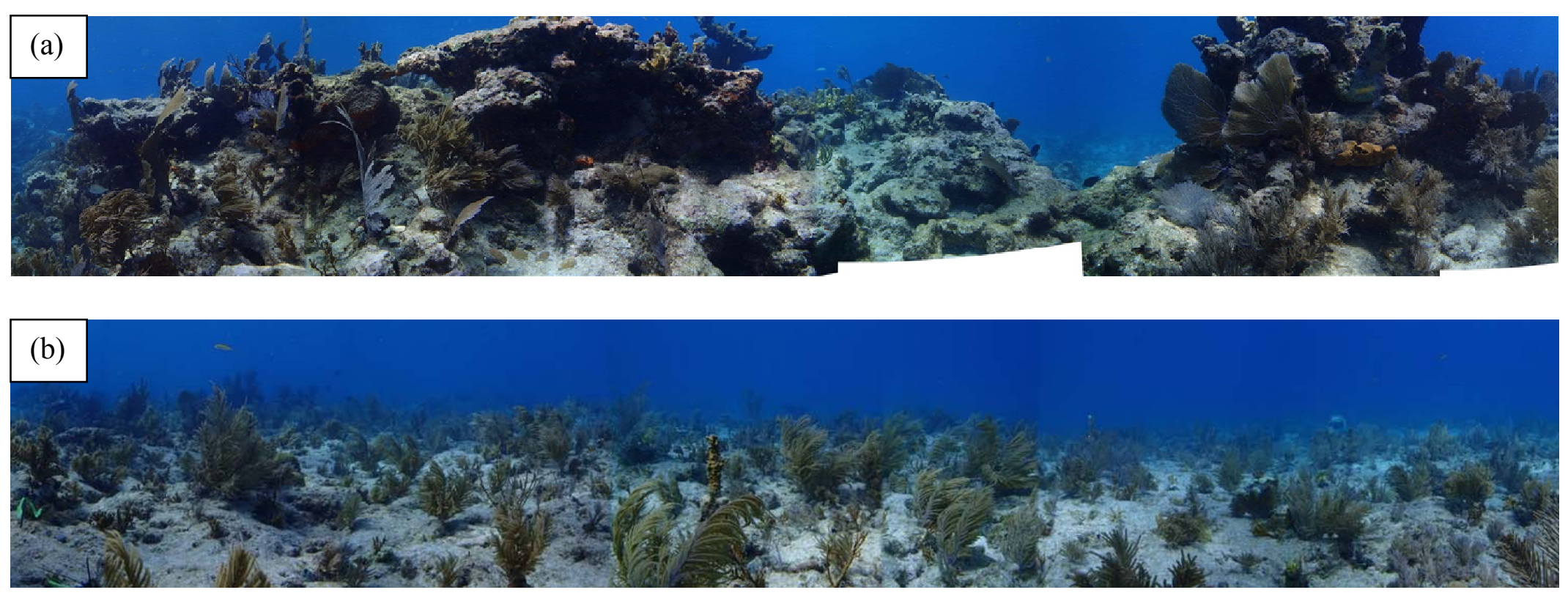
Figure 4.3 - Species distributions of foragers at different rugosity (HR: high rugosity, LR: low rugosity) and predator treatments (i.e., Grouper and Control)

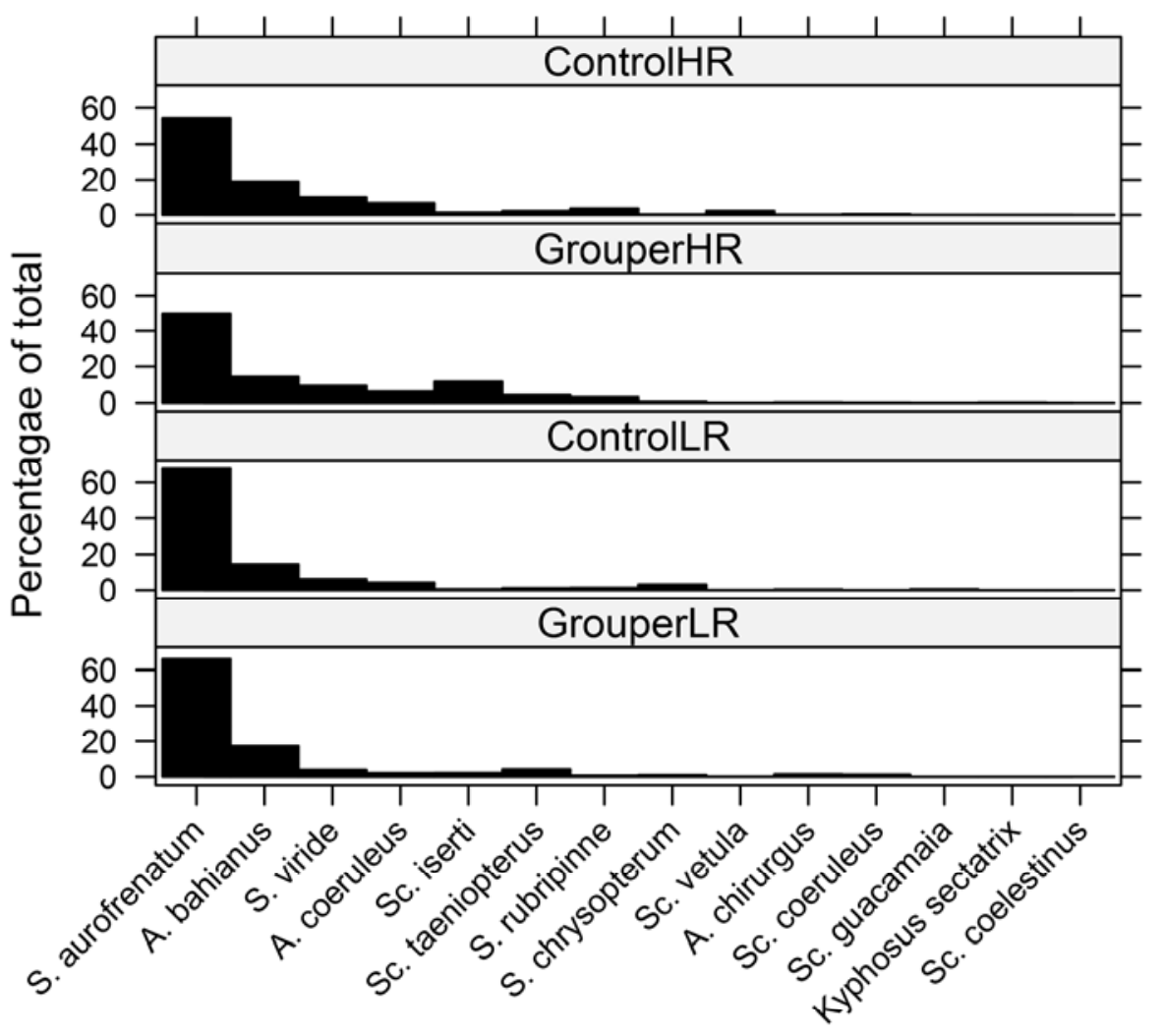

Species 
Figure 4.4 - Mean \pm SE (a) percentage of seagrass consumed/hour based on seagrass measurements, and based on video observations: (b) bites on seagrass/hour, (c) bites on benthos/hour, (d) individual feeding rates (bites/minute) and (e) forager size ( $\mathrm{cm}$ ) at high and low rugosity sites and control and grouper treatments. Letters above bars in panel (e) represent differences among groups based on TukeyHSD post-hoc analysis.
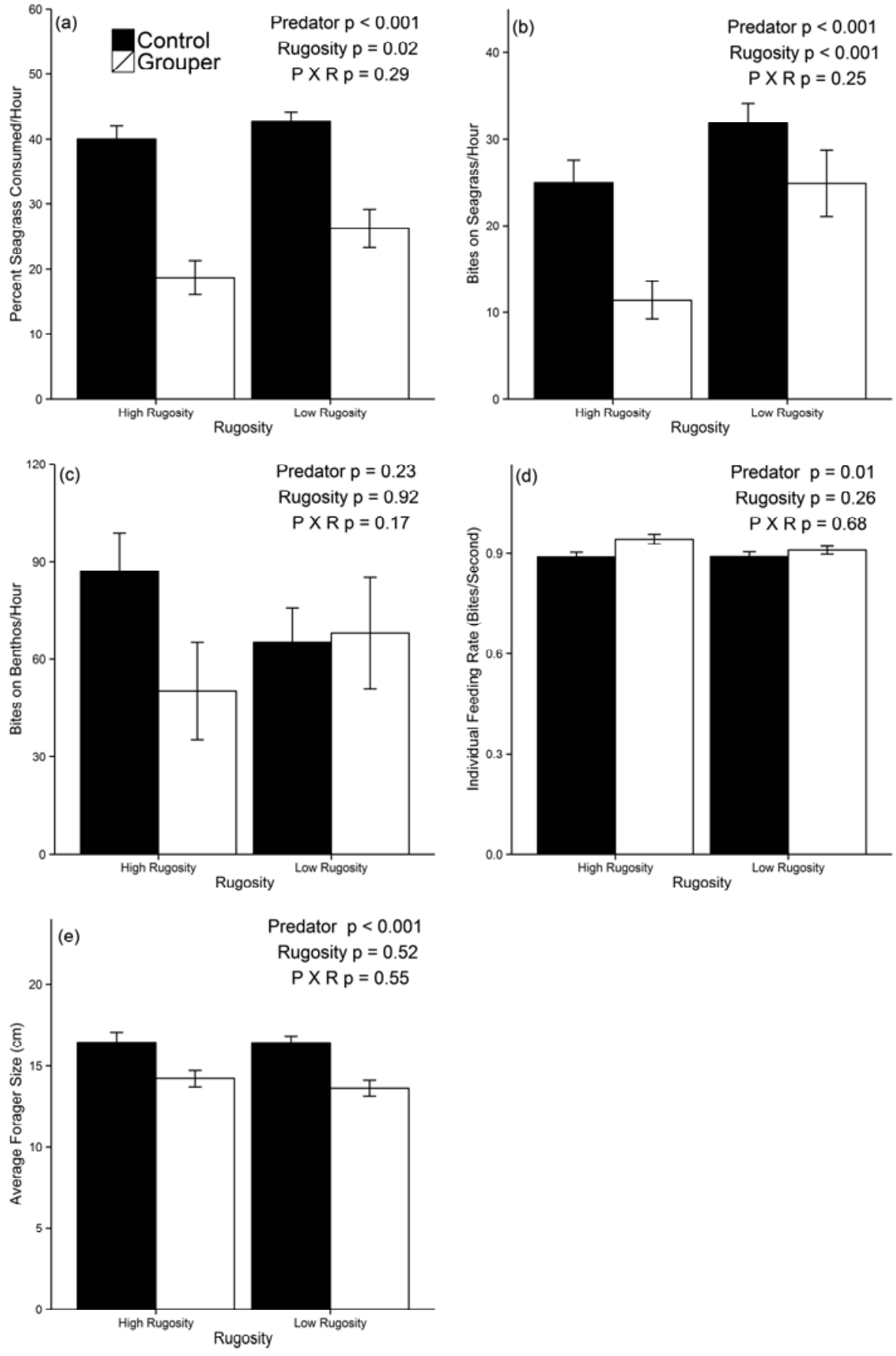
Figure 4.5 - Mean \pm SE (a) percentage of seagrass consumed/hour based on seagrass measurements, and based on video observations: (b) bites on seagrass/hour, (c) bites on benthos/hour, (d) individual feeding rates (bites/minute) and (e) forager size ( $\mathrm{cm}$ ) at increasing distances from predator model. Asterisks $(*)$ represent significant differences between rugosity treatments based on Tukey HSD post hoc comparisons.
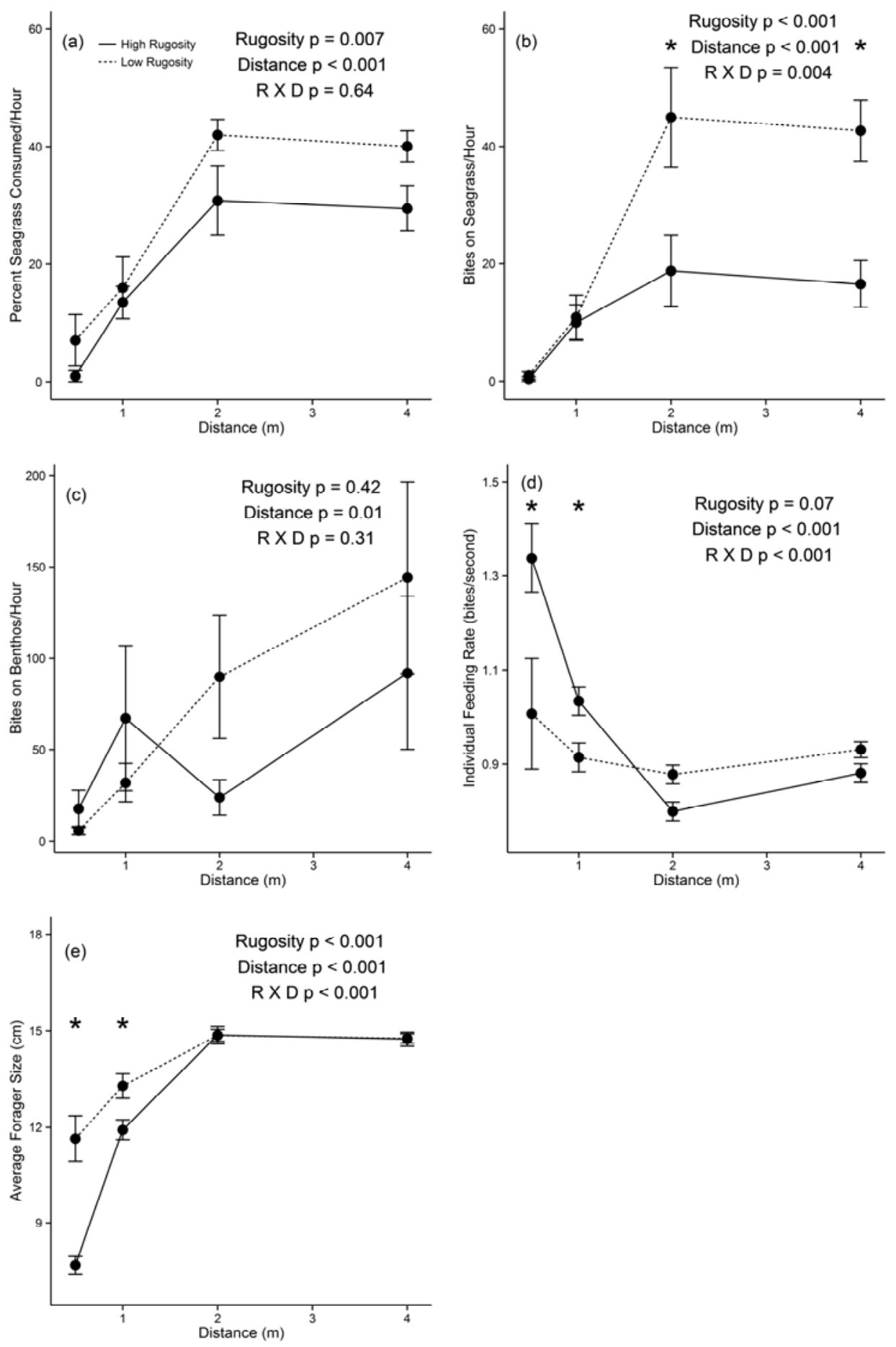
Figure 4.6 - Individual feeding rates (bites/second) at increasing distances from predator model for fishes $12-15 \mathrm{~cm}$. Asterisks ${ }^{*}$ ) represent significant differences between rugosity treatments based on a TukeyHSD post hoc test.

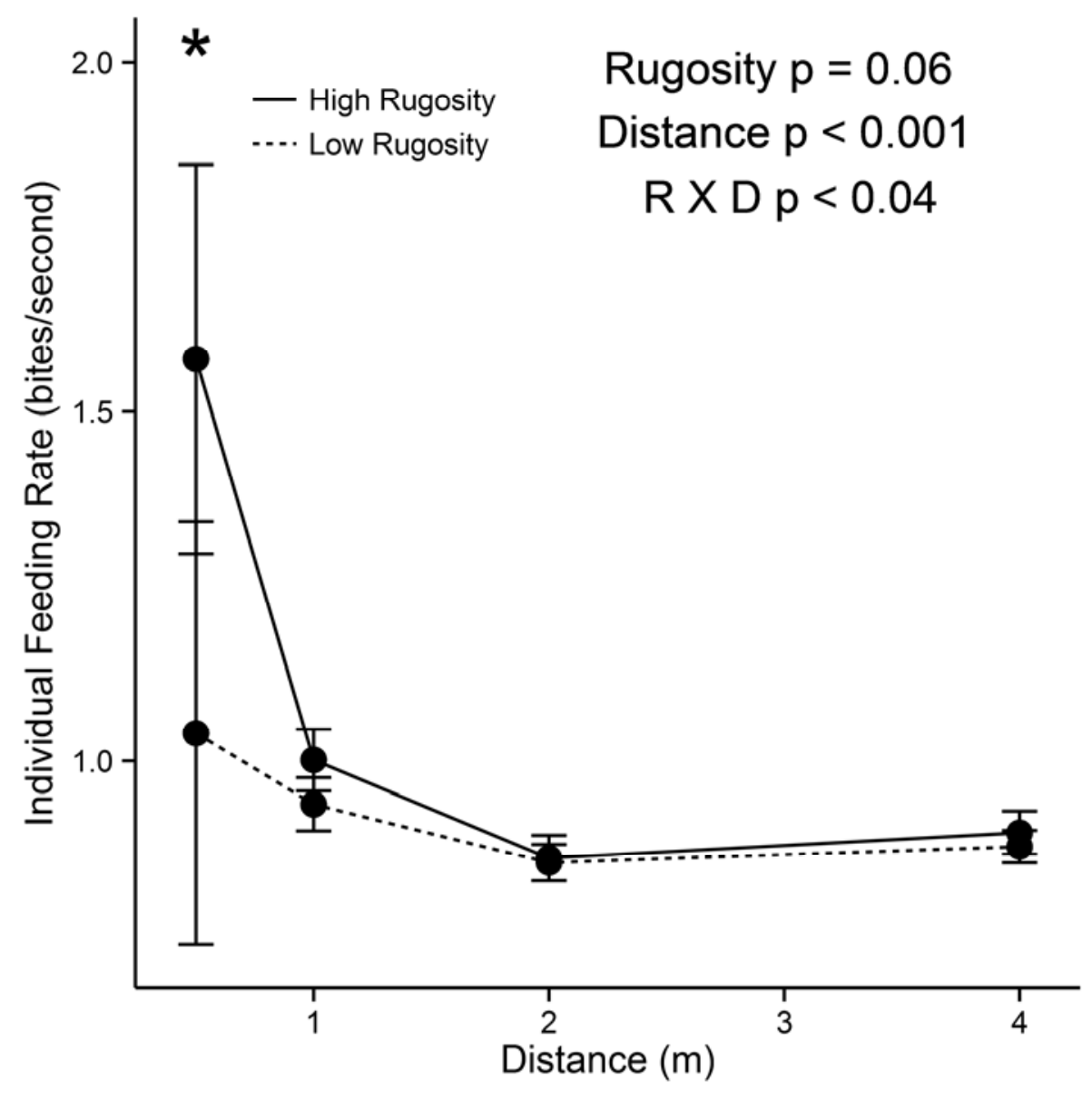


Figure $4.7-$ Mean $\pm \mathrm{SE}$ (a) \& (b) bites/hour on seagrass or benthos, (c) \& (d) individual feeding rates (bites/minute) and (e) \& (f) forager size $(\mathrm{cm})$ at increasing distances from predator model for S. aurofrenatum and A. bahianus. Asterisks (*) represent significant differences between rugosity treatments based on Tukey HSD post hoc comparisons.
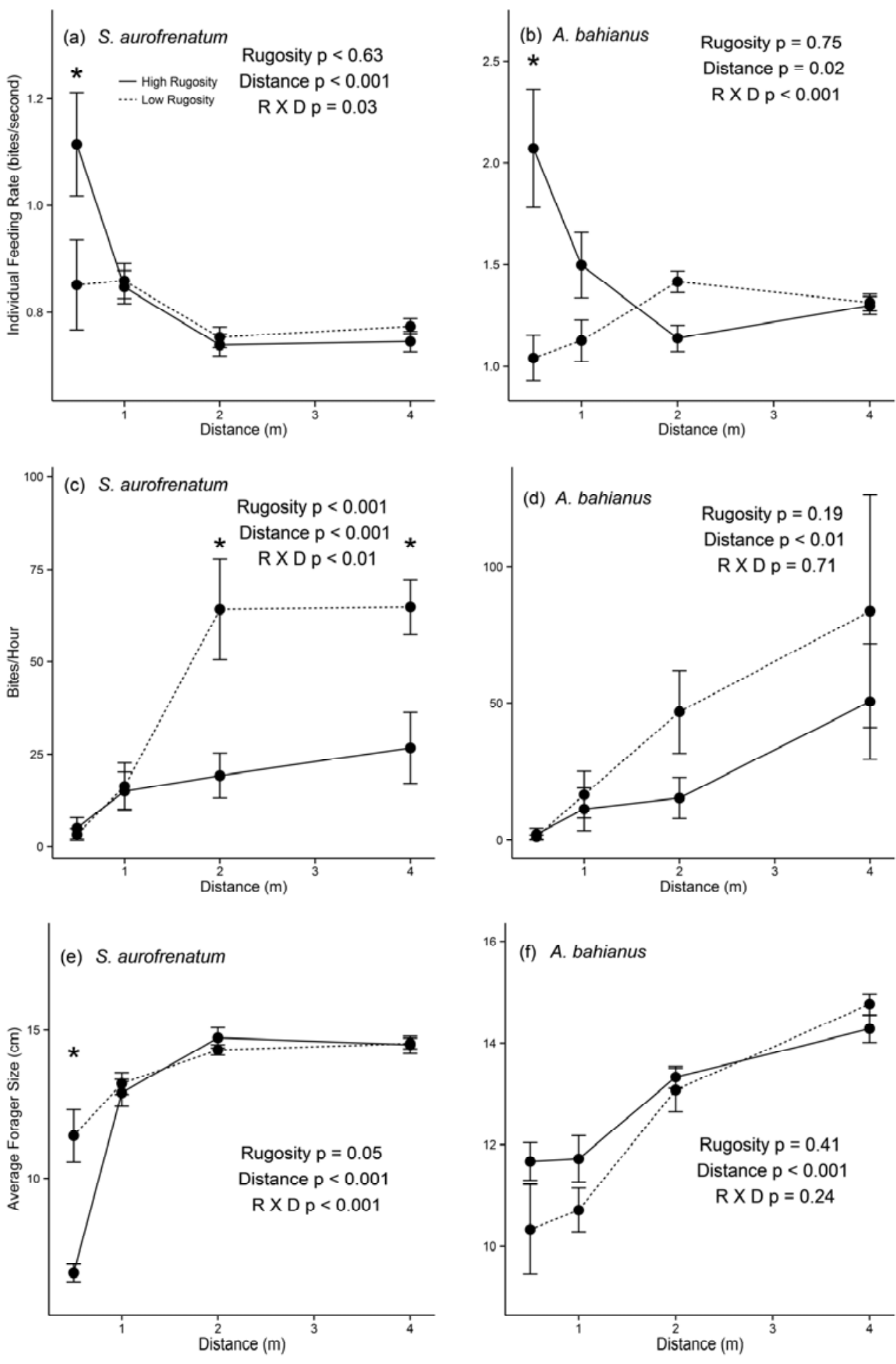
Figure 4.8 - Predicted probability of individual fishes taking multiple forays as a function of distance at (a) high and (b) low rugosity sites in grouper and control treatments based on logistic regression model. Dashed lines represent $95 \%$ confidence intervals.
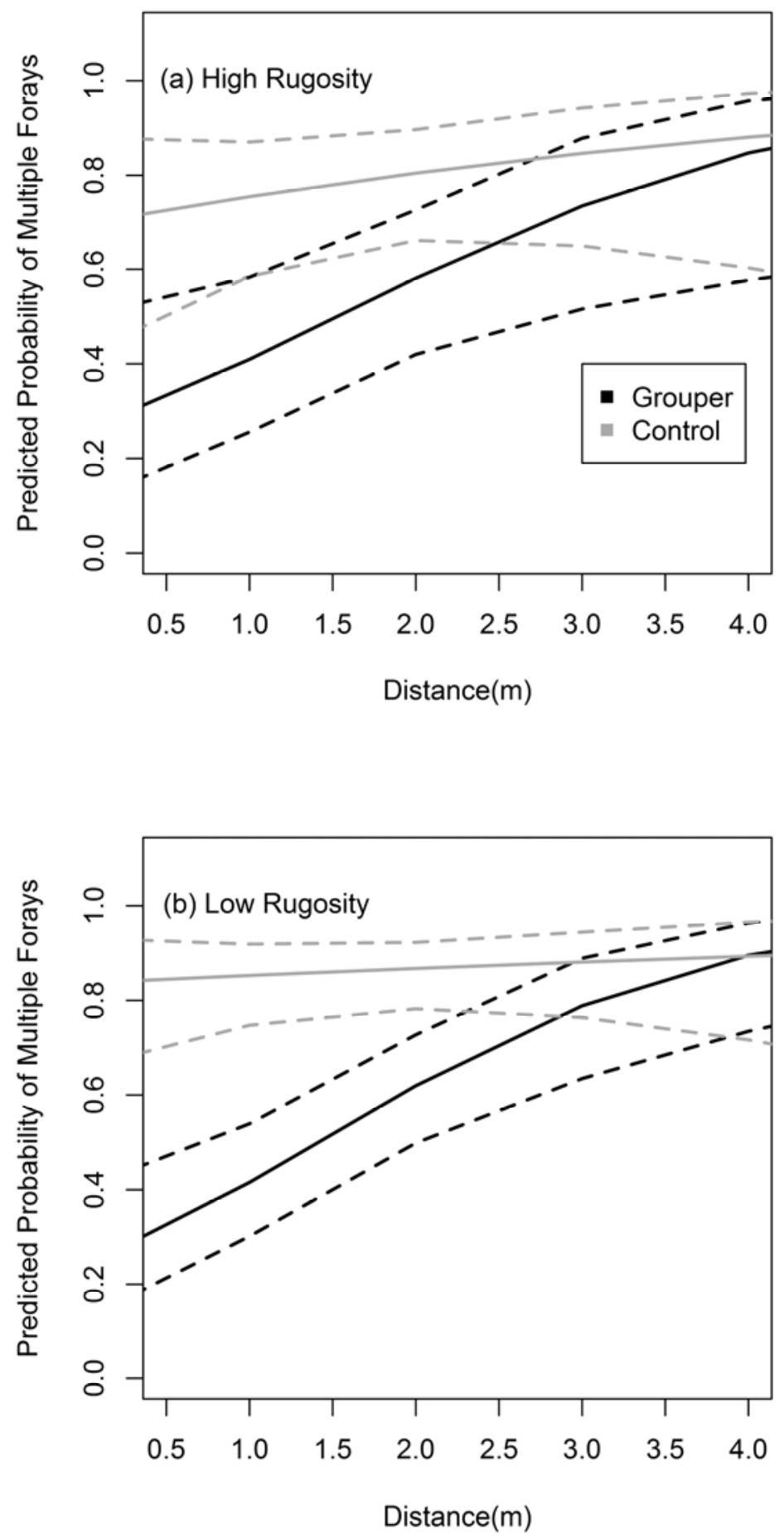
Figure 4.9 - Size distributions of foragers near the predator model (at the 0.5 and 1 meter) at each predator (i.e., grouper and control) and rugosity (HR: High Rugosity and LR: Low Rugosity) treatment.

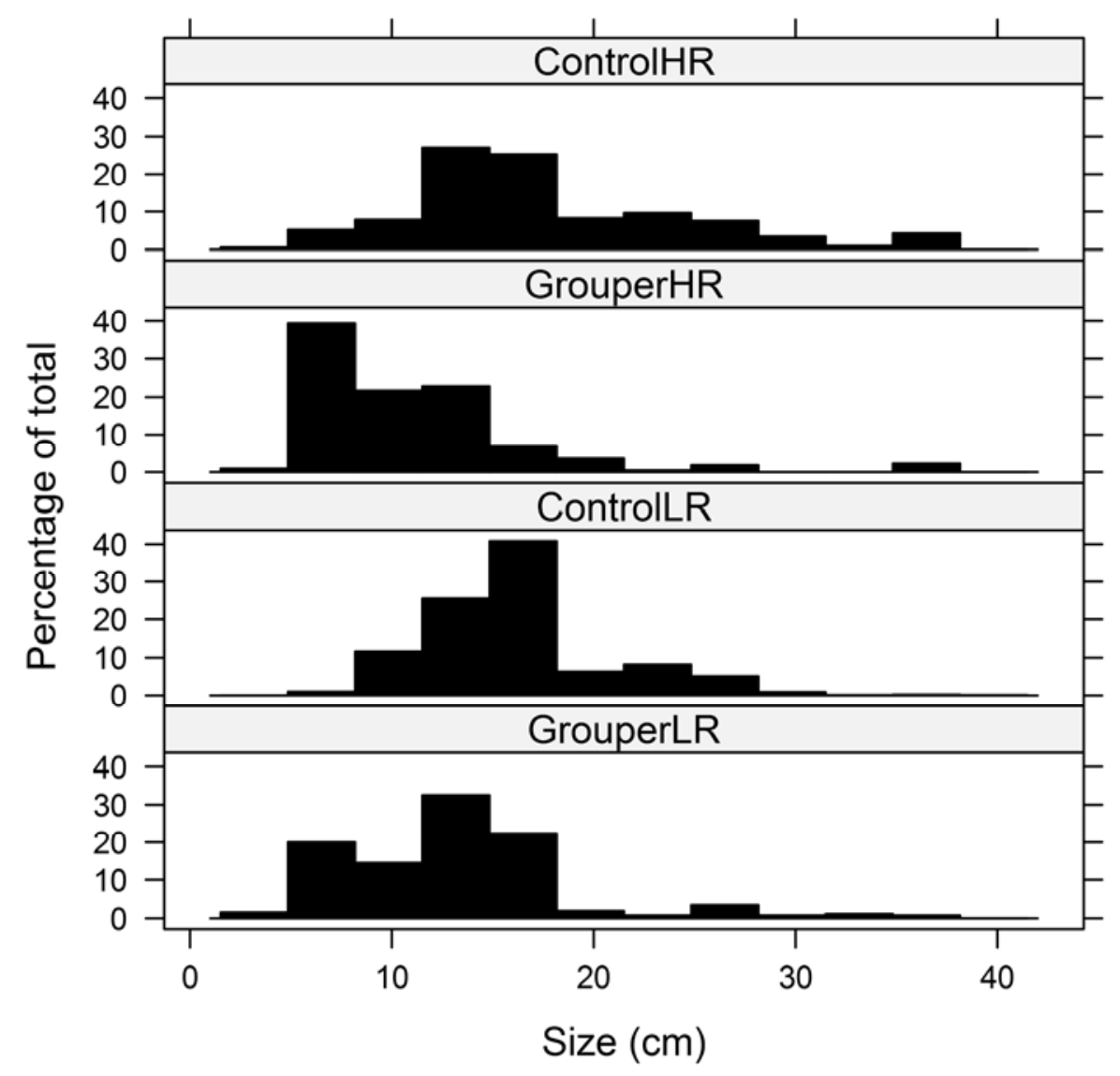


Figure 4.10 - Plot of the nonmetric multidimensional scaling (NMDS) scores for the two most important axes for species abundance of herbivorous fishes. The red and black minimim convex polygons surround the grouper and control treatments, respectively. Squares and triangles represent high and low rugosity treatments, respectively. Species abbreviations are as follows: SA: S. aurofrenatum, AB: A. bahianus, SV: S. viride, AC: A. coeruleus, ScI: Sc. iserti, ST: Sc. taeniopterus, SR: S. rubripinne, SC: S. chrysopterum, ScV: Sc. vetula, ACh: A. chirurgus, ScCor: Sc. coeruleus, ScG: Sc. guacamaia, CH: Kyphosus sectatrix, ScC: Sc. coelestinus. Stress =0.20.

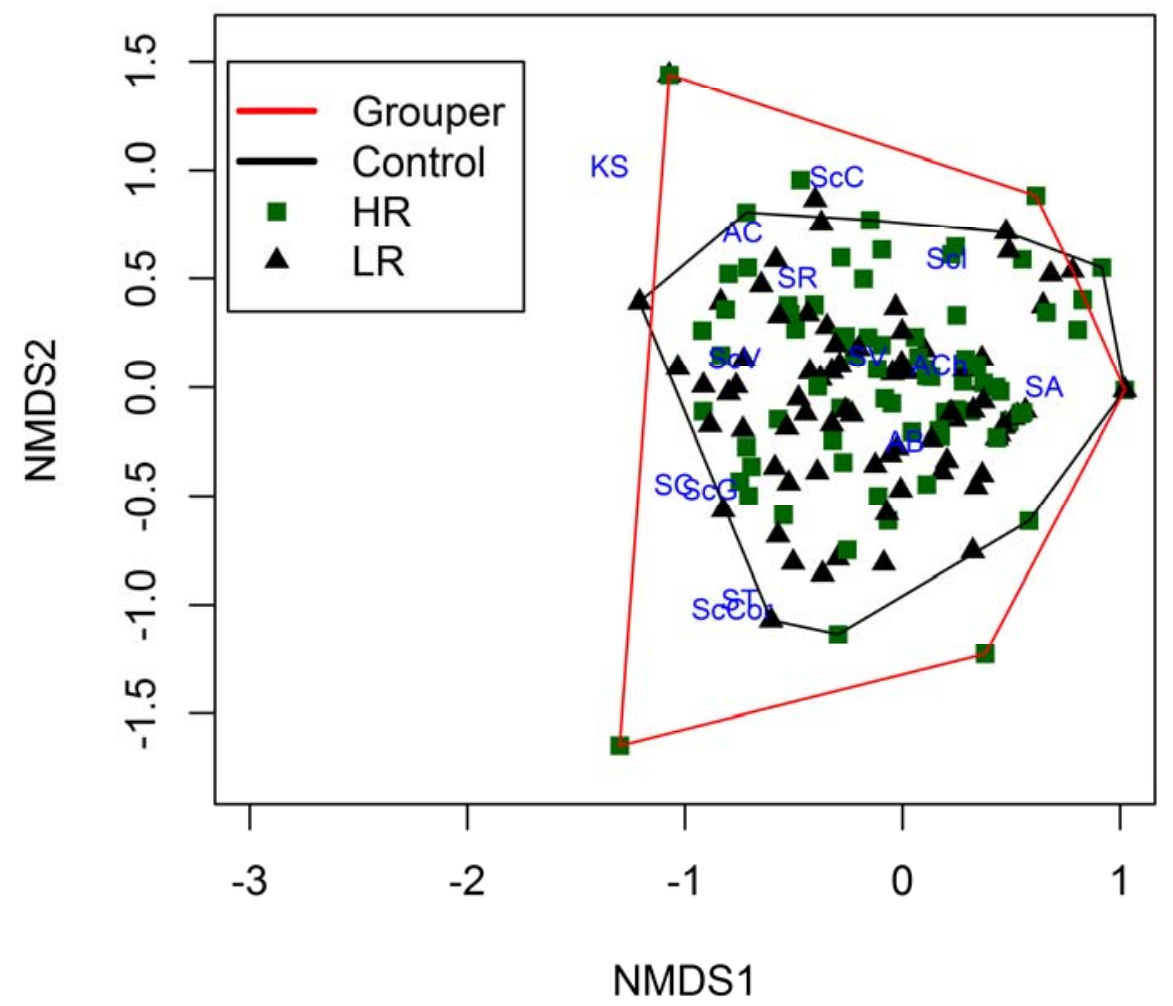


Figure 4.11 - Predators observed per minute of video observation at four reefs in high and low rugosity sites.

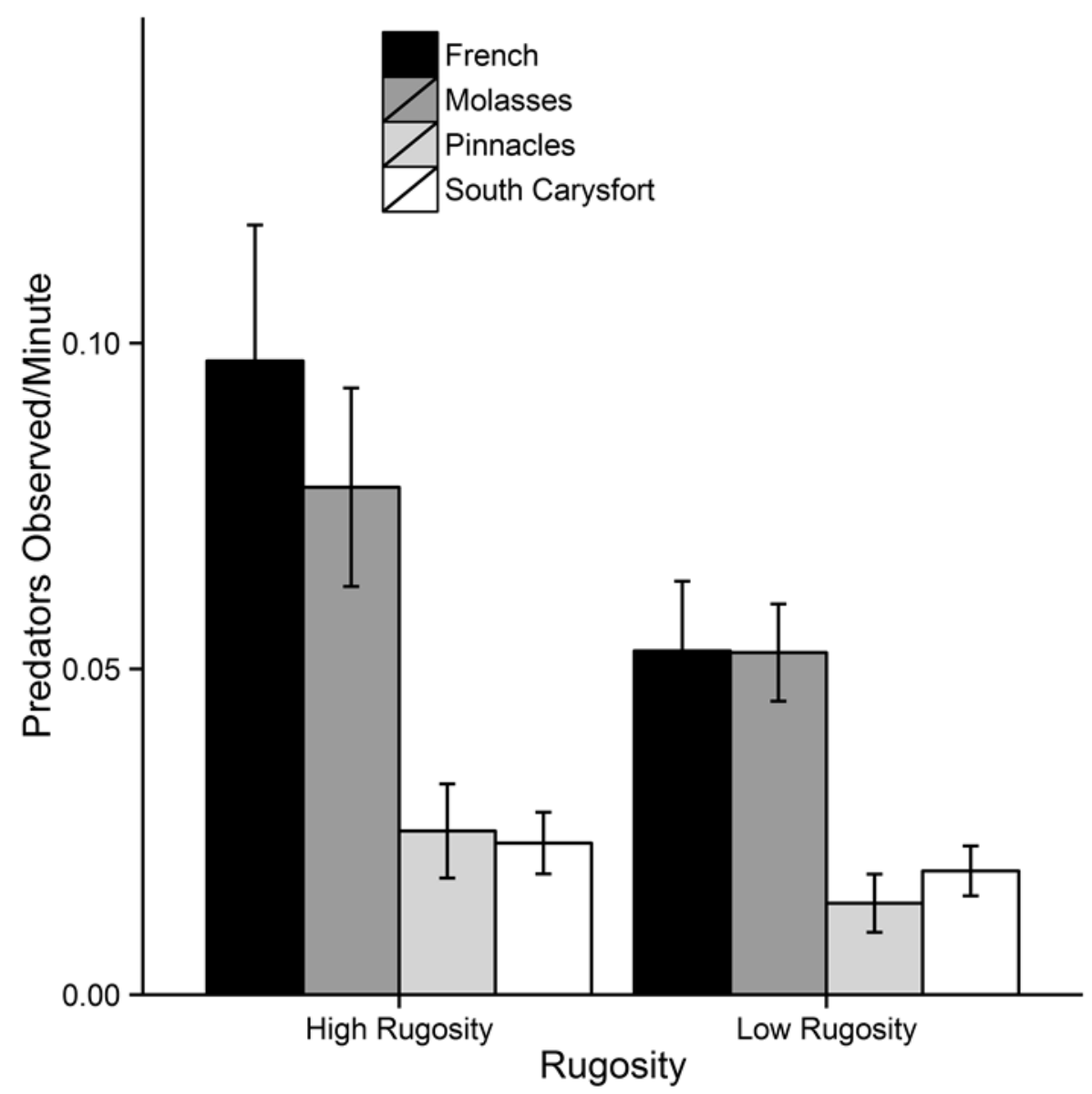




\section{CHAPTER V}

PREDATOR HUNTING MODE AND TIME OF DAY SHAPE THE RISK-REWARD TRADE-OFF IN FEEDING BEHAVIOR OF HERBIVOROUS FISHES ON A CORAL

REEF 
Abstract

The non-consumptive effects (NCEs) of predators occur as prey alter their habitat use and foraging decisions to avoid predation. The strength and importance of NCEs can vary depending on ecological context (e.g., light availability, predator hunting mode, prey condition, etc.), however in many ecosystems these contingencies are not well understood. In a coral reef ecosystem (Conch Reef, Florida Keys (USA)), we simulated predation risk using predator decoys (grouper or barracuda decoys) during three times of day to investigate how predator hunting mode (sit-and-wait vs. sit-and-pursue) affected foraging behavior of herbivorous fish within a temporally explicit context. We measured how herbivory changed with increasing distance from the decoys to examine how herbivorous fishes reconcile the conflicting demands of avoiding predation vs. foraging during different times of day (dawn, mid-day and dusk). We found that the threat of predation reduced herbivore foraging which intensified with prey hunger level (i.e., during dawn). Furthermore, we found that predator identity altered threat-sensitive responses of herbivores, with more threatening predators evoking greater responses in prey. Our work elucidates context-dependent causal linkages between predation risk, herbivore foraging behavior and resource consumption. Understanding the role of various contingencies in mediating NCEs provides greater insight into the emergent effects of predator-prey interactions on food webs. This knowledge will be important for interpreting how anthropogenic driven changes to coral reef ecosystems such as overfishing will affect coral reefs in the decades to come. 
Introduction

Foragers must often balance conflicting needs such as obtaining food and avoiding predation. The resolution of these decisions comes in the form of trade-offs, where foragers forgo highly profitable feeding opportunities in order to stay safe (Lima and Dill 1990, Werner and Anholt 1993). Predators can have important influences on ecological communities via these sub-lethal or non-consumptive effects (NCEs) (Schmitz et al. 1997, Heithaus \& Dill 2002, Preisser et al. 2005, Ripple \& Beschta 2007). Yet, the risk that a prey species will tolerate often depends on ecological context (e.g., physical environment, predator attributes and prey state), thereby altering the outcome of NCEs. Thus, to gain a more complete understanding of the strength and importance of NCEs in ecological systems it is important to identify sources of contingency in predator-prey interactions.

Prey must evaluate multiple factors to assess risk and make anti-predator decisions (Liley and Creel 2007, Creel 2011). Attributes of predators (e.g., hunting mode), physical environment (e.g., light availability, habitat complexity), and prey status (e.g., hunger state) can influence the magnitude of their responses. The different strategies that predators use to find and attack prey can elicit different kinds of antipredatory responses in prey. For instance, actively hunting predators, or 'coursing' predators, that rely on covering large areas to maximize contact with prey are often unpredictable in space and time and generate diffuse cues identifying their presence. Thus, prey are less likely to engage in energetically expensive avoidance behaviors for these active predators (Lima and Bednekoff 1999). Other predators utilize a "sit-andwait" or "sit-and-pursue" strategy which involves remaining in a fixed location until a 
prey is within striking or pursuit distance, respectively. Unlike more active strategies, these more patient hunting modes provide more predictable and persistent point source cues which are more likely to evoke behavioral responses in their prey (Schmitz 2007, Preisser et al. 2007). For example, in a South African game reserve, ungulates (e.g., impala, warthog, wildebeest) avoided activity areas of sit-and-pursue predators (lion and leopard) but not those of actively hunting species (cheetah and African wild dog) (Thaker et al. 2011). Most empirical work investigating anti-predatory behavior focuses on interactions of a single prey and predator species. However, in most natural systems prey must often evaluate relative predation risk from multiple predators simultaneously (Sih et al. 1998), suggesting that many studies may be underestimating the behavioral complexity of predator-prey relationships.

On a diel scale there are predictable changes in predator activity that prey anticipate and respond to with adaptive behaviors that minimize their risk (KronfeldSchor and Dayan 2003). Many predators possess physiological adaptations for visually detecting prey in low light conditions and primarily hunt during twilight periods. Diurnal prey, which may be well adapted for seeking out resources in daylight are at a disadvantage during dawn and dusk (Munz and McFarland 1973, Jacobs 1993, van Schaik and Griffiths 1996). Additionally, prey experience diel periodicity in physical state (e.g., hunger) that can affect their tolerance of risk. Hunger may drive prey to forage in potentially risky situations to avoid imminent starvation thereby decreasing the strength of NCEs (Heithaus et al. 2008). As a consequence, prey may exhibit seemingly maladaptive behaviors during high risk periods. For example, green turtles at risk from tiger sharks select profitable, high risk microhabitats when in poor body condition and 
safer, less profitable microhabitats when in good body condition (Heithaus et al. 2007). Therefore, to understand how organisms allocate risk-taking behaviors it is necessary to incorporate the influence of multiple factors including predator hunting mode, temporal periodicity in risk and prey physical state.

Coral reefs are high diversity, multi-predator systems that exhibit a predictable sequence of events during a diel cycle (Hobson 1972). Prey species (e.g., herbivores of the families Scaridae and Acanthuridae) encounter sit-and-wait (e.g, grouper), sit-andpursue (e.g., barracuda) and active, coursing predators (e.g., sharks and jacks), which likely necessitate different anti-predator strategies. Additionally, predator avoidance strategies often follow diel patterns because many reef predators hunt primarily at dawn and dusk when their attacks become more successful (Danilowicz and Sale 1999, Holbrook and Schmitt 2002). Despite recent work showing the importance of predation risk for determining foraging behavior on coral reefs (Madin et al. 2010b, Rizzari et al. 2014, Catano et al. 2014), no studies have investigated how prey respond to both diel patterns of risk and differences in predator hunting modes. Incorporating contextual variation in anti-predator responses provides a realistic level of understanding necessary to evaluate the role of NCEs on coral reefs.

Here, we investigated how predator hunting mode affects foraging behavior of herbivorous fish within a temporally explicit context on Conch Reef, Florida Keys (USA). In multiple controlled experiments, we used predator decoys of a black grouper (Mycteroperca bonaci) (a sit-and-wait predator) and great barracuda (Sphyraena barracuda) (a sit-and-pursue predator) to manipulate predation risk during three times of day: dawn, mid-day and dusk. We measured how herbivory changed with increasing 
distance from the decoys to examine how herbivorous fishes reconcile the conflicting demands of avoiding predation vs. foraging. We hypothesized that herbivory would decrease as predation risk increased (i.e., near predator decoys) and that herbivorous fishes would perceive low light conditions of twilight as riskier, resulting in even further suppressed herbivory. We expected both predator decoys to reduce foraging activities, however we expected the barracuda to have a greater effect at further distances from the decoy because of its sit-and-pursue hunting strategy.

Materials and Methods

Site Description

Conch Reef $\left(24^{\circ} 57^{\prime} \mathrm{N} / 80^{\circ} 27^{\prime} \mathrm{W}\right)$ lies in the Florida Keys reef tract which is a large bank reef system located approximately $8 \mathrm{~km}$ offshore of the Florida Keys, USA. Experiments were conducted in November 2013 during a 7-day saturation diving mission to the Aquarius Reef Base (ARB), a 43 × 20 x 16.5-foot undersea laboratory anchored at $19 \mathrm{~m}$ to the sea floor at Conch Reef. ARB is located within a "Research Only Area" of the Florida Keys National Marine Sanctuary (FKNMS) where all recreational use, including fishing and diving, is prohibited. The location is similar in benthic structure to other reefs of the Florida Keys and characterized by high relief spur and groove reef habitat. Experimental sites were spaced a minimum of $20 \mathrm{~m}$ apart and located at least 50 $\mathrm{m}$ from the ARB habitat at depths of 15-18 $\mathrm{m}$.

Experimental Design

We used $\approx 90 \mathrm{~cm}$ fiberglass models of two predators, black grouper (Mycteroperca bonaci) (Fig. 5.1a) and great barracuda (Sphyraena barracuda) (Fig. 
5.1b), to simulate risk during three time periods: dawn $(07: 00 \mathrm{~h})$, mid-day $(12: 00 \mathrm{~h})$ and dusk $(16: 30 \mathrm{~h})$. The decoys were anchored to the seafloor using nails and monofilament and feeding responses of herbivorous fishes were evaluated using standardized assays of a palatable seagrass (Thalassia testudinum). Assays consisted of five seagrass blades that were each cut to $10 \mathrm{~cm}$, scraped free of epiphytes, and clipped to wooden clothespins (Fig. 5.1b). Assays were then secured to the seafloor at 0.5, 1, 2, 3, and $4 \mathrm{~m}$ from either predator decoys or control areas of reef with no decoys. Assays and decoys were collected after two hours of deployment, and we determined the percentage of seagrass removed over the course of the trial by measuring the length of each remaining blade. At each time period (i.e., dawn, mid-day and dusk) fish feeding responses to a control, barracuda decoy, and grouper decoy were tested over the course of six days resulting in $\mathrm{n}=6$ replicates of each treatment at each time period. We rotated the control and decoys among sites so that the same predator treatment was used only once at a single site for each day.

In prior experiments, a decoy control (a large plastic carboy of similar dimensions to the predator decoy) did not affect fish foraging behavior while the grouper decoy significantly affected foraging behavior. Thus, fishes responded to the decoys because of the threat of predation, not simply because they were a novel object in the water column (L. Catano, unpubl. data). We did not include decoy controls since our previous work clearly showed that the responses of prey fishes to the predator decoy were due to the decoy looking like a predatory fish.

Many parrotfish species (mostly Sparisoma spp.) readily consume T. testudinum, however, it is rarely eaten by surgeonfishes or juvenile parrotfish. Therefore, to 
understand how predator treatments could differentially affect herbivore species and size classes, we used video to record feeding on the assays and on the benthos on approximately half of all trials (3/time period/predator treatment). To capture the responses of the suite of herbivorous fishes, we counted bites from all herbivorous fishes on the benthos that were within a $25 \mathrm{~cm}$ radius of the seagrass assay in addition to counting the bites taken on seagrass. We estimated the sizes of fishes using markers of known length located in the field of view.

Changes in ambient predator abundance across time periods could also alter levels of background predation risk (i.e., chronic risk integrated over time or space) and impact herbivore feeding behavior. Therefore, we estimated background predation risk by counting piscivorous fishes of the families Carangidae, Lutjanidae, Serranidae and Sphyraenidae that are known to consume adult parrotfishes and surgeonfishes (based on Randall 1967) that passed through the video frame. We then calculated the number of predators observed per hour of observation.

\section{Statistical Methods}

All statistical analyses were conducted using R version 3.0.1. Parametric assumptions of normality and homoscedasticity were verified using plots of the residuals. Individual feeding rates were square-root transformed to improve homogeneity of variance. We examined the effect of predator treatment (i.e., grouper decoy, barracuda decoy, or control), time period (i.e., dawn, mid-day, or dusk), and their interaction using ANOVA on the following four feeding metrics: (1) percent seagrass consumed per hour, (2) bites per hour on seagrass or benthos, (3) forager size, and (4) individual feeding rates 
(bites/second). For forager size, we aggregated data for each camera and calculated the mean size of all individuals observed to reduce pseudoreplicating by counting the same fishes multiple times. For all of the above analyses we pooled all distances to understand the overall effect of the decoys vs. the control. We then used pairwise t-tests with Bonferroni adjustment to evaluate significance in contrasts among predator treatments and/or time periods. Next, to understand how foraging changed with distance from the predator decoys, we used analysis of covariance (ANCOVA) to examine the effect of distance on the four foraging metrics for each predator decoy separately.

To understand how uncontrolled factors, such as herbivore community composition and background levels of predation risk, could influence foraging we examined their variation among treatment levels. We used non-metric multidimensional scaling (NMDS) using a Bray-Curtis dissimilarity matrix followed by an envfit procedure in the vegan package of $\mathrm{R}$ to examine differences in forager community composition across predator and time treatments and with distance from the decoys. To understand diel variation in background levels of risk we used analysis of variance (ANOVA) to test differences in predators observed per hour among time periods (i.e., dawn, mid-day and dusk).

Results

All of the bites on the seagrass were taken by Sparisoma aurofrenatum. The majority of bites on the benthos were taken by S. aurofrenatum (56\%), followed by Acanthurus coeruleus (14\%), Scarus taeniopterus (12\%), Acanthurus bahianus (8\%) and Scarus iserti (6\%). Overall, there was a significant effect of predator treatment and time 
period on the percentage of seagrass consumed with no interaction (Table 5.1, Fig. 5.2a). Pairwise comparisons among predator treatments showed a significant decline in seagrass consumed in the barracuda treatment relative to the control $(\mathrm{p}=0.02)$, a marginal decline in seagrass consumption in the grouper treatment relative to the control $(p=0.06)$, but no difference between predator decoys $(\mathrm{p}=0.59)$. The greatest amount of seagrass consumed occurred during the dawn period declining at mid-day and again at dusk. All pairwise comparisons between time periods showed statistically significant differences. There was a significant effect of predator treatment on total bites per hour based on video observations, with no effect of time period or an interaction (Table 5.1, Fig. 5.2b). Pairwise comparisons showed that fishes took fewer bites when the barracuda decoy was present relative to the control $(\mathrm{p}=0.03)$, but no difference for the grouper decoy vs. the control $(p=0.83)$ and no difference between predator decoys $(p=0.24)$. In terms of individual feeding rates, there was an effect of predator treatment but not time period with no significant interaction (Table 5.1, Fig. 5.2c). Individual fishes bit the food source faster near both the grouper $(p=0.002)$ and barracuda $(p=0.04)$ decoys relative to the control. Finally, in terms of forager size, there was an effect of time period but not predator treatment with a non-significant interaction term (Table 5.1, Fig. 5.2d). Based on pairwise comparisons among time periods, fishes were significantly smaller at mid-day ( $p$ $=0.03)$ and marginally smaller at dawn $(\mathrm{p}=0.10)$ relative to dusk. Fishes were not significantly different in size between dawn and mid-day $(\mathrm{p}=1.0)$ (Fig. 5.3).

In ANCOVA models we found an influence of distance from predator decoys for some foraging metrics that varied with time period (Table 5.2). For the grouper decoy, the percent of seagrass consumed increased with increasing distance with a marginally 
significant interaction between distance and time period $\left(\mathrm{R}^{2}=0.24, \mathrm{~F}_{5,84}=6.59, \mathrm{p}<\right.$ 0.001). The change in percent seagrass consumed with distance was greater for the dawn $($ slope $=8.28)$ and mid-day $($ slope $=6.30)$ periods relative to dusk $($ slope $=1.62)($ Fig. 5.4a). For the barracuda decoy, the percent seagrass consumed also increased with distance with a significant interaction (Fig. $5.4 \mathrm{~b}, \mathrm{R}^{2}=0.29, \mathrm{~F}_{5,84}=8.19, \mathrm{p}<0.001$ ). The change in percent seagrass consumed with distance was greater for dawn (slope $=9.25$ ) relative to both mid-day (slope $=2.82)$ and dusk $($ slope $=3.52)$.

The total number of bites per hour increased with distance for the grouper decoy similarly for all time periods (i.e., there were no significant interaction terms) (Fig. 5.4c, $\mathrm{R}^{2}=0.14, \mathrm{~F}_{3,24}=2.50, \mathrm{p}=0.08$ ). Likewise, for the barracuda decoy, bites increased with distance similarly for all time periods (Fig. $5.4 \mathrm{~d}, \mathrm{R}^{2}=0.36, \mathrm{~F}_{3,31}=7.38, \mathrm{p}<0.001$ ). However, there was also an effect of time of day for the barracuda decoy, with overall more bites at dawn relative to mid-day $(\mathrm{p}=0.04)$ or dusk $(\mathrm{p}=0.03)$.

There was no effect of distance or time period on individual feeding rates for either predator decoy (Table 5.2, Fig. 5.4e\&f). For the grouper decoy, fish size increased with increasing distance, but was unaffected by time period with no interaction (Fig. $\left.5.4 \mathrm{~g}, \mathrm{R}^{2}=0.27, \mathrm{~F}={ }_{5,19}=2.79, \mathrm{p}=0.05\right)$. For the barracuda decoy, fish size was unaffected by distance or time period (Fig. 5.4h).

The species composition of fishes did not vary with distance from decoys ( $\mathrm{p}=$ $0.58)$ or among predator treatments $(\mathrm{p}=0.87)$ or time periods $(\mathrm{p}=0.07)$ (Fig.5.5) suggesting that the differences we show in overall consumption and feeding rate were not related to differences in the species of herbivore present across treatments or times. There was a significant effect of time period on the number of predators observed per hour (Fig. 
5.6, $\left.\mathrm{F}_{2,77}=14.48, \mathrm{p}<0.001\right)$. Significantly more predators were observed during dusk than dawn $(\mathrm{p}<0.001)$ or mid-day $(\mathrm{p}<0.001)$ and there was no difference between dawn and mid-day $(\mathrm{p}=0.98)$.

\section{Discussion}

The role of predators in affecting the foraging behavior of their prey is increasingly being recognized as an important structural force in coral reef communities (Madin et al. 2010b, 2010a, Rizzari et al. 2014, Catano et al. 2014). However, these studies do not incorporate many important contingencies that can have strong effects on the predator-prey interaction (e.g. Preisser et al. 2007). For instance, anti-predator decisions often vary depending on attributes of predator, prey, and their physical environment (Liley and Creel 2007, Creel 2011). Our work shows that herbivorous fishes exhibited a threat-sensitive response by decreasing foraging near predatory fish decoys. Importantly, herbivores not only responded to general level of risk but they also respond differently to different types of predators. The grouper and barracuda decoys had differential effects on multiple feeding metrics with the latter eliciting stronger effects, likely because of their more active hunting strategies. We also showed that predation risk had the least effect on herbivorous fish foraging at dawn but the greatest effect at dusk, despite low light availability at both times of day. Thus, herbivores appeared more likely to forage in riskier areas when they are hungry (dawn) vs. when they are not (dusk). These data support the idea that prey often exhibit state-dependent risk taking, foraging in risky situations in times of increased hunger (Heithaus et al. 2008). Thus, herbivorous 
fishes on coral reefs show complex responses to acute predation risk that is shaped by predator identity, light availability, and hunger level.

We demonstrate that when faced with the conflicting demands of obtaining resources and avoiding predation herbivorous fish make a trade-off, forgoing profitable feeding opportunities in order to stay safe. Our data support the threat-sensitive avoidance hypothesis which predicts that prey should match the intensity of their antipredator response to the level of predation risk they experience (Helfman 1989). Greater threats (i.e., closer proximities to decoys) evoked greater responses from fishes with fewer bites and overall less seagrass consumption. The predator decoys clearly influenced the decision to feed, however for those individuals that accepted the risk, the decoys also affected how they consumed food. Individual feeding rates were greater when the decoys were present relative to the control, suggesting that fishes were attempting to minimize the time they spent exposed to risk while still obtaining reward. Similarly, Rizzari et al. (2014) concluded herbivorous reef fish demonstrated a threat sensitive response by reducing macroalgal consumption in the presence of a predator decoy. Our study furthers this conclusion by testing herbivore responses along a gradient of risk (i.e., at different distances from decoys). In doing so we demonstrate that herbivores perceive and respond not only to the presence of risk, but also to the magnitude of that risk.

By altering prey behavior, predators can have indirect effects on prey resource distribution and abundance resulting in a behaviorally-mediated trophic cascade (Dill et al. 2003). Evidence from theoretical and empirical studies suggests that via behaviorallymediated pathways predators can have dramatic influences on plant communities (Schmitz et al. 1997, Heithaus and Dill 2002, Werner and Peacor 2003, Creel et al. 2005, 
Stallings 2008, Gervasi et al. 2013), however work in coral reef ecosystems is limited (Madin et al. 2010a, Rizzari et al. 2014). Herbivorous fish play a crucial role in the functioning of reef ecosystems because by grazing algae they help maintain reefs in a state of coral dominance (Mumby et al. 2006, Hughes et al. 2007). Our work suggests that by altering patterns of herbivory, predators could play an important role in the functioning of coral reef ecosystems via behaviorally mediated trophic cascades. Predators may function to concentrate herbivory in areas of low risk. Spatially constrained grazing is more likely to lead to increases in coral recruitment and coral cover relative areas where the same amount of grazing is more disperse (Sandin and McNamara 2012). When predators are rare, herbivory may be diluted on a reef-wide scale thereby impeding algal removal and coral settlement.

Differences in the hunting mode of predators often elicit different anti-predator responses in prey (Preisser et al. 2007), which could affect the strength and importance of behaviorally mediated cascades. For example, in a grassland ecosystem, sit-and-wait spiders decreased grasshopper activity but did not change their habitat domain (i.e., the extent of spatial movement within a chosen microhabitat), whereas sit-and-pursue spiders reduced grasshopper activity and constricted their habitat domain (Miller et al. 2014). Thus, the more active predator had a greater impact on the spatial scale of their prey's movement. Although they are both important reef predators, black grouper and great barracuda have different hunting strategies and modes of attack. Groupers are opportunistic feeders (Randall 1967) that tend to forage during dawn and dusk to take advantage of low light conditions and decreased detectability by their prey (Koch 2011). They typically adopt a "sit-and-wait" strategy, lying in wait for prey until it is near 
enough to swallow using their large mouths and operculum as a vacuum (Thompson and Munro 1978). Barracuda forage diurnally and will either stalk or "sit-and-pursue" their prey, remaining at a fixed location and rushing to attack prey when they are within striking vicinity (de Sylva 1968). Barracuda have long striking distances, approximately equivalent to their body length (Porter and Motta 2004), and pursue prey at high velocities $(\approx 12.2 . \mathrm{m} / \mathrm{s})$ once an attack ensues (O'Toole et al. 2010$)$.

As we expected, both predator decoys elicited anti-predator responses in prey, however the barracuda decoy suppressed both overall bites taken and seagrass consumed more relative to the no-predator control than did the grouper decoy. Furthermore, the effect of the barracuda decoy extended over a greater distance from the decoy as the total number of bites and amount of seagrass consumed stayed relatively low at increasing distances from the decoy relative to the grouper model where consumption increased dramatically at the farther distances. Fishes may have been more hesitant to forage even at greater distances from the barracuda model because of their tendency to quickly pursue prey over longer distances. Barracuda likely represent a greater potential threat and result in stronger anti-predator responses, generating a wider "zone of fear". Thus, as demonstrated in terrestrial systems, multiple types of predators can reduce prey activity, but more active predators have a greater spatially-explicit impact because they alter the area over which these activities takes place (Miller et al. 2014).

Ultimately, predator identity and differential risk effects can alter the outcome of behaviorally-mediated trophic cascades. In a grassland ecosystem, sit-and-wait and active spider predators had differential effects on plant diversity, elemental cycling and production via their effect on grasshopper prey (Schmitz 2008a). Sit-and-wait spiders 
elicited chronic foraging shifts in grasshoppers that ultimately increased plant species diversity and reduced aboveground net primary production and nitrogen mineralization rate relative to actively hunting spiders, which had opposite effects. We show that the spatial impact of barracuda on prey foraging is wider than grouper, which could ultimately lead to strong cascading effects on benthic communities. However, the lack of empirical examples examining the effect of reef predators on benthic communities precludes any generalization of how predator diversity alters ecosystem function in coral reef systems. Predictive models suggest that dramatically different distributions of herbivore foraging intensity can result from changes in predator biomass, thereby altering the spatial heterogeneity of macroalgae (Madin et al. 2010a). However, this model and most other studies that have investigated the role of NCEs in reef communities, have quantified risk by aggregating all predators into a single biomass metric (Madin et al. 2010b, Catano et al. 2014). Our work argues for more emphasis on individual predator effects, particularly in systems with high predator functional diversity.

This could be an important yet unexplored area of research, particularly because selective fishing practices, which target economically important species, alter the composition of predatory species on reefs. For instance, in the Florida Keys large predatory fishes including snapper and grouper are heavily fished and often abundant only in marine reserves (Bohnsack et al. 1994), whereas barracuda are generally not targeted and are abundant in both fished and unfished areas. Thus, selective fishing practices and reserve implementation may have altered landscape patterns of risk in this region. Assessments of marine reserves that measure reserve success in terms of increases in density, biomass and body size of targeted fishes (e.g., Halpern and Warner 
2002, Halpern 2003) often overlook the importance of changes in predator functional diversity (Jennings et al. 1996). Understanding the variable effects of multiple predators with different hunting modes can provide a more nuanced and realistic view of predatorprey interactions and greater insight into their emergent effects on food webs.

In addition to the differential effects of predators, prey often must deal with diel variability in predation risk. Crepuscular periods are often more risky for diurnal species due to increased predator activity and lower light levels that make predator detection more difficult (Hobson 1972, Danilowicz and Sale 1999, Holbrook and Schmitt 2002). We found that reef herbivores exhibit diel changes in risk taking behavior likely influenced by changes in light availability and their hunger level. We found from video footage that predator activity increased roughly $300 \%$ at dusk relative to mid-day and dawn. Although we may not have deployed our cameras early enough to capture peak predator movement in our dawn trials, the large peak in predator observations at dusk suggests this is the peak time of predator activity. Coinciding with the peak in background predation risk at dusk, we found a dramatic overall decline in herbivore foraging based on the seagrass consumed and an increase in the number of large herbivorous fish $(>25 \mathrm{~cm})$, which are likely less predator-prone.

During dusk, diurnal reef herbivores are likely both more wary of predators and more satiated, given a day's worth of feeding, relative to other time periods making them less willing to expose themselves to risky situations. However, at dawn these same species may be willing to forage in areas of higher risk because their guts are nearly completely evacuated after remaining dormant through the night (Polunin et al. 1995). High hunger levels in the morning likely explain why fishes removed more seagrass at 
closer distances to both predator decoys, as opposed to dusk when feeding remained low at all distances. Additionally, for the barracuda decoy, feeding remained low at all distances at mid-day as well. This further supports the idea that herbivores are more willing to trade-off food for safety when satiated, particularly for predators with a wider zone of fear. Over longer temporal scales, chronic hunger can result in greater risk-taking behavior. For instance, in a seagrass ecosystem, green sea turtles (Chelonia mydas) in poor body condition were more likely to forage in highly profitable risky habitats, whereas those in good body condition chose low-risk, less profitable habitats (Heithaus et al. 2007). Our work suggests that this result may be more pervasive than suspected because acute changes in prey hunger level (i.e., experienced over the course of a single day) resulted in dramatic changes in risk-taking behavior. Thus, it is important to consider the settings in which individuals make foraging decisions because risk-taking behavior may be more or less pronounced depending on prey condition.

Evidence from multiple ecosystems has demonstrated that top predators clearly have an important functional role by consuming their prey and by influencing prey behavior (Estes et al. 2011). To understand the strength and magnitude of predator effects in communities it is necessary to test prey responses across the variability inherent in natural systems. In terrestrial systems, considerable evidence supports the importance of various contingencies in influencing the magnitude of risk effects (Schmitz 2008a, Valeix et al. 2009, Kauffman et al. 2010, Thaker et al. 2011), however in marine systems these contingencies are understudied, but likely just as important. For instance, on coral reefs, greater habitat structure heightened the anti-predator behavior of herbivorous fishes (L. Catano, unpublished data). In lower complexity regions of the reef, where predators were 
less abundant and there were fewer potential impediments to escape, herbivores showed muted responses to predation risk. Thus, the context of reefscape influenced the importance of risk effects in a coral reef community. However, besides this evidence, there is a general lack of understanding about the contingencies that influence NCEs in these systems. The declines in predator abundance and alterations in predator composition that reef ecosystems have undergone in recent decades have fundamentally changed the nature of predator-prey interactions. Knowing how these changes will impact reef ecosystem processes requires an understanding of NCEs and the contexts that influence their strength. Incorporating NCEs into a predictive framework is imperative for understanding how these systems will respond to predator losses from overfishing and selective fishing practices and predator recovery through the establishment of marine reserves.

\section{Acknowledgments}

Funding for this work was provided by a NOAA Coral Reef Conservation Program grant to D.E.B. We are indebted to M. Heithaus, J. Fourqurean, A. Shantz, C. Lopez, M. Rojas, R. Malossi, A. Zenone, and C. Catano for their time and advice with this project. We thank the personnel of FIU's Aquarius Reef Base, Key Largo, FL, USA for their assistance facilitating this research. This work was conducted with permission from the Florida Keys National Marine Sanctuary under permit no. FKNMS-2013-141. 


\section{References Cited}

Bohnsack, J. A., D. E. Harper, and D. B. Mcclellan. 1994. Fisheries trends from Monroe County, Florida. Bulletin of Marine Science 54:982-1018.

Catano, L., A. Shantz, and D. Burkepile. 2014. Predation risk, competition, and territorial damselfishes as drivers of herbivore foraging on Caribbean coral reefs. Marine Ecology Progress Series 511:193-207.

Creel, S. 2011. Toward a predictive theory of risk effects: hypotheses for prey attributes and compensatory mortality. Ecology 92:2190-2195.

Creel, S., J. Winnie, B. Maxwell, K. Hamlin, and M. Creel. 2005. Elk Alter Habitat Selection As an Antipredator Response To Wolves. Ecology 86:3387-3397.

Danilowicz, B. S., and P. F. Sale. 1999. Relative intensity of predation on the French grunt, Haemulon favolineatum, during diurnal, dusk, and nocturnal periods on a coral reef. Marine Biology 133:337-343.

Dill, L., M. R. Heithaus, and C. Walters. 2003. Behaviorally mediated indirect interactions in marine communities and their conservation implications. Ecology 84:1151-1157.

Estes, J. a, J. Terborgh, J. S. Brashares, M. E. Power, J. Berger, W. J. Bond, S. R. Carpenter, T. E. Essington, R. D. Holt, J. B. C. Jackson, R. J. Marquis, L. Oksanen, T. Oksanen, R. T. Paine, E. K. Pikitch, W. J. Ripple, S. a Sandin, M. Scheffer, T. W. Schoener, J. B. Shurin, A. R. E. Sinclair, M. E. Soulé, R. Virtanen, and D. a Wardle. 2011. Trophic downgrading of planet Earth. Science (New York, N.Y.) 333:301-6.

Gervasi, V., H. Sand, B. Zimmermann, J. Mattisson, P. Wabakken, and J. D. C. Linnell. 2013. Decomposing risk: landscape structure and wolf behavior generate different predation patterns in two sympatric ungulates. Ecological applications : a publication of the Ecological Society of America 23:1722-34.

Halpern, B. S. 2003. The Impact of Marine Reserves : Do Reserves Work and Does Reserve Size Matter? Ecological Applications 13:S117-S137.

Halpern, B. S., and R. R. Warner. 2002. Marine reserves have rapid and lasting effects. Ecology Letters 5:361-366.

Heithaus, M. R., and L. Dill. 2002. Food availability and tiger shark predation risk influence bottlenose dolphin habitat use. Ecology 83:480-491.

Heithaus, M. R., A. Frid, A. J. Wirsing, L. M. Dill, J. W. Fourqurean, D. Burkholder, J. Thomson, and L. Bejder. 2007. State-dependent risk-taking by green sea turtles 
mediates top-down effects of tiger shark intimidation in a marine ecosystem. The Journal of animal ecology 76:837-44.

Heithaus, M. R., A. Frid, A. J. Wirsing, and B. Worm. 2008. Predicting ecological consequences of marine top predator declines. Trends in ecology \& evolution 23:202-10.

Helfman, G. S. 1989. Threat-sensitive predator avoidance in damselfish-trumpetfish interactions. Behavioral Ecology and Sociobiology 24:47-58.

Hobson, E. S. 1972. Feeding Patterns among Tropical Reef Fishes. American Scientist 63:381-392.

Holbrook, S. J., and R. J. Schmitt. 2002. Competition for shelter and space causes density-dependent predation mortality on damselfishes. Ecology 83:2855-2868.

Hughes, T. P., M. Rodrigues, D. R. Bellwood, D. M. Ceccarelli, O. Hoegh-Gudberg, L. J. Mccook, N. Moltschaniwskyj, M. Pratchett, R. S. Steneck, and B. Willis. 2007. Phase shifts, herbivory, and the resilience of coral reefs to climate change. Current Biology 17:360-365.

Jacobs, G. 1993. The distribution and nature of colour vision among the mammals. Biological Reviews 68:413-471.

Jennings, S., E. M. Grandcourt, and N. V. C. Polunin. 1996. The effects of fishing on the diversity, biomass and trophic structure of Seychelles' reef fish communities. Coral Reefs 14:225-235.

Kauffman, M. J., J. F. Brodie, and E. S. Jules. 2010. Are wolves saving Yellowstone's aspen? A landscape-level test of a behaviorally mediated trophic cascade. Ecology 91:2742-55.

Koch, V. 2011. The Spatial Ecology of Black Groupers ( Mycteroperca bonaci ) in the Upper Florida Keys. University of Miami Scholarly Repository.

Kronfeld-Schor, N., and T. Dayan. 2003. Partitioning of time as an ecological resource. Annual Review of Ecology, Evolution, and Systematics 34:153-181.

Liley, S., and S. Creel. 2007. What best explains vigilance in elk: characteristics of prey, predators, or the environment? Behavioral Ecology 19:245-254.

Lima, S. L., and P. a. Bednekoff. 1999. Temporal Variation in Danger Drives Antipredator Behavior: The Predation Risk Allocation Hypothesis. The American Naturalist 153:649-659. 
Lima, S. L., and L. M. Dill. 1990. Behavioral decisions made under the risk of predation: a review and prospectus. Canadian Journal of Zoology 68:619-640.

Madin, E. M. P., S. D. Gaines, J. S. Madin, and R. R. Warner. 2010a. Fishing indirectly structures macroalgal assemblages by altering herbivore behavior. The American Naturalist 176:785-801.

Madin, E. M. P., S. D. Gaines, and R. R. Warner. 2010b. Field evidence for pervasive indirect effects of fishing on prey foraging behavior. Ecology 91:3563-3571.

Miller, J. R. B., J. M. Ament, and O. J. Schmitz. 2014. Fear on the move: predator hunting mode predicts variation in prey mortality and plasticity in prey spatial response. The Journal of animal ecology 83:214-22.

Mumby, P. J., C. P. Dahlgren, A. R. Harborne, C. V Kappel, F. Micheli, D. R. Brumbaugh, K. E. Holmes, J. M. Mendes, K. Broad, J. N. Sanchirico, K. Buch, S. Box, R. W. Stoffle, and A. B. Gill. 2006. Fishing, trophic cascades, and the process of grazing on coral reefs. Science (New York, N.Y.) 311:98-101.

Munz, F. W., and W. N. McFarland. 1973. The significance of spectral position in the rhodopsins of tropical marine fishes. Vision research 13:1829-74.

O’Toole, A. C., K. J. Murchie, C. Pullen, K. C. Hanson, C. D. Suski, a. J. Danylchuk, and S. J. Cooke. 2010. Locomotory activity and depth distribution of adult great barracuda ( Sphyraena barracuda ) in Bahamian coastal habitats determined using acceleration and pressure biotelemetry transmitters. Marine and Freshwater Research 61:1446.

Polunin, N. V. C., M. Harmelin-Vivien, and R. Galzin. 1995. Contrasts in algal food processing among five herbivorous coral-reef fishes. Journal of Fish Biology $47: 455-465$.

Porter, H. T., and P. J. Motta. 2004. A comparison of strike and prey capture kinematics of three species of piscivorous fishes: Florida gar (Lepisosteus platyrhincus), redfin needlefish (Strongylura notata), and great barracuda (Sphyraena barracuda). Marine Biology 145:989-1000.

Preisser, E. L., D. I. Bolnick, and M. E. Benard. 2005. Scared to death? The effects of intimidation and consumption in predator-prey interactions. Ecology 86:501-509.

Preisser, E. L., J. L. Orrock, and O. J. Schmitz. 2007. Predator hunting mode and habitat domain alter nonconsumptive effects in predator-prey interactions. Ecology $88: 2744-51$. 
Randall, J. E. 1967. Food habits of reef fishes of the West Indies. Studies in Tropical Oceanography 5:655-847.

Ripple, W., and R. Beschta. 2007. Restoring Yellowstone's aspen with wolves. Biological Conservation 138:514-519.

Rizzari, J. R., A. J. Frisch, A. S. Hoey, and M. I. McCormick. 2014. Not worth the risk: apex predators suppress herbivory on coral reefs. Oikos:no-no.

Sandin, S. a, and D. E. McNamara. 2012. Spatial dynamics of benthic competition on coral reefs. Oecologia 168:1079-90.

Van Schaik, C., and M. Griffiths. 1996. Activity periods of Indonesian rain forest mammals. Biotropica 28:105-112.

Schmitz, O. 2007. Predator Diversity and Trophic Interactions. Ecology 88:2415-2426.

Schmitz, O. J. 2008. Effects of predator hunting mode on grassland ecosystem function. Science 319:952-954.

Schmitz, O. J., A. P. Beckerman, and K. M. O’Brien. 1997. Behaviorally mediated trophic cascades : Effects of predation risk on food web interactions. Ecology 78:1388-1399.

Sih, A., G. Englund, and D. Wooster. 1998. Emergent impacts of multiple predators on prey. Trends in ecology \& evolution 13:350-355.

Stallings, C. D. 2008. Indirect effects of an exploited predator on recruitment of coralreef fishes. Ecology 89:2090-2095.

De Sylva, D. 1968. Systematics and life history of the great barracuda Sphyraena barracuda (Walbaum). Toxicon 5:227-232.

Thaker, M., A. T. Vanak, C. R. Owen, M. B. Ogden, S. M. Niemann, and R. Slotow. 2011. Minimizing predation risk in a landscape of multiple predators: effects on the spatial distribution of African ungulates. Ecology 92:398-407.

Thompson, R., and J. L. Munro. 1978. Aspects of the biology and ecology of Caribbean reef fishes : Serranidae (hinds and groupers). Journal of Fish Biology 12:115-146.

Valeix, M., A. J. Loveridge, S. Chamaillé-Jammes, Z. Davidson, F. Murindagomo, H. Fritz, and D. W. Macdonald. 2009. Behavioral adjustments of African herbivores to predation risk by lions: spatiotemporal variations influence habitat use. Ecology 90:23-30. 
Werner, E. E., and B. R. Anholt. 1993. Ecological consequences of the trade-off between growth and mortality rates mediated by foraging activity. The American Nautralist 142:242-272.

Werner, E. E., and S. D. Peacor. 2003. A Review of Trait-Mediated Indirect Interactions in Ecological Communities. Ecology 84:1083-1100. 
Table 5.1 - Summary of two-way ANOVAs testing for effects of predator treatment (i.e., barracuda decoy, grouper decoy or control), time period (i.e., dawn, mid-day or dusk) and their interaction on the percentage of seagrass consumed, the total bites on seagrass or benthos, individual feeding rates and forager size.

\begin{tabular}{|c|c|c|c|c|c|c|c|c|}
\hline & \multicolumn{2}{|c|}{ \% Seagrass Consumed } & \multicolumn{2}{|c|}{ Total Bites } & \multicolumn{2}{|c|}{ Feeding Rates } & \multicolumn{2}{|c|}{ Forager Size } \\
\hline & $\mathbf{F}$ & $\mathbf{p}$ & $\mathbf{F}$ & $\mathbf{p}$ & $\mathbf{F}$ & $\mathbf{p}$ & $\mathbf{F}$ & $\mathbf{p}$ \\
\hline Predator & 4.29 & 0.01 & 3.41 & 0.04 & 5.94 & 0.002 & 3.8 & 0.89 \\
\hline Time Period & 16.15 & $<0.001$ & 2.02 & 0.14 & 2.01 & 0.14 & 3.08 & 0.03 \\
\hline Predator $x$ Time Period & 1.32 & 0.26 & 0.57 & 0.68 & 2.77 & 0.55 & 1.93 & 0.54 \\
\hline
\end{tabular}


Table 5.2 - Summary of ANCOVAs testing for effects of distance among three time periods (i.e., dawn, mid-day or dusk), and their interaction for two predator treatments (i.e., barracuda decoy, grouper decoy) on the percentage of seagrass consumed, the total bites on seagrass or benthos, individual feeding rates and forager size.

\begin{tabular}{|c|c|c|c|c|c|c|c|c|c|}
\hline & & \multicolumn{2}{|c|}{ \% Seagrass Consumed } & \multicolumn{2}{|c|}{ Total Bites } & \multicolumn{2}{|c|}{ Feeding Rates } & \multicolumn{2}{|c|}{ Forager Size } \\
\hline & & $\mathbf{F}$ & $\mathbf{p}$ & $\mathbf{F}$ & $\mathbf{p}$ & $\mathbf{F}$ & $\mathbf{p}$ & $\mathbf{F}$ & $\mathbf{p}$ \\
\hline \multirow[t]{3}{*}{ (a) Grouper } & Distance & 17.95 & $<0.001$ & 4.51 & 0.05 & 1.51 & 0.22 & 6.49 & 0.02 \\
\hline & Time Period & 5.10 & 0.008 & 1.29 & 0.30 & 2.48 & 0.09 & 1.33 & 0.29 \\
\hline & $\begin{array}{l}\text { Distance x Time } \\
\text { Period }\end{array}$ & 2.40 & 0.09 & 0.32 & 0.73 & 0.05 & 0.95 & 2.41 & 0.12 \\
\hline \multirow[t]{3}{*}{ (b) Barracuda } & Distance & 19.85 & $<0.001$ & 12.65 & 0.001 & 3.56 & 0.06 & 0.00 & 0.99 \\
\hline & Time Period & 7.51 & $<0.001$ & 4.96 & 0.01 & 0.32 & 0.72 & 1.28 & 0.30 \\
\hline & $\begin{array}{l}\text { Distance } x \text { Time } \\
\text { Period }\end{array}$ & 3.04 & 0.05 & 1.31 & 0.29 & 2.15 & 0.12 & 0.12 & 0.89 \\
\hline
\end{tabular}


Figure 5.1 - (a) Predator decoys of a black grouper (Mycteroperca bonaci) and (b) a great barracuda (Sphyraena barracuda) anchored to the seafloor with a standardized assay of Thalassia testudinum in the foreground.
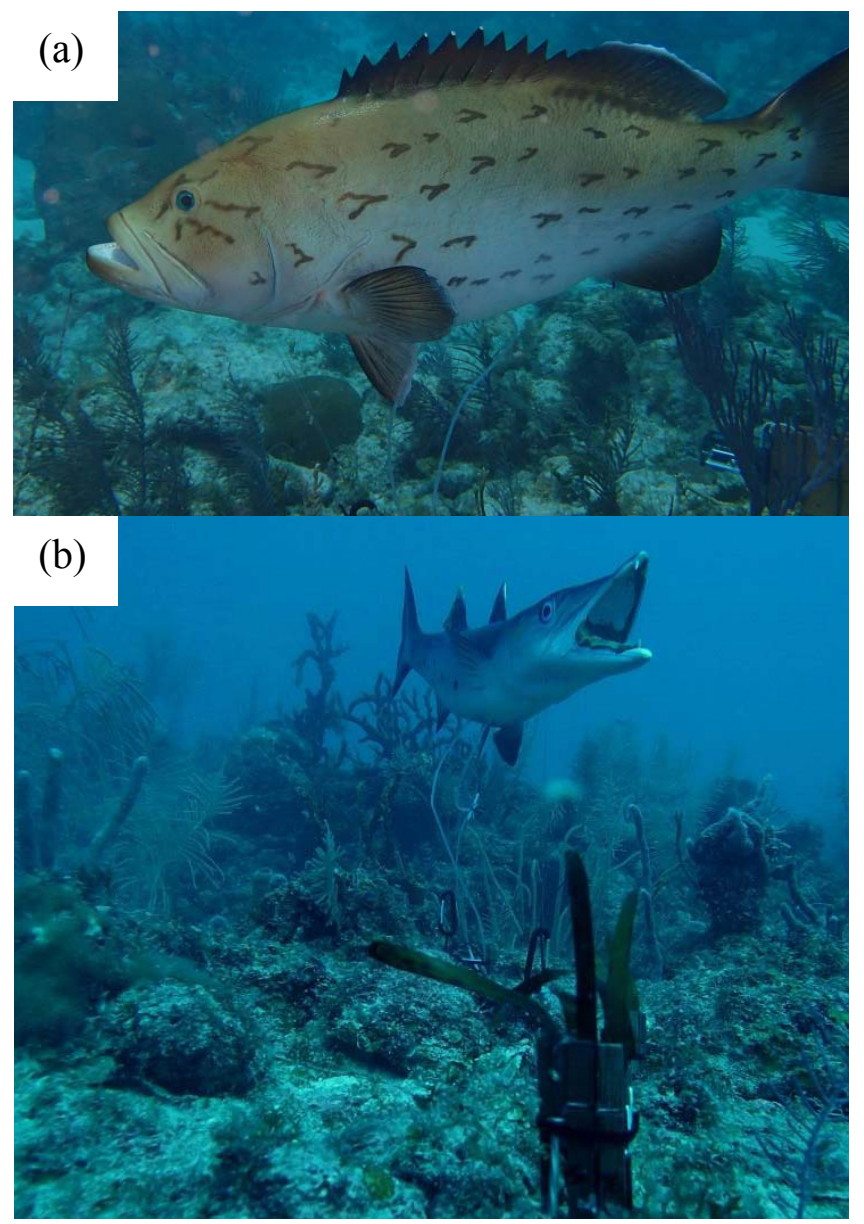
Figure 5.2 - Mean $\pm \mathrm{SE}$ (a) percent seagrass consumed/hour, (b) total bites/hour, (c) individual feeding rates (bites/second) (square-root transformed) and (d) forager sizes amoung predator treatments (i.e., barracuda decoy, grouper decoy and control) and time periods (i.e., dawn, mid-day and dusk). Results of two way ANOVAs testing for the effects of predator and time period and their interaction $(\mathrm{P} \times \mathrm{T})$ on each feeding metric are indicated on each panel.
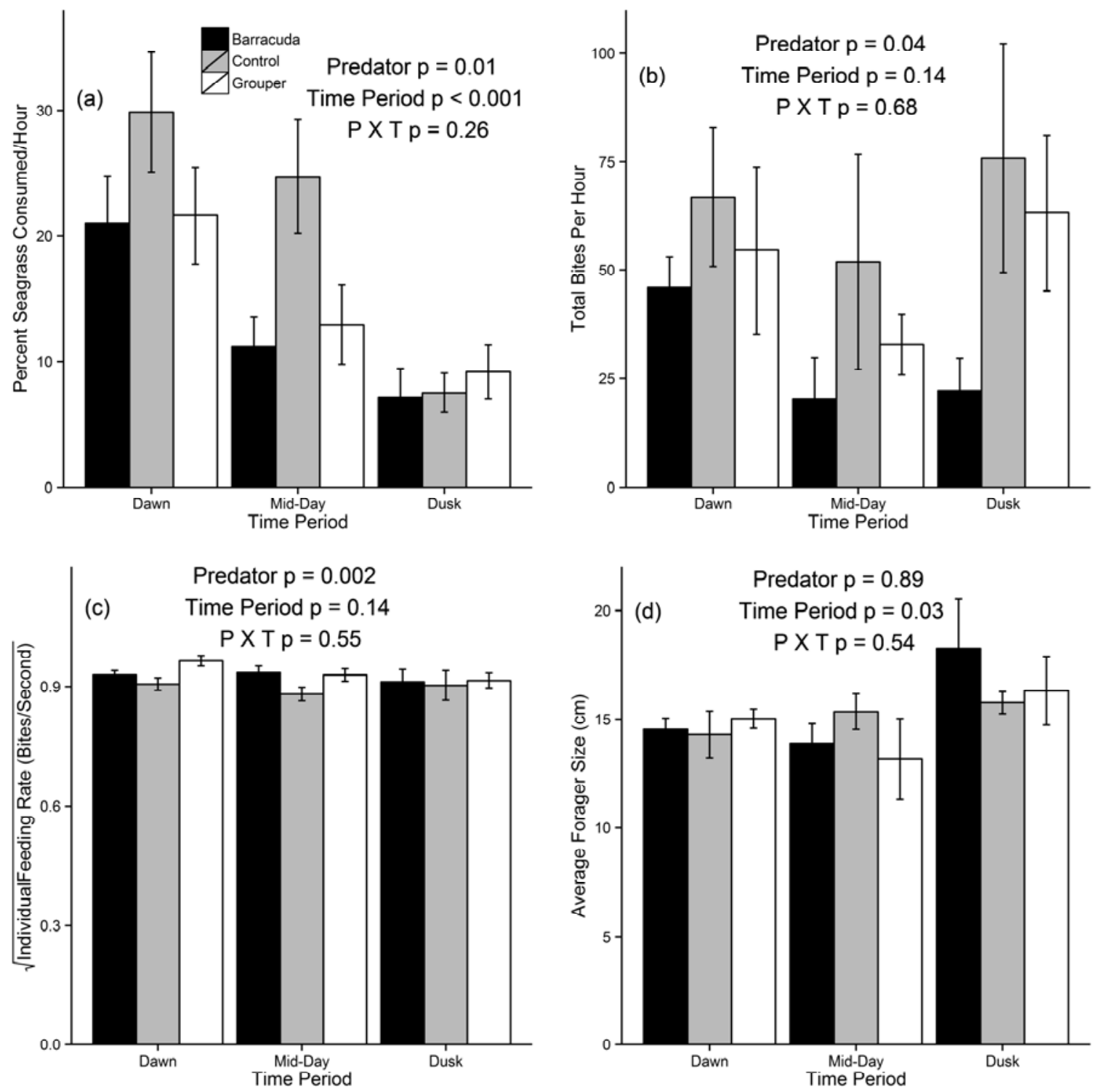
Figure 5.3 - Histograms of average forager size from predator decoy trials at dawn, midday and dusk.

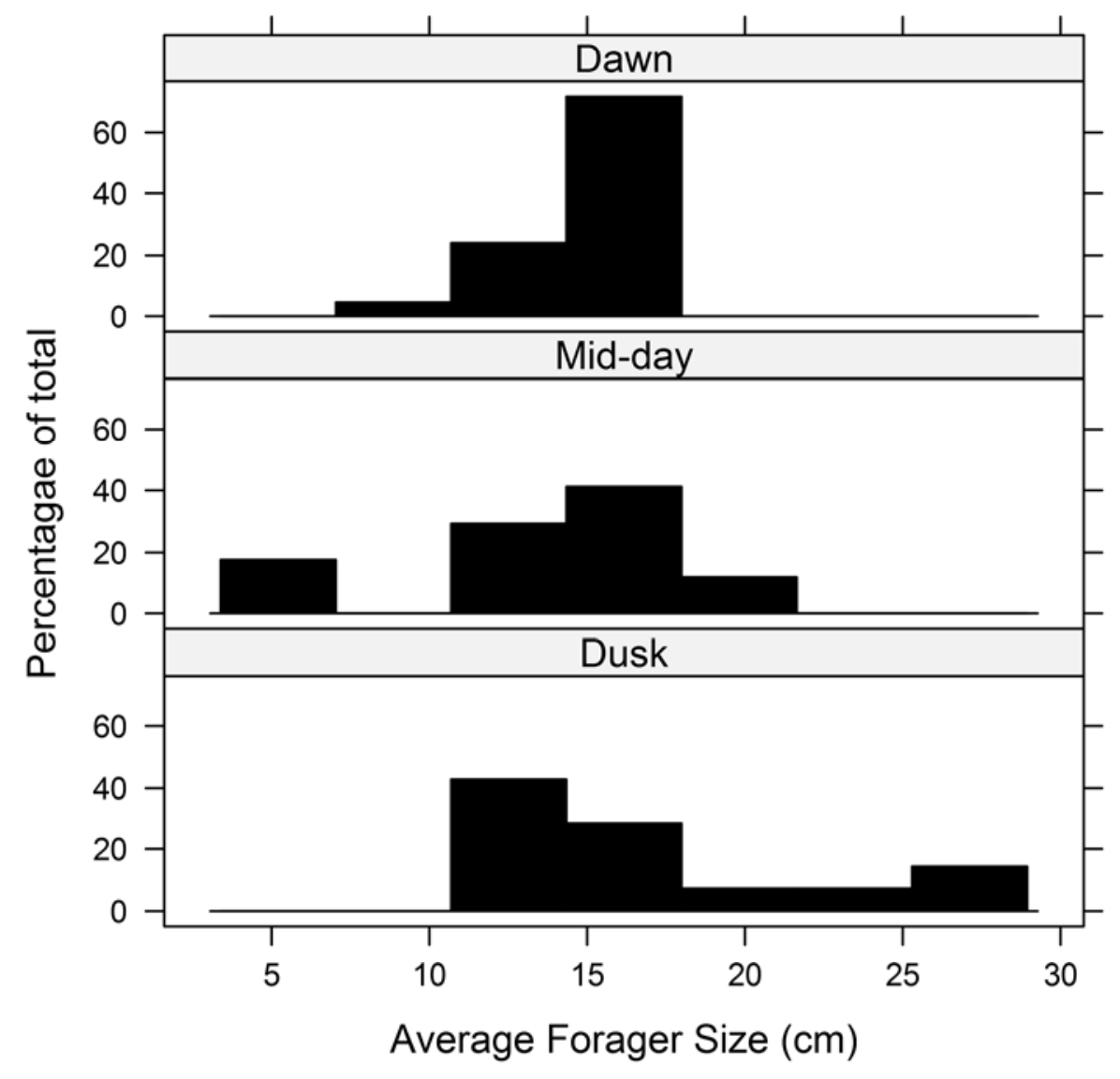


Figure $5.4-(a-b)$ The percent segrass consumed per hour, (c-d) total bites per hour and (e-f) forager size for grouper and barracuda treatments with increasing distance decoys. Solid lines represent fitted linear regressions for three time periods: dawn, mid-day and dusk.
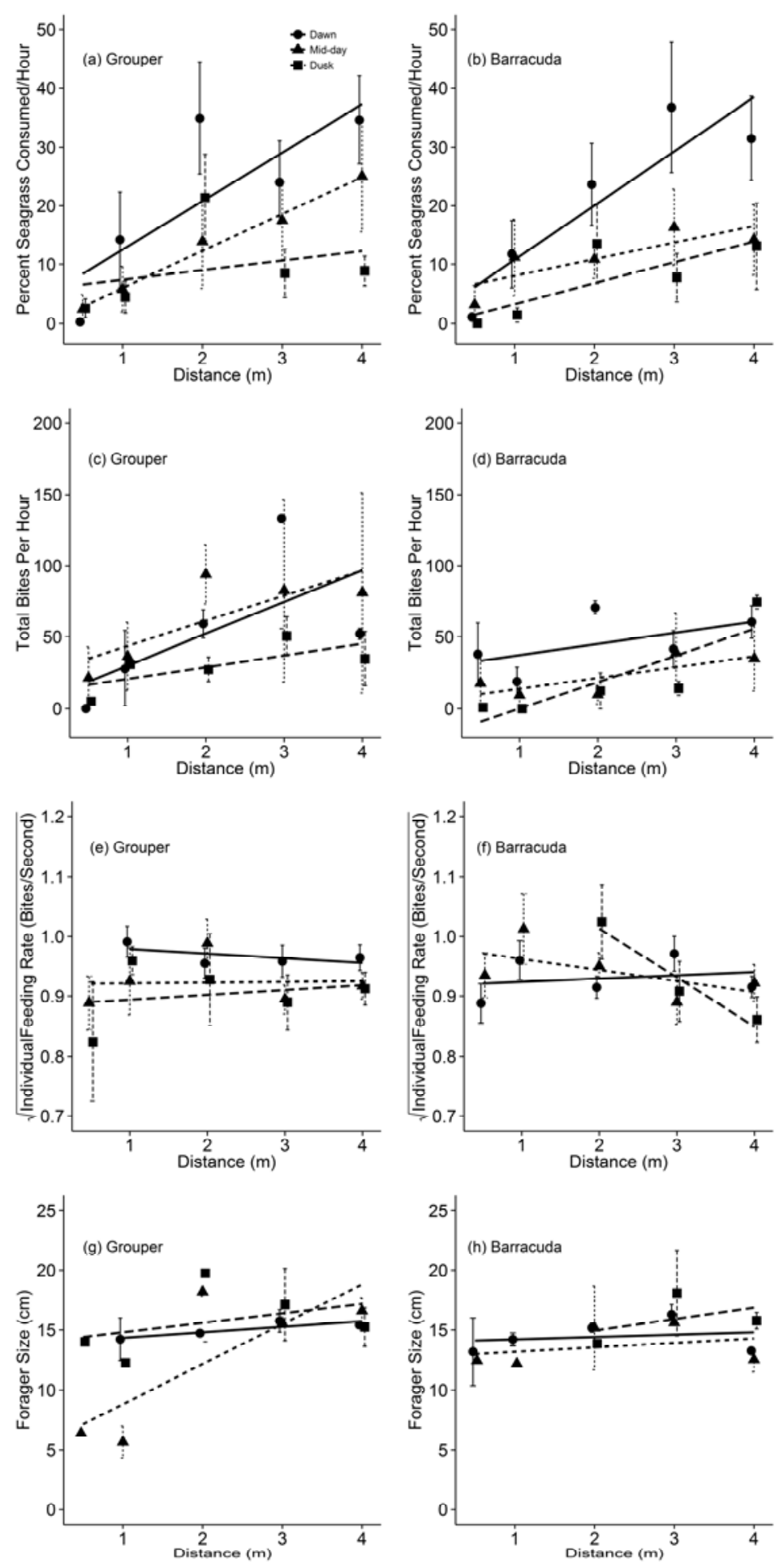
Figure 5.5 - Plot of the nonmetric multidimensional scaling (NMDS) scores for the two most important axes for species abundance of herbivorous fishes. The red, black and green minimim convex polygons surround the barracuda, control and grouper treatments, respectively. Squares, triangles and diamonds represent dawn, dusk and mid-day treatments, respectively. Species abbreviations are as follows: SA: S. aurofrenatum, AB: A. bahianus, SV: S. viride, AC: A. coeruleus, SI: Sc. iserti, ST: Sc. taeniopterus, and $\mathrm{ScV}$ : Sc. vetula. Stress $=0.13$.

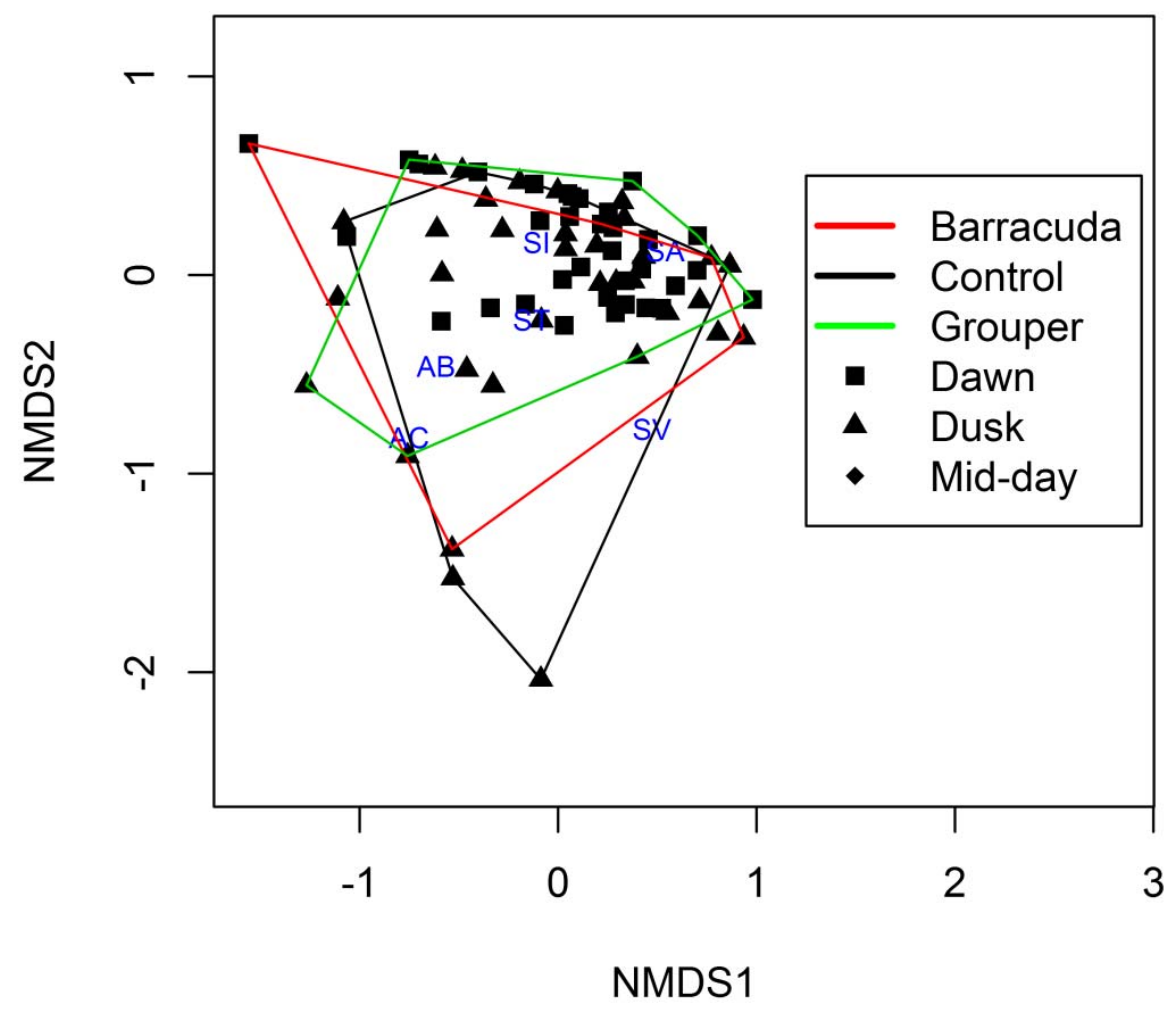


Figure 5.6 - Mean $\pm \mathrm{SE}$ of the number of predators observed per hour among dawn, midday and dusk periods. Letters above bars indicate significance based on a Tukey HSD post hoc test.

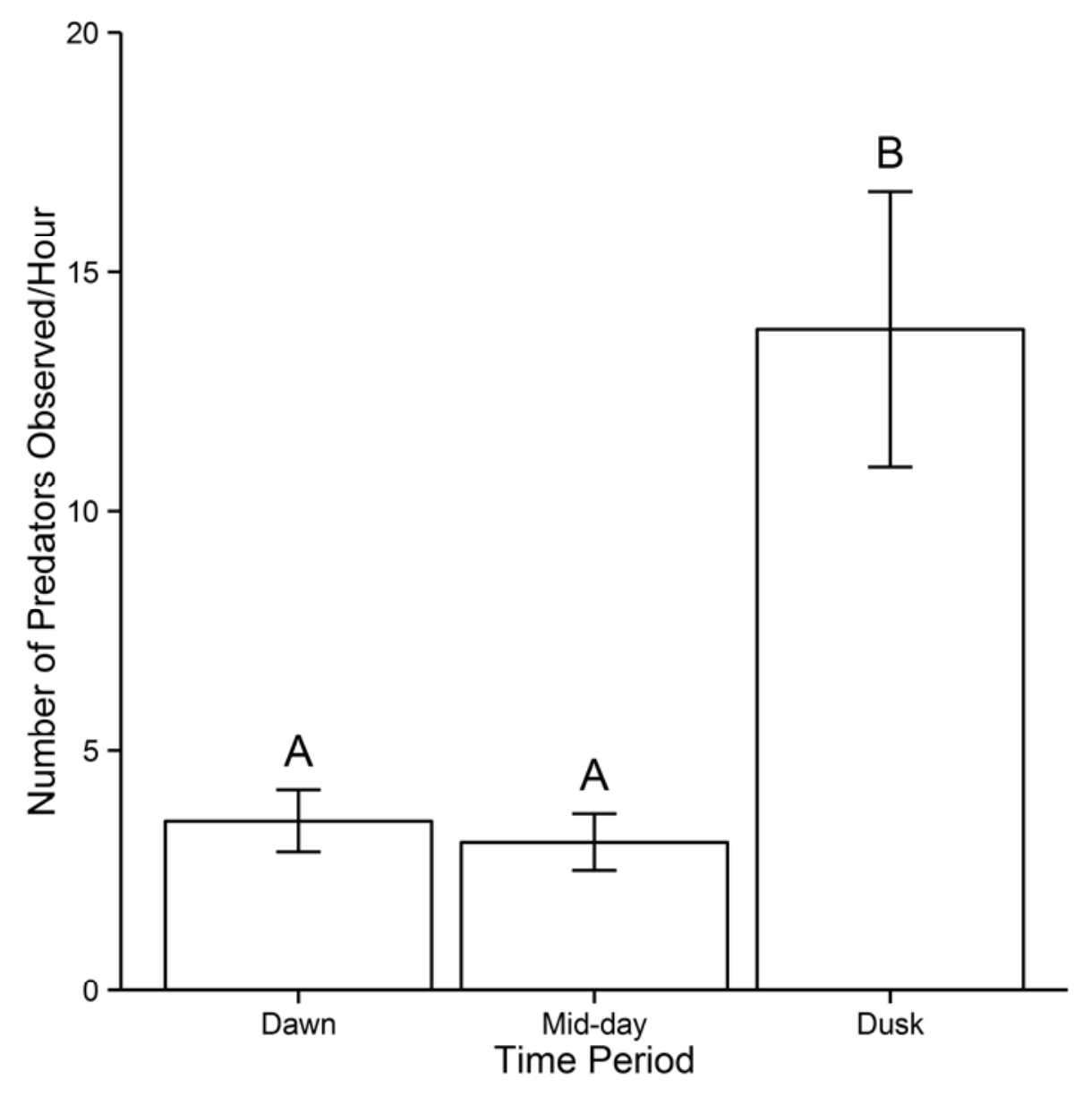




\section{CHAPTER VI}

CONCLUSION AND FUTURE DIRECTIONS 
Predators exert strong direct and indirect effects on ecological communities by intimidating their prey. Sub-lethal or non-consumptive effects (NCEs) are important features of many ecosystems and have changed the way we understand predator-prey interactions (Lima and Dill 1990). By altering prey behavior, predators can have effects that ripple through food webs resulting in behaviorally mediated trophic cascades (Dill et al. 2003). Evidence from theoretical and empirical studies suggests that via behaviorally mediated pathways predators can have dramatic influences on plant communities (Schmitz et al. 1997, Heithaus and Dill 2002, Werner and Peacor 2003, Creel et al. 2005, Stallings 2008, Gervasi et al. 2013). Furthermore, risk effects are often not uniform across landscapes, time periods or among species, but instead vary widely depending on context. It is critical to incorporate such contingencies to develop a deeper understanding of NCEs across ecosystems. Despite the ubiquity of NCEs across multiple disparate ecosystems, it is only recently that scientists have started to recognize the importance of predator intimidation in coral reef ecosystems (Madin et al. 2010b, 2010a, Rizzari et al. 2014). However, no reef studies have examined how herbivore foraging behavior changes across the range of riskiness prey may experience in nature while also integrating the role various contingencies in mediating these effects. The results of my dissertation research help to fill this gap in knowledge about NCEs in coral reef ecosystems. Based on my findings, I suggest that NCEs be incorporated into predictions of how overfishing, coral decline and MPA establishment will affect coral reefs in the decades to come.

In Chapter II, I found evidence that suggested large predators altered herbivore diets directly by influencing foraging behavior via risk and indirectly by influencing food 
availability via positive indirect effects on damselfishes. Importantly, both predator and damselfish abundance impacted diet diversity in different ways for the two species I investigated. For S. aurofrenatum I found that greater predator biomass was associated with an increase in the diversity of resources consumed within populations. In contrast, increasing densities of damselfishes, which aggressively defend resource-rich algal gardens, was associated with lower diet diversity. However, within A. coeruleus populations, diet diversity increased with damselfish abundance, but was unrelated to predator biomass. Differences between species may be linked to differences in sociality and group foraging. The results of this research argue for more emphasis on the role of predation risk in affecting individual herbivore foraging behavior in order to understand the implications of human-mediated predator removal and recovery in coral reef ecosystems.

In Chapter III, I found that in protected reefs, where predators are recovering, territories of S. aurofrenatum were smaller but had greater algal nutritional quality relative to unprotected reefs. This result suggests that males may compensate for smaller territories, which support fewer females, by choosing nutritionally rich areas, which support larger females. Thus, reef protection and the associated recovery of large predators appear to shape the trade-off reef herbivores make between territory size and quality. Furthermore, males chose territories with high structural complexity, suggesting the importance of this type of habitat for feeding and reproduction in S. aurofrenatum. This work argues that coral loss and the resulting decline in structural complexity, as well as declining predator abundances from overfishing, could alter the territory dynamics and reproductive potential of important herbivore species. 
In Chapters IV and V, I elucidate context-dependent causal linkages between predation risk, herbivore foraging behavior and resource consumption. In Chapter IV, with novel field experiments using predator decoys, I investigated how reef complexity interacts with predation risk to affect the foraging behavior and spatially-explicit impact of large herbivorous fishes (e.g. parrotfishes and surgeonfishes). I found that predation risk altered both feeding behavior and the impact of herbivorous fishes. I show species and size differences among herbivores in how predation risk influenced the decision to feed and how food was consumed (i.e., feeding rate), with smaller individuals showing muted responses to fear. Habitat heterogeneity mediated these risk effects with predation risk more strongly impacting herbivore feeding in more complex areas. Thus, predators appear to create a reefscape of fear that both changes the size structure of herbivores and decreases their feeding, potentially altering an ecosystem process critical for healthy coral reefs.

In Chapter V, I built on the results of Chapter IV by incorporated a temporally explicit component to experimental manipulations. I found that predators reduced herbivore foraging activity and that the more active barracuda predator had a greater spatially-explicit impact because they altered the area over which these activities took place. Furthermore, herbivores were less sensitive to risk and showed a diminished threat sensitive response to predator decoys when they were hungrier (i.e., during dawn). Finally, I show dramatic declines in herbivore foraging activity coinciding with peaks in natural predator activity (i.e., during dusk). Thus, the results of these two chapters suggest that in order to understand the role of NCEs in ecosystems, it is important to 
consider various contingencies that influence predator prey interactions such as structural complexity, predator hunting mode, prey state and light availability.

All four of my data chapters support that the NCEs of predators are an important, but often overlooked component of predator prey interactions on coral reefs. This research not only advances our theoretical understanding of NCEs, but also highlights the important implications for how we manage and understand coral reef ecosystems. A crucial question that remains is what cascading influences predator-herbivore interactions can have on the reef community. Emerging evidence from other reef ecosystems suggests that increased predation risk lowers rates of herbivory and results in areas of increased macroalgal cover (Madin et al. 2010a). But it is yet unknown how this can, in turn, affect corals. It is clear that a management approach that incorporates restoring important species interactions is essential to preserving the tremendous economic and ecological value of coral reefs in an era of anthropogenic-driven decline.

\section{References Cited}

Creel, S., J. Winnie, B. Maxwell, K. Hamlin, and M. Creel. 2005. Elk Alter Habitat Selection As an Antipredator Response To Wolves. Ecology 86:3387-3397.

Dill, L., M. R. Heithaus, and C. Walters. 2003. Behaviorally mediated indirect interactions in marine communities and their conservation implications. Ecology 84:1151-1157.

Gervasi, V., H. Sand, B. Zimmermann, J. Mattisson, P. Wabakken, and J. D. C. Linnell. 2013. Decomposing risk: landscape structure and wolf behavior generate different predation patterns in two sympatric ungulates. Ecological applications : a publication of the Ecological Society of America 23:1722-34.

Heithaus, M. R., and L. Dill. 2002. Food availability and tiger shark predation risk influence bottlenose dolphin habitat use. Ecology 83:480-491. 
Lima, S. L., and L. M. Dill. 1990. Behavioral decisions made under the risk of predation: a review and prospectus. Canadian Journal of Zoology 68:619-640.

Madin, E. M. P., S. D. Gaines, J. S. Madin, and R. R. Warner. 2010a. Fishing indirectly structures macroalgal assemblages by altering herbivore behavior. The American Naturalist 176:785-801.

Madin, E. M. P., S. D. Gaines, and R. R. Warner. 2010b. Field evidence for pervasive indirect effects of fishing on prey foraging behavior. Ecology 91:3563-3571.

Rizzari, J. R., A. J. Frisch, A. S. Hoey, and M. I. McCormick. 2014. Not worth the risk: apex predators suppress herbivory on coral reefs. Oikos:no-no.

Schmitz, O. J., A. P. Beckerman, and K. M. O’Brien. 1997. Behaviorally mediated trophic cascades : Effects of predation risk on food web interactions. Ecology 78:1388-1399.

Stallings, C. D. 2008. Indirect effects of an exploited predator on recruitment of coralreef fishes. Ecology 89:2090-2095.

Werner, E. E., and S. D. Peacor. 2003. A Review of Trait-Mediated Indirect Interactions in Ecological Communities. Ecology 84:1083-1100. 
VITA

\section{LAURA BHATTI CATANO}

Born, Granville, Ohio

1996-2000

B.S., Biology

Canisius College

Buffalo, New York

2002-2004

Research Assistant

Edinboro University of Pennsylvania

Edinboro, Pennsylvania

2009-2014

Doctoral Candidate

Florida International University

Miami, Florida

\section{PUBLICATIONS}

Morris, SR, Clark A., Bhatti L., \& Glasgow J. (2003) Television tower mortality of migrant birds in Western New York and Youngstown, Ohio. Northeastern Naturalist

Burkepile DE, Allgeier JE, Shantz A, Pritchard CE, Lemoine NP, Bhatti LH, Layman C. (2013) Nutrient supply from fishes facilitates macroalgae and suppresses corals in a Caribbean coral reef ecosystem. Scientific Reports

Catano LB, Shantz A and Burkepile DE. (2014) Predation risk, competition, and territorial damselfishes as drivers of herbivore foraging on Caribbean coral reefs. Marine Ecology Progress Series 